\title{
Hakki Kestin
}

\section{IMPERIALISMUS - UNTERENTWICKLUNG - MILITARREGIE- RUNG IN DER TÜRKEI}

\section{Der Untergang des Osmanischen Reiches}

Das Osmanische Reich war seit Beginn des 15. bis Ende des 16. Jhs eines der mächtigsten und größten Länder der Welt,nicht nur wegen seiner militärischenStärke und seiner Ausdehnung bis nach Asien, Europa und Afrika, sondern auch wegen seines Entwicklungsstandes. Dieses riesige Reich bildete eine Brücke zwischen Westeuropa und Ostasien. Neben den indischen und chinesischen Produkten, die auf den Handelsstraßen des Osmanischen Reiches transportiert wurden, waren auch die osmanischen Erzeugnisse, vor allem Tuch und Seide, als Luxusartikel in ganz Europa sehr begehrt. Bis zum 18. Jahrhundert gehörten die Manufakturerzeugnisse des Osmanischen Reiches zu den führenden Artikeln. (1) Außerdem exportierte es Nahrungsmittel, vor allem Weizen. Wie war es möglich, daß dieses Reich spätestens Ende des 18. Jahrhunderts zu einer Halbkolonie der westeuropäischen Staaten wurde? Warum war eine industrielle Kapitalakkumulation in Westeuropa möglich und nicht im Osmanischen Reich?

Im Rahmen dieser Arbeit können wir diese Fragen nicht ausreichend beantworten, deshalb begnügen wir uns mit einem kurzen Ubberblick. Die Gründe der nicht erfolgten industriellen Kapitalakkumulation sind sowohl interner als auch extemer Natur.

Zunächst zu den internen: Das Osmanische Reich erreichte Ende des 16. Jahrhunderts seine größte Ausdehnung, seine Grenzen verliefen durch drei Kontinente.

1) Der französische König Francois I ersuchte seinerzeit die 'Hohe Pforte' (Bezeichnung für Hof und Regierung des Sultans in Istanbul bis 1918) 
Das bis dahin hauptsächlich aus Plïnderungen der eroberten Gebiete erzielte Ein. kommen fiel aus, da es volkommen von den Militärausgaben für die Sicherung der langen Grenzen gegen die westeuropäischen Staaten im Westen, gegen Rußland im Norden und gegen Persien im Sudosten aufgezehrt wurde und eine weitere Plüderungspolitik im Ausland nicht mehr möglich war. Hinzu kam der langsame Zerfall der Agratordnung und gleichzeitig der mit ihr in engem Zusammenhang stehenden Militärordnung.

Der Boden gehörte im Osmanischen Reich grundsåtzlich dem Sultan, der ihn den Sipahi (Beamte) zuteilte. Sipahi erhoben Steuern von den Rea (Bauern) und mußten dafï je nach der Größe ihres Einkommens eine besimmte Anzahl von Cebeli (bewaffnete Soldaten) jederzeit zur Verfügung stellen können. (1 a) So befand sich das Reich in einer ständigen "halben Mobilisation". Die Sipahi hatten kein Eigentumsrecht, ihre Aufgabe bestand darin, die Steuern von den Rea einzuziehen. Dafür mußten sie die Kosten für die bewaffneten Soldaten tragen. Im Kriegsfall konnten sofort im ganzen Reich hunderttausende von bewaffneten Soldaten mobilisiert werden.

Die Bewirtschafung des Bodens, der dem Bauer zuge teilt war, übernahm nach dessen Tod sein Sohn. Bebaute der Bauer sein Land ordentlich und gewissenhaft und hatte er ein Haus gebaut, so konnte er Besitzer dieses Teils des Bodens werden. Es bestand eine Art "Erbpacht des Grund und Bodens." (2) Ebenso übemahm der Sohn des Sipahi die Aufgaben seines Vaters nach dessen Tod. (3)

Ein Vergleich mit dem Feudalismus europäischer Prägung drängt sich auf: Sipahi $=$ Feudalherr, Rea $=$ Bauer.. Diese Analogie ist aber nicht ganz zutreffend. Der Bauer war im Osmanischen Reich nicht Leibeigner, wie es in Europa der Fall war. Er durfte zwar ohne triftigen Grund sein Feld nicht verlassen, er war angehalten seine Pflichten zu erfüllen, die gesetzlich geregelt waren. (4) Über die Frage, ob das Osmanische Reich ein feudaler Staat gewesen ist, wird noch immer diskutiert, sic kann auch im Rahmen dieser Arbeit nicht entschieden werden. (4a) Woraus es uns ankommt ist zu zeigen, daß das Osmanische Reich eine in man. cher Hinsicht differierende Entwicklung der politisch-ökonomischen Formen als die westeuropäischen Staaten mitmachte. Da es einige feudale Züge aufweist, andererseits viel zentralistischer organisiert war, scheint die Bezeichnung "militärisch-zentralistischer Feudalstaat" angebracht.

Unter dem Druck der hohen Verteidigungskosten für die Sicherung der eroberten Gebiete, die zudem ihren Tributleistungen nicht mehr nachkommen konnten,

ia) Vgl. Aksoy, S., Türkiyede Toprak Meselesi, Istanbul, 1969, S. 22

2) Vgl. ibid., S. 28

3) Vgl. Köprülü, F. Osmanli Devletinin Kurulusu, Ankara, 1959, Band VIII. 8, S. 109

4a) Avcioglu, D., /Türkiyc'nin Düzeni, S. 1, 17) neigt mehr dazu, diese als "prä-kapitali stisch" zu kennzeichnen. Aksoy, S., (Türkiye'de Toprak Meselesi, S. 10) sowie H.A.R. Gibb und H. Bowen (Islamic Society and the West, I, S. 45 - 47), Hüsrev,II, (Türkiye Köy lktisadiyati, S. 153-167) bezeichnen die Struktur des Osmanischen Reiches als "Eeudal". Erdost, M., (Türkiye Sosyalizmi ve Sosyalizm, S. 64-75) und Steinhaus, K. (Soziologie der türkischen Revolution S. 17) reden von "feudalem Militärstaat". Baran P., (Turkiye ve Sosyalizm Sorunlari, S. 8) bezeichnet es als "zentralen Feudalstaat". Berkes, N., (Türkiye Iktisat Tarihi Bd. I., S. 25) meint daß das Osmanische Reich politisch nicht feudalistisch, okonomisch zum Teil "Feudal-Staat" ist, Sencer, M., behandelt in seinem Buch "Osmanli Toplum Yapisi" (Dic Struktur der osmanischen Ge sellschaft) dieses. Thema sehr ausführich und kommt zum Ergebnis, daß das osm. Reich mehr Ahnlichkeit mit "asiatischer und ostasiatischer Produktionsweise" hat. (S. 327) 
gab die 'Hohe Pforte' die aite Bodenordnung und das mit ihr zusammenhängende Militärsystem auf.

Um der Geldknappheit zu begegnen, verkaufte der Sultan die bis dahin den Sipahi zustehender jähllichen Bodenerträge an Geldbesitzer, hohe Beamte und Wucherer etc. (Diese Leute wurden Mültezin, diese Art von Geschäft Iltizam genannt.). Der Staat verkaufte die Bodenerträge an die Mültezin schon für ein oder mehrere Jahre im voraus. Diese versuchten ihrerseits die Bauern soviel wie möglich zu plündem. (5) Unter einem dieser Mültezin wurden die Verhältnisse für die Rea derart unerträglich, daB sie mit den in der türkischen Geschichte berühmten Bauernaufständen antworteten. Viele Bauem verließen ihre Dörfer und zogen in die Städte oder flohen auî das unfruchtbare Hochgebirge. So entstanden zehntausende kleiner Dörfer. (Heutzutage gibt es in der Türkei über 40.000 Dörfer, die für den Aufbau der Infrastruktur ein großes Problem darstellen.) Die Folge der Zerstörung der Agrarordnung war eine chronische Lebensmittelknappheit.

Was waren die externen Gründe? In Westeuropa setzte auf Kosten der Kolonien zwischen dem 16. und 18. Jahrhundert die industrielle Kapitalakkumulation ein. Allein in den Jahren zwischen 1521 bis 1560 flossen nach Spanien 18.000 Tonnen Silber und 200 Tonnen Gold. Zwischen 1500 und 1550 emöhten sich die Goldreserven Europas um das 57-fache. (6) "Im Osmanischen Reich, wo die auf dem inneren Marki produzierte Warenmenge sich kaum vergrößerte, fürte der Zufluß billigen Silbers seit dem 16. Jahrhindert zu einem rapiden Kaufkraftschwund der auf Silber basierenden Währung." (7) Allein zwischen 1584 und 1589 büßte die türkische Währung 50 \% ihres Wertes ein, die Preise stiegen äußerst schnell. (8) Hinzu kam, daß durch die Entdeckung der neuen Seewege nach Ostasien um Afrika die Bedeutung der alten Handelsstrafen durch das Osmanische Reich zum größten Teil verloren ging. Dadurch wurde vielen Städren an den Handelsstraßen die Existenzgrundage teilweise entzogen.

Die umfangreichen Gold-und Silberlieferungen aus den Kolonialgebieten nach Westeuropa verteuerten hier die Nahrungsmittel und Rohstoffe. Verglichen mit den westeuropäischen Staaten waren die Nahrungsmittel und Rohstoffe im Osmanischen Reich wesentlich billiger. Deshalb kauften die Europäer statt der tirkischen Luxusartikel und Fertigwaren nummehr alle Arten von pflanzlichen und tierischen Lebensmitteln und Rohstoffen. Diese Umstellung untergrub einerseits die tirkische Manufaktur und das türkische Handwerk und fühte andererseits zu Preissteigerungen im Inland. Die chinesischen und indischen Erzeugnisse, die friher durch Vermittung der Turken nach Westeuropa gelangt waren, wurden nun von den Europäem zu füf̂́mal höheren Preisen als ursprünglich im Osmanischen Reich verkauft. (9) Wie war es möglich, daß die Westeuropäer im Osmanischen Reich ungehindert Handel trei ben durften?

5) Vgi. Cem, 1., a.a.O., \$.113146

Vgl. Aksoy, S., a.a. O., s. $44=47$

Sencer, M., Osmanli Topum Yapis, Istawbu, 1969, S. 287-291

6) Vg. Cem, I., a.a.O., S. 120

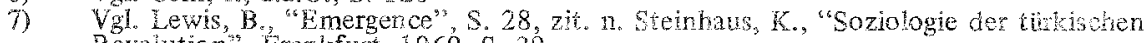
Revolution" wanfint, 1969, S, 30

8) Vgl. Gucer, L., XVI. ve XVII.? asirlarda Osmanli Imparatorlugunda Hububat Koselesi, Stanbui, 1964 , zit. n. Cem, I.4 a.a.O., S. 1.29

9) Vgl. Eewis, E., The Emergence of Modern Turkey, London, 1965, S. 28, rit. n. Avcioglu, D., a.a.0.,, 28 
Bis zu Beginn des 16. Jahrhunderts war das Osmanische Reich militärisch kaum zu besiegen, d.h. die westeuropäischen Staaten hatten nicht die Möglichkeiten einer Eroberungspolitik gegen das Osmanische Reich wie in Lateinamerika, im Fernen Osten und in Südwest-Afrika. Ihre Politik gegen das Osmanische Reich ähnelte der modernen neoimperialistischen Expansionspolitik. Es wurden auf "freundschaftlicher Basis" Handels- und Geschäftsverträge getätigt, die in der Türkei als die Kapitulationen (9a) bekannt sind. Zunächst erreichte Frankreich, das damals gute Beziehungen mit dem türkischen Sultan Suleyman unterhielt, im Jahre 1536 die Gewährung dieser Kapitulationen, ihm folgten England 1579, Österreich 1615, Holland 1680, die Schweiz 1737, Preußen 1761, Rußland 1783 und die USA 1830. Diese Kapitulationen gewährten ungehinderte und gesicherte Handelsfreiheit innerhalb des Osmanischen Reiches. Diese Länder waren weitgehend von Steuern und Zollabgaben befreit. Je größer die politischen, wirtschaftlichen und militärischen Schwierigkeiten des Osmanischen Reiches wurden, desto mehr nutzten die westeuropäischen Staaten sie aus, um die durch die Kapitulationen erlangten Vorteile weiter auszudehnen.

\subsection{Das Todesurteil des Osmanischen Reiches}

1838 war die Hohe Pforte gezwungen, mit England einen Handelsvertrag abzuschließen, den Dogan Avcioglu als das "Todesurteil" des Osmanischen Reiches bezeichnet. In den folgenden Monaten wurde der Vertrag auch mit anderen westlichen Staaten abgeschlossen. Der damalige englische Außenminister Palmerstone begrïßte den Vertrag als "Meisterwerk": "In den Handelsbeziehungen gewährt uns die Türkei größere Freiheiten als den anderen Staaten." (10) Die Wirkung des Vertrages beschreibt Avcioglu: "Die Türkei wurde durch den 1838 unterschriebenen Vertrag zu einem offenen Markt des fortschrittlichen Europa. So war die ökonomische Entwicklung, die durch eigene Anstrengungen möglich erschien, blockiert." (11)

K. Steinhaus behauptet in seinem Buch "Soziologie der türkischen Revolution", daß die nicht erfolgte industrielle und bürgerliche Revolution im Osmanischen Reich nicht auf das Wirken externer Faktoren zurückgeführt werden könne. "Die Tatsache, daß im Osmanischen Reich niemals die Voraussetzungen einer industriellen (von uns hervorgehoben) und einer bürge rlichen Revolution entstanden, kann nicht auf das Wirken externer Faktoren zurückgeführt werden. Die Hauptursachen dieser besonderen Entwicklung sind vielmehr in der spezifischen sozialhistorischen Genesis und gesellschaftlichen Struktur dieses Staates selbst zu suchen." (12) Und an anderer Stelle: "Insgesamt hat die innere Dynamik des türkischen Feudalismus das Erstarken eines nationalen Bürgertums verhindert." (13)

Es ist kaum zu verstehen, wie Steinhaus in seiner sonst recht guten Analyse der Struktur der osmanischen Gesellschaft zu diesem Ergebnis kommt, obwohl er sich ansonsten der Rolle bewußt ist, die die außenstehenden Kräfte spielten.

9a) Sehr wesentliche rechtliche und wirtschaftliche Privilegien, die das Osmanische Reich den ausländischen Staaten gewährte.

10) Palmerston, zitiert nach: Avcioglu, D., a.a.O., S. 51

11) Avcioglu, D., a.a.O., S. 99-102

12) Steinhaus, K., a.a.O., S. 23

13) ibid., S. 26 
In diesem entscheidenden Punkt sind wir der Meinung, daß die Möglichkeiten für eine industrielle Kapitalakkumulation, d.h. für eine kapitalistische Entwicklung, durchaus vorhanden waren, daß sie aber in erster Linie durch die Politik der westeuropäischen Mächte zunächst blockiert und dann ganz verhindert wurden. Die Bildung von Industriekapital setzt die Existenz von Handels- und Wucherkapital und "freie" Arbeiter historisch voraus. Nach Baran verfügten 1561 allein in Bursa 159 Wucherer über 3,5 Mill.Akce. In einem Jahr brachte dieses Geld Zinsen in Höhe von 333.000 Akce. In den Bezirken um Bursa belief sich 1580 das Gesamtwucherkapital auf 2,7 Mill.Akce. Die Zinsen betrugen 10 bis $15 \%$, manchmal sogar 30 bis $60 \%$. (14) "Wucher war nicht nur in den Städten, sondern auch in den Dörfern eine wichtige Tätigkeit." (15) 1638 beschäftigte das private Gewerbe 46.226 Personen. In manchen Einzelbetrieben waren durchschnittlich bis zu 20 Personen beschäftigt. (16)

Ein bedeutender Teil der Bergbauunternehmen und Manufaktur-Betriebe war staatliches Eigentum. Sie stellten "Rüstungsgüter wie Schiffe, Waffen, Munition, Uniformen und Sattelzeug her . . Unter Murad IV (1609 - 1640) etwa verfügte die Hohe Pforte neben Fabrikationsstätten für Waffen und Zeltstoffe mit 5200 Beschäftigten über Werften, Gerbereien, eine Holzfabrik, eine Papierfabrik und 70 kleine Betriebe der Glasbläserei, Färberei, Weberei, Spinnerei etc." (17) Selbst Venedig ließ zwischen 1590 und 1616 seine Schiffe auf türkischen Werften bauen. (18) Nach Steinhaus blieb die gewerbliche Produktion des Osmanischen Reiches bis zum 18. Jahrhundert "nach Quantität und Qualität" beachtenswert. "Die türkischen Manufakturerzeugnisse waren international durchaus konkurrenzfähig." (19)

$\mathrm{Zu}$ Beginn des 19. Jahrhunderts beschäftigte eine Manufaktur, die Hanftaue für die Flotte herstellt, 1.000 Arbeiter. (20)

Im Osmanischen Reich gab es einen entwickelten Handel, der zur Spezialisierung der Arbeiten zwischen den Städten führte. In Bursa wurde hauptsächlich Seide hergestellt, in Ankara Wollstofferzeugnisse, in den Städten Anatoliens (vor allem Urfa-und Sivos-Teppiche, in Moras Eisenerzeugnisse und in Gaziantep Lederartikel. Trazien wurde Bergbauzentrum). (21) Avcioglu zieht daraus die Schlußfolgerung: "Das heißt, seit den Selcuken (Vorfahren der Osmanen - H.K.) entwickelten sich, begünstigt durch die geographische Lage (Transitwege zwischen Europa und dem Fermen Osten - H.K.) und die internationalen Handelsbeziehungen, zwei wichtige Voraussetzungen für den Übergang von mittelalterlichen Verhältnissen zur modernen Ära: a) das Gewerbe trennte sich von der Landwirtschaft, b) durch Handelsbeziehungen zwischen den Städten trennte sich das Gewerbe vom Handel." (22)

Ebenso betont der Soziologe Sencer, daß zwei Vorbedingungen der kapitalistischen Entwicklung spezialisiertes und organisiertes Gewerbe in den Städten und

14) Vgl. Avcioglu, D., a.a.O., S. 21

15) Ibid., S. 21

16) Vgl. ibid., S. 22

17) Heyersberg, F.A., "Maschinen-Verwendung im Wirtschaftsleben der Türkei". Berlin, 1934, zit. n. Steinhaus, K., a.a.O., S. 21

18) Vgl. Tuna, O., "Durchbruch der Türkei zur nationalen Staatswirtschaft", Philippsburg, 1938 , zit. n. Steinhaus, K., a.a.O., S. 22

19) Steinhaus, K., 2.2.O., S. 23

20) Vgl. v. Hagenmeister, J., "Der Europäische Handel in der Türkei und Persien", RigaLeipzig, 1838, S. 27, zit. n. Steinhaus, K., a.a.O., S. 21

21) Vgl. Sencer, M., a.a.O., S. 269

Vgl. Avcioglu, D., a.a.O., S. 12

22) Avcioglu, D., a.a.O., S. 12 
Kapitalakkumulation durch Handel und Wucher im Osmanischen Reich gegeben waren. (23) Nach unserer Meinung kommt aber Sencer in einem Aspekt (ebenso wie Steinhaus) zu der falschen Annahme, daß die Bildung der kapitalistischen Akkimulation dadurch verhindert wurde, daß infolge der Struktur der osmanischen Gesellschaft keine "freie" Arbeiterschaft als weitere notwendige Bedingung der Kapitalakkumulation entstehen konnte. Dem ist entgegen zu halten, daß im Verlauf der Zerstörung der alten Agrarordnung viele Bauern ihre Dörfer verließen und in die Städte zogen. Die reich gewordenen Wucherer und hohen Beamten konnten dadurch den brachliegenden Boden, der bis zum 16. Jahrhundert dem Sultan gehört hat, ver. pachten oder aufkaufen. Die zurückgebliebenen Bauern verschuldeten gegenibiber diesen Wucherem und Verpächtern. Die Folge waren die schon erwähnten Aufstände, nach deren blutiger Niederwerfung noch mehr Bauern verarmten und in die Städte ubersiedelten. AuRerdem vermehrte sich die Bevölkerung um 40 bis $50 \%$, in man chen großen Städten sogar um $100 \%$. Auch Steinhaus erkennt, daß " die fur den tobergang zu maschinell-industriellen Produktionsweisen und kapitalistischen Verhältnissen rotwendigen Produktivkräfte zwar potentiell vorhanden waren...." behauptet aber unseres Erachtens zu Unrecht, daß sie "sich jedoch von der bestehenden Organisation der gesellschaftlichen Arbeit her als nicht aktualisierbar erwie$\operatorname{sen}^{\prime \prime}(24)$

\subsection{Die eigene Entwicklung wird blockisert}

Halsen wir fest: Die Bedingungen für eine kapitalistische Entwickling waren vorharden. Die entscheidende Frage ist also, warum sich diese potenliell vorhandenen Produktivkräfte für eine industrielle Entwicklung às nicht aktualisierbor arweisen? Die Hohe Pforte hatte bereits seit 1536 die Tore des Reiches durch die Kapitulationer den westeuropäischen Staaten für ein weitgehend ungehindertes Agiem. ren in allen Bereichen der Wirtschaft, später der Politik und Kultur en̈ffiet. Der Ein. fluß der "rivalisierenden euiopäischen Großmächte" (Barthel) wurde großßer, so daß in den folgenden Jahrhunderten das Reich den Status einer Halbkolonie anahm. Zu dieser Politik meint Kücikömer spötisch: "Eine solche liberale Polktik wurde, glaube ich, in der Welt zum ersten Mal praltizert." (25) Die Folge dieser Kapitulationen war, daß viele gewerbliche Betriebe und Fabriken ihre Tore schlieken mubten oder aumindest ihre Produktion einschränken nuBten."In der esten Wallfte des 19. Jahrhunderts betrug beispielsweise die Produktion von Seidenwaren in Kleinasien nut mehr eir Zehntel der Produktion der zweiten Halfte des 18. Jahrhunderts." (26) Nach den Angaben einer im Jahre 1866 eingesetzten Kommission werringerte sich allein in Istanbul die Zahl der Stoffwerke von 2750 auf 25 innerhalb von 40 Jahrer, in Bursa von 1000 auf $75 .(27)$

Großbritannen exportierte 1828 in das Osmanische Reich Baumwollwaren ira Werte von 465.000 Pfdstering, 1831 bereits im Werte von 1,04 Mull.Pfd.Sterling

33) Vgl, Sencer, M., a., $0,3,373$

24) Steinhaus, K. a.a.O., S. 26

25) Kücüköner, 1, Duzenin Yabancilasmasi, Larabul, 1969,5.67

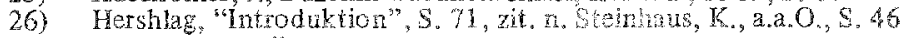

27 Vg. Sarne, C.O., "Tanzimar wantiznz" Ystanbul, 1940, S. 43\%, zit. n. Avcioglu,D.

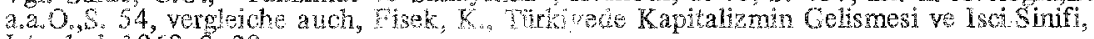
rentur, $1959,8.30$ 
(28) und $1860 \mathrm{im}$ Werte von 11 Mill. Pfd. Sterling. (29) Aus Frankreich wurden 1846 Waren im Werte von 97 Mill. Franc, 1862 im Werte von 251 Mill. Franc importiert. (30) Nachdem die industrielle Entwicklung in ihrer Anfangsphase durch die Kapitulationen etc. "auf freundschaftlicher Basis" verhindert worden war, gewährten die westeuropäischen Staaten der Hohen Pforte zu einem Zeitpunkt, als sich das Reich in einer außerordentlich schlechten wirtschaftlichen Lage befand, umfangreiche Anleihen, die die wirtschaftliche Abhängigkeit des Osmanischen Reiches von Westeuropa vollends besiegelte. Ab diesem Zeitpunkt (1854), nachdem das Fremdkapital sich endgültig festgesetzt hatte, ist die Bezeichnung "Kolonie" für das Reich zutreffend. Die Anleihen mußten dem Sultan mehr oder weniger aufgezwungen werden, da er es mit seiner Würde nicht vereinbaren wollte, im Ausland Schulden zu haben. Ein Sadrazam (Ministerpräsident), der gegen die Anleihen war, wurde auf Betreiben des englischen Botschafters Palmer gestürzt. (31) Die "Times" berichtete, Frankreich konnte durch massiven Druck die Hohe Pforte zur Annahme der Anleihen bewegen. (32) Die Geberländer verstanden es zudem, durch verschiedene Geschäftstricks die Anleihen zu einer wahren Goldgrube zu machen. Von den 402 Mill. Schulden zwischen 1854 und 1941 erhielt das Osmanische Reich nur 243 Mill. Goldlira, da fast die Hälfte der "Schulden" von den Geberländern einbehalten wurden. (33) Die Anleihen wurden mit $6 \%$ Verzinsung gewährt, da aber fast nur die Hälfte im Reich eintraf, betrug die Verzinsung in Wirklichkeit fast $12 \%$. (34) 1874 waren die Schulden derart angewachsen, daß das Reich $80 \%$ der Gesamtanleihen allein für Rückzahlungen und Zinsen ausgeben mußte. (35) 1875 war die Hohe Pforte schließlich nicht mehr in der Lage, ihre Verpflichtungen zu erfullen. Auf dem Berliner Kongreß wurde 1878 gegen den Willen der tükischen Delegierten von den europäischen Ståten die Gründung einer intemationalen Koinmission beschlossen, die den Etat des Osmanischen Reiches in die Hand nehmen und kontrollieren sollte. Drei Jahre später konstituierte sich die Kommission unter dem Namen "Düyun-u Umimiye" (allgemeine Schuldenkommission);Mitglieder der Düyunu Umimiye waren England, Frankreich, Österreich, Italien und das Osmanische Reich. Die Kommission hatte die Aufgabe, über ein Drittel der Einkommensquellen des Reiches direkt zu verfügen und mit den gesammelten Geldern die Schulden zurückzuzahlen. Sie entwickelte sich zu "einem Staat im Staat", der alle wirtschaftlichen und politischen Entscheidungen traf. (35a)

Die Kommission wurde von der eigens von Engländern und Franzosen gegrïndeten Zentralbank des Reiches "Osmanli Bankasi" unterstïrzt, die deren Investi-

28) Vgl. Bailex, F. E., British Policy and Turkish Reform Movement, London, 1942, S. 86-88, zit. n. Fisek, K., a.a.O., S. 32

29) Vgl. Karal, E.Z., Osmanli Tarihi, (Islahat Fermani), S. 256, zit. n. Cem, 1., a.a. O., S. 191

30) Vgl. Edin, J. Cohn., Yenilikcileri Etkileyen Toplumsal ve Kültürel Unsurlar, zit. n. Cem, I., a.a.O., S. 192

31) Vgl. Bleistell, D. C., Osmanli Imparatorlugunda Avrupa Mali Kontrolii, Istanbul 1940 , S. 45 , zit. n. Avcioglu, D., a.a. O., S. 60

32) "Times", 30. Ok tober 1889, zit, n. ibid. S. 60

33) Vgl. Karamürsel, Z., Osmanli Imparatorlugu Mali Tarihine bir Bakis, S. 35, zit. n. Cem, I. a.a.O., S. 178

34) Vgl. Bulutoglu, K., Türkiyede Yabanci Sermaye, Ǐstanbul, 1970, S. 70, siehe auch Avcioglu, D., a.a.O., S. 61

35) Vgl. Mutlucag, H., "Düyun-1 Umimiye ve Reji Soygunu" Belgelerie Türk Tarihi Dergisi, Band 2, Istanbul, 1967, zit. n. Cem, I., a.a.O., S. 179

35a) In Wirtschaftsangelegenheiten beschäftigte das Reich 5.500 Personen, Düyun-u Umimiye 8.000 
tionsinteressen in allen Bereichen (Bergbau, Rohstoffe, Häfen, Eisenbahn, Elektrizität) gewährleisten sollte.

Diesen Aktivitäten konnte das Deutsche Reich nicht untätig zusehen. Die 1888 gegründete "Deutsche Bank" übernahm die Finanzierung großer Projekte wie beispielsweise den Bau der Bagdad-Bahn. Das Bagdad-Bahn-Unternehmen bezeichnet Avcioglu als ein Unternehmen, um Anatolien und Mesopotamien in eine Kolonie des Deutschen Reiches zu verwandeln. (36)

Ebenso mißt Bucharin diesem Unternehmen für den deutschen Imperialismus große Bedeutung bei: “Wenn die Deutsche Bank die Bagdad-Bahn baut,so benutzt sie in derTürkei nicht nur deutsches Material,das unmittelbar für den Bahnbau bestimmt ist, sondern schafft auch ein ganzes Netz von Marktbeziehungen, in das gerade deutsche Waren leicht eindringen können. Der Kapitalexport schafft somit auch für die Industrie, die in der Heimat dieses Kapitals produziert, günstige Bedingungen." (37) Bucharins Aussage wird durch die folgende Erhöhung der Ausfuhren des Deutschen Reiches in das Osmanische Reich um 35\% noch unterstrichen.

Nachdem die imperialistischen Mächte erst einmal im Osmanischen Reich Fuß gefaßt hatten, versuchten sie, sich auch in militärischer und kultureller Hinsicht Einfluß zu verschaffen.

Im ganzen Reich wurden in wichtigen Städten Konsulate und Schulen eröffnet; Zeitungen erschienen in englischer, französischer und deutscher Sprache. Bis zum ersten Weltkrieg dominierte eindeutig Frankreich. Es unterhielt 48 Konsulate und konsularische Vertretungen und 73 Schulen (die religiösen Einrichtungen sind nicht berücksichtigt) mit 8939 Schülem. Großbritannien hatte 30 Schulen mit 2996 Schülern und 131 englischen Lehrern. Das Deutsche Reich unterhielt 15 Konsulate und konsularische Vertretungen und 10 Schulen mit einigen Tausend Schülern. (38) Von den deutschen Vertretem sind im Osmanischen Reich vor allem Feldmarschall von Moltke und General von der Goltz zu nennen, die nicht nur auf türkisches Mili tär, sondern auch auf die Politik einen großen Einfluß gehabt hatten. Moltke war zwischen 1883 und 1895 als 2. Stabschef der osmanischen Armee tätig. Von der Goltz kommandierte im 1. Welkrieg die 1. und 6. Armee des Osmanischen Reiches. (38a) (39)

36) Vgl. Avcioglu, D., a.a.O., S. 71

37) Bucharin, N., Imperialismus und Weltwirtschaft, Frankfurt, 1969, S. 109

38) Vgl. Cavdar, T., Osmanlilarin Yari-Sömürge olusu, Istanbul, 1970, S. 84-100

38a) Was für eine Funktion diese Generäle und was für einen Einfluß das Deutsche Reich im Osmanischen Reich hatten, belegt der folgende Brief von General von der Goltz an Bismarck aus Istanbul: "Ich hoffe, daß wir von den Paschas (R), (M) und $(H)$ (die Buchstaben bezeichnen den Namen der Paschas, H.K.) große Unterstützung bekommen werden, die für uns große Dienste geleistet haben. Sie kennen diese Paschas; wie Sie mir befohlen haben, habe ich ihnen zweimal die für sie bestimmten Gelder übergeben. Falls wir die Schenkungen wiederholen, bin ich davon überzeugt, daß die oben genannten Paschas uns große und wertvolle Hilfe leisten werden. Eine ganze Reihe von Generälen sind unsere guten Freunde. In regelmäßigen Abständen erhalten sie die für sie bestimmten Geldsummen." (Da das Original nicht auffindbar war, müssen wir uns mit einer Rückübersetzung aus dem Türkischen begnügen). In einem anderen Brief an Feldmarschall Walderze schrieb Goltz, daß er hoffe, die Führung der türkischen Armee so fest in die Hände der Deutschen zu bekommen,daß sie nie wieder verloren geht. (Zitiert nach Hayri Multlucag, Dost bildigimiz ve ordumuzun islahi icin icimizde bulundurduklarimizin marifetleri, 'belgelerle Türk tarihi dergisi, sayi 12, Eylül 1968, vgl. Cem, I., Türkiye de Geri kalmisligin tarihi, CY, Istanbul 1970, \$. 183) 
Nach diesem kurzen Überblick über die Rolle der westeuropäischen Mächte im Osmanischen Reich können wir folgende Schlußfolgerungen ziehen: Das Osmanische Reich wurde zunächst durch die Kapitulationen, dann durch noch ungünstigere Verträge und letztlich durch "Düyun-u Umimiye", die Osmanli-Bank und die Deutsche Bank zu dem "Kranken Mann am Bosporus" gemacht. Seit den Kapitulationen wurde seine Souveränität immer mehr beschnitten, so daß in der Folgezeit nicht mehr von eigenen nationalen Entscheidungen die Rede sein konnte. Da das Osmanische Reich im Grunde von den westeuropäischen Staaten kommandiert wurde, war jeglicher weiteren Entwicklung der eigenen Potenzen der Boden entzogen. Das soll nicht heißen, daß für die nicht erfolgte industrielle Entwicklung die Struktur der osmanischen Gesellschaft keine Rolle gespielt hätte, aber ebenso wie in Indien, China, Lateinamerika und den afrikanischen Ländern sind für die Blockierung der Weiterentwicklung der eigenen Potenzen die externen Ursachen ausschlaggebend, "Die Faktoren, die die Quelle der Rückständigkeit sind, diese Rückständigkeit bestimmen und fortsetzen lassen, sind externe Faktoren. Die innere Dynamik, die durch äußere Faktoren kontrolliert wird, kann lediglich die imperialistische Ausbeutung erleichtern und verschleiern, mit einem Wort: Die Rückständigkeit ist nicht das Produkt des fehlenden Kapitals und Unternehmers, sondern der alten und neuen Ausbeutung, d.h. ein Produkt des natürlichen Entwicklungsprozesses des Kapitalismus." (40) Ebenso urteilt Avcioglu: "Die Türkei ist nicht zurückgeblieben, sondern durch den Imperialismus zurïckgehalten worden." (41)

\section{Atatürks unabhängige Türkei}

Das jahrhundertelange Joch der rivalisierenden imperialistischen Staaten führte nicht nur dazu, daß das industrielle Nive au der Türkei 1915 unter dem eines europäischen Großkonzems mit einer Produktion im Wert von 40 Mill.Dollar lag (42), sondern zwang auch das Osmanische Reich in den 1. Weltkrieg. Das Osmanische Reich, das auf der Seite der Mittelmächte beteiligt war, brach nach dem Sieg der Entențe zusammen, und sofort setzte das Feilschen der Entente-Mächte um möglichst große Teile des besiegten Landes ein.

Mustafa Kemal (in einer Parlamentssitzung erhielt er 1934 den Ehrentitel "Atatürk", der Vater der Türken), der eine neue Ära in der türkischen Geschichte eröffnete, beschrieb die Situation am 19. Mai 1919: "Die Mächte, mit denen das Osmanische Reich im allgemeinen Krieg (1. Weltkrieg) kämpfte, wurden besiegt, die osmanische Armee zerschlagen und unter schweren Bedingungen wurde ein Waffenstillstand unterschrieben. Nach langen Jahren des großen Krieges ist die Nation abgekämpft und arm. Diejenigen, die die Nation und die Heimat in den Krieg führten, kümmerten sich um sich selbst und sind aus dem Land geflohen. Der Sultan, der zugleich Kalif ist, ist entartet und versucht mit unverschämten Mitteln seinen Thron zu retten... Die Armee wurde entwaffnet.

Die Entente hält sich nicht an den Waffenstillstand. Ohne triftigen Grund sind ihre Marine und ihre Soldaten in Istanbul. Die Franzosen besetzten Adana, die Eng.

40) O̊̊kol, S., Emperyalizm, Tekelci kapitalizm ve Türkiye, Istanbul, 1970, S. 9

41) Avcioglu, D., a.a.O., S. 106

42) Steinhaus, K., a.a.O., S. 57 
länder Urfa, Maras, Merzifon, Samsun und Antep und die Italiener Kanya und Antalya, und die Griechen besetzten mit Einwilligung der Entente Izmir.

Überall arbeiten fremde Offiziere, Beamte und Spezialisten. Außerdem bemühen sich die christlichen Minderheiten, um ihre teils versteckten, teils offenen Wünsche und Ziele zu erreichen, den totalen Zusammenbruch so schnell wie möglich herbeizufuhiren ... Was konnte unter diesen Umständen eine solide und reale Entscheidung sein? Meine Herren! Unter diesen Umständen konnte es nur eine Entscheidung geben, die Grïndung eines auf unbeschränkter nationaler Souveränität basierenden neuen turkischen Staates." (43)

Dieser neue Staat, die "Türkische Republik", wurde am 23. April 1923, nachdem die heutigen Grenzen der Türkei freigekämpft waren, ausgerufen. Bei diesem antiimperialistischen Kampf hat die KPdSU der "Nationalen Befreiungsbewegung der Türkei" große Hilfe geleistet. Dieser Kampf unter der Führung Mustafa Kemals wurde als Muster von vielen Völkem der Dritten Welt angesehen (Nehru, Nasser und viele afrikanische Staaten). Nach Meinung von M.A. Aybar, dem fruheren Vorsitzenden der türkischen Arbeiterpartei, wurde das türkische Volk sich in diesem Krieg be. wuBt, eine Nation zu sein. (44) "Während des Befreiungskrieges und der folgenden Ara, etwa bis zum Tode Atatürks, erreichte die Führung (gemeint ist die kemalistische Führung-H.K.), weil sie antiimperialistisch und zugleich antikapitalistisch war, weil sie gegen die traditionell-feudalistisch-zentrale osmanische Führung und gegen die osmanische Gesellschafisstruktur war, ein hohes ideologisches Niveau, und stellte die Prinzipien Revolution, Populismus und später Laizismus und Etatismus auf." $(45)$

Mustafa Kemal trat eine schwere Erbschaft an: Im Innern allenthalben Armut, Elend, Hungersnöte, Analphabetentum $(90 \%$ der Bevölkerung konnte weder lesen noch schreiben) und eine große Schuldenlast gegenüber dem Ausland. Es gab kaum ausgebildete türkische Ingenieure und Techniker. Das tïrkische Handwerk ging durch die ungehinderte Einfuhr von Massenproduktion ausländischer Herkunft zu Grunde. $80 \%$ der Bevölkerung war in der Landwirtschaft beschäftigt, die überwiegend mit primitiven Methoden betrieben wurde. 1921 gab es insgesamt 386 meist in ausländischer Hand befindliche Betriebe mit 76.216 gewerblichen Arbeitern. (46) Der Bau eines Straßennetzes steckte in den Anfängen, und die wenigen Straßen, die es gab, waren kaum befahrbar. 1923 gab es ein Schienennetz von $4018 \mathrm{~km}$ Länge,das zu $67 \%$ den Deutschen, zu 19,8\% den Franzosen und zu 12,7\% den Engländern gehörte. (47)

Das Schiffswesen war noch weniger entwickelt. Die Schiffe, die dem Staat und Privatpersonen gehörten, hatten zusammen eine Kapazität von nur 20.000 BRT. (48)

1923 betrug das Zahlungsbilanzdefizit 60,1 Mill.TL. (49) Die Türkei importierte Waren im Wert von 144,8 Mill.TL und exportierte Waren im Wert von nur 84,7 Mill. TL. (50)

43) Atatürk, M. K., Söylev, Band I, Ankara, 1966, S. 1-10

44) Boran, B., Türiye ve Sosyalizm Sorunlari,

45) Boran, B., a.a.0., S. 2, Istanbul, 1968, S. 17

46) Tarih, Türkiye Cumhuriyeti tarafindan hazirlanmistir, Istanbu1, 1934, Band IV, S. 297, zit. n. Sertel, Y., Türkiyede Ilerici akimlar, S. 17, Istanbul, 1969

47) Vgi. Sertel, Y., ebd., S. 13

48) Vgl. ebd.

49) $1 \mathrm{TL}=0,48$ Dollar

50) Vgl "Kücük Istatistik Yilligi", Ankara, 1934, S.247, zit. n. Sertel, Y., a,a.O., S. 97 
Bei ihrer Grindung hatre die Türke insgesamt Schulden in Höhe von 84,5 Mill, tiukkischer Goldlira. (51)

A tatürk wurde bei dem Aufbau der Türkei mit vielfältigen Problemen konfrontiert: die Hinterlassenschaft des Imperialismus, die völlig zerriitteten Verhältnisse im Innem des Landes und gleichzeitig der stete Kampf gegen die Ambitionen des Imperialismus, außerdem Aberglaube und mittelalterliche Sitten, die dem Neuaufbau entgegenstanden. Br mußte einen ganz neuen Weg einschlagen, um nicht wieder in die Klauen des "einzehiger Drachens" zu gelangen, wie der berihmte türkische Dichter Mehmet Akif den neven Imperialismus einmal genannt hat, und um so schnell wie möglich die Versäumnisse der vergangenen Jahrhunderte wieder rückgängig zu machen. Welche Möglichkeiren hatte Atatïk, um dieses desolaten Zustands Herr zu werden? Für eine sozialistische Revolution, wie sie manche turkischen Sozialisten erträumten, fehlten die objektiven und subjektiven Voraussetzungen. Ataturk gab der Turkei eine bürgerlich parlamentarische Statsform. Die verschiedenen Klasser entsandten ihe Vertreter in das Parlament, wobei das Proletariat und die Bauen kaum repräsentiert waren. (52)

Der zuveriässige Beschützer der Bewegung des Fortschritts und der Reformen war das Offizierskorps. Unter den zivilen Palamentarieren gab es Anhänger des Sultans, das Kalifats tha der alten osmanischen Ordnung. Allerdings waren damals die Klassengegensåtze nicht sehr grob (wie auch P. Baran betont), da die Bourgeoisie noch nicht wie in Europa erstarkt war: "Insbesondere während des Krieges waren die Lebenshedingungen der Fihrung nicht viel besser als die des Volkes." (53)

Die ersten notwendigen Mabnahmen waren die vollständige Abschaffung der Feudalverhältnisse, die Enteignung der Grobgrundbesitzer und die vollkommene Befreiung der Bauern von diesen Verhältnissen gewesen. Dazu waren aber die Möglich ksiten sowohl von den Kräfteverhältnissen her als auch von dem Bewußtsein der Fihrung ncht gegeber. Der gute Wille der revolutionären, intellektuellen Schicht der Führurg der Bewe ging war vorhanden, die okonomisch-sozialpolitischen Kenntnisse nicht. Es herrschte Ungewilhert dariber, wie die Probleme zu bewältigen seien, auf welchem Weg "die neue Tuirke!, die dem Niveau der zivilisierten Völker gleich sein solte" "verwiklich werden kömnen, Diese neve Fühung konnte nicht einmal er. Kennen, dab ohne die Abschaffung der Feudalherren und der Croßgrundbesitzer der Weg hiu eine schnelle und modeme Fintwicklung nicht frei würde, und sie konnte nicht erkennen, dals die noch schwach entwickelte nationale Bourgeoisie (und Reak. tionäre wie Ulemas, die die alte Ordnung wieder herstellen wollten) in der Zukunft aufsässig werden wïrden, wem man iben Aktionsradius nicht von Anfang an stark enengte. So blieben der" betsplehafte antimperalistische Kampf und die kemalistischen Reformen in den Anfängen selbst einer "bürgerlich-demokratischen Revolution"s stecken.

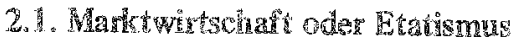

Dic kemalistische Ara (1923-1938) läft sich in zwei Phasen einteilen. Diese Binteifung ergibt sich aus der Anderung der Politik nach der Wirtschat tskrise. Die erste Phase ist charakterisiert durch staalliche Unterstitzung der nationalen Bour-

51) Vgl. Rulutoglu, K., a.a.0., S.97

52) Vgh. Frey, Eriedrick, w. "Whe Turksh Political Elite", Cambridge, 1965, S.77, 181, 279,

3) Borka, $\mathbb{B}_{2}, a_{2}, \mathrm{O}_{0}, \mathrm{~S}, 17$ 
geoisie, während auf die zweite Phase die Bezeichnung "Etatismus" zutrifft. Die Startbedingungen der neuen Türkei waren denkbar schlecht. Die Entente-Mächte erkannten die Aufhebung der Bindungen an "Düyun-u Umimiye" nicht an. Im Lausanner Vertrag übemahm die Türkei notgedrungen die Schulden des Osmanischen Reiches, allerdings nur den Teil, die für das Kernland gemacht worden waren und nicht für die von der Entente besetzten Provinzen (Arabische Länder etc). Diese Schulden in Höhe von 84,6 Mill.TL wurden in jährlichen Raten bis 1954 bezahlt.

Die neue Regierung leitete die dringend gebotenen Wirtschaftsreformen mit einem umfangreichen Nationalisierungsprogramm (54) ein, das erst 1944 abgeschlossen werden konnte. Aber noch im Jahre 1929 liegt der Anteil der mit ausländischem Kapital finanzierten Investitionen bei 77,9 Mill.TL gegenüber 78,2 Mill.TL, die von der Türkei für Investitionsvorhaben aufgebracht wurden. (55) Hinter diesen Zahlen verbergen sich die großen Probleme, mit denen der junge Staat noch jahrelang zu kämpfen hatte."Politische und militärische Siege mögen noch so gewaltig sein, sind sie nicht von wirtschaftlichen Erfolgen gekrönt, so werden sie nicht von Dauer sein, sondem in kurzer Zeit zunichte gemacht werden" erklärte Atatürk. (56) Aber gerade über die wirtschaftlichen Maßnahmen herrschte vollkommene Ungewißheit. "Die Wirtschaftler hatten keine Kenntnisse, die über liberal-kapitalistische hinausgingen." (57)

Für diese Situation sind die Worte des Journalisten und Abgeordneten der 1. Legislaturperiode Falih Rifkis kennzeichnend: "Wir wußten nichts. Es gab niemanden, der uns hätte lehren können. Hätten wir auf diejenigen gehört, die den Wirtschaftstheorien des 19. Jahrhunderts huldigten, müißten wir jetzt unsere Hände in den Schoß legen und ein Jahrhundert warten. Als der Ministerpräsident sagte 'Unsere Eisenbahnlinien werden vom Staat gebaut,' war von allen Seiten zu hören: 'Der Staat baut keine Eisenbahnen, so etwas steht nicht im Buch.' " (58)

Einer der wenigen, die einige ökonomische Kenntnisse hatten, war der Schriftsteller Ziya Gökalp. Nach seiner Meinung waren die englischen ökonomischen Theoreme nur verwirrend. Daß der Staat keine Fabriken, keine nationale Industrie etc. bauen sollte, sei absurd. Er meinte: "Die Türkei braucht dringend Schwerindustrie. Dies kann aber nicht von Privatpersonen oder Privatfirmen ermöglicht werden. Umgekehrt! Nur durch den Staat, durch die provinzialen Staatsverwaltungen kann jegliche Art von Industrie aufgebaut werden!" (59)

\subsection{Schaffung einer einheimischen Bourgeoisie}

Die Grundlinien der Wirtschafts- und Sozialpolitik für den Zeitraum von 1923 bis 1929 wurden auf dem "Alltürkischen ökonomischen Kongress" in Izmir, der am 17. Februar 1923 mit 1135 Delegierten aus dem ganzen Land eröffnet wurde, beschlossen:

1. Es wird eine nationale Wirtschaftspolitik betrieben. Sämtliche Wirtschaftszwtige sollen nationalisiert werden.

54) Vgl. Bulutoglu, K, a.a.O., S. 99-109, nähere Einzelheiten über Nationalisierung.

55) Vgl. Tahsin, H.-Saka, R., Sermaye Hareketi, Istanbul 1930,S. 212-213, zit. n. Bulutoglu, K., a.a.O., S. 101

56) Atatürk, M.K., Söylev, Band II, S. 107, zit. n. Steinhaus, K., a.a.O., S. 124

57) Avcioglu, D., a.a.O., S. 156

58) Atay, F.R., Cankaya, S. 263, 264, zit. n. Avcioglu, D., a.a.O., S. 157

59) Gökalp, Z., Yeni Tïkiyenin Hedefleri, Ankara, 1956,S.56, zit. n. Avcioglu, D., a.a.O., S. 157 
2. Die bisherige Rolle, die die ausländischen oder nichttürkischen Untemehmer gespielt haben, soll die türkische nationale Bourgeoisie übernehmen. Da sie für diese Aufgaben noch zu schwach ist, soll sie vom Staat geschützt und unterstüzzt werden. 3. Der Ửbergang von der Manufaktur- und Kleinindustrie zur Fabrikindustrie soll beschleunigt werden.

4. Die Position des Fremdkapitals soll geschwächt und nur soweit zugelassen werden, wie es "den neuen Gesetzen gehorcht und den nationalen Interessen entspricht."

5. Die Türkei ist noch ein Agtarstaat. Die Produktivität der Landwirtschaft soll durch Modemisierung erhöht werden. Die landwirtschaftlichen Erzeuger sollen vom Staat unterstïtzt werden.

6. Das einheimische Gewerbe soll gestärkt und vor der ausländischen Konkurrenz geschützt werden.

7. Der Außenhandel soll vom Staat kontrolliert werden.

8. In den Zweigen, wo die privaten einheimischen Untemehmer nicht in der Lage sind zu investieren, soll der Staat diese Aufgabe übernehmen. (60)

In dieser Phase kann von Etatismus kaum die Rede sein. Die ganze Politik war daraufhin abgestellt, die Wirtschaft zugunsten der einheimischen Bourgeoisie zu nationalisieren. Gegenüber dem Fremdkapital taktierte der neue Staat sehr vorsichtig. In seiner Rede auf dem alltürkischen ökonomischen Kongress betonte Atatürk, daß "die nationale Souveränität" durch wirtschaftliche Unabhängigkeit gewahrt werden müsse. "Das Ziel unseres heutigen Kampfes ist die volle nationale Souveränität. Die volle Souveränität kann aber nur durch ökonomische Unabhängigkeit garantiert werden. Ist die Wirtschaft eines Landes nicht unabhängig, so ist dieses Land in jeder Hinsicht in seiner Bewegungsfreiheit eingeschränkt." (61) Seine Haltung gegenüber dem Fremdkapital brachte er mit den Worten zum Ausdruck: "Wir brauchen viel Kapital. Deshalb sind wir bereit, im Rahmen unserer Gesetze dem ausländischen Kapital Sicherheit zu gewähren. Es ist begrïßenswert, daß das Fremdkapital für unsere Industrie einen Beitrag leistet,daß es für uns und die Geberländer positiv wirkt.Aber nicht mehr so (einseitig - H. K. ) wie früher. Wie jeder zivilisiertc Staat, jedes zivilisierte Volk kann die Türkei es (das Fremdkapital alten Stils - H.K.) nicht mehr gestatten. Es kann uns nicht mehr zur einer Kolonie degradieren." (62) Die Regierung nahm 1930 zum ersten Mal einen Kredit von 10 Mill.Dollar mit 6,5\% Zinsen und einer Laufzeit von 25 Jahren von den USA in Anspruch. (63) Dies war dringend nötig geworden, um die im selben Jahr beginnende Zahlung der "Schulden" des Osmanischen Reiches zu leisten. 1930 wurden 32 Mill.TL davon bezahlt.

Bei der Durchführung des ersten Fünfjahresplans wurden von der Sowjetunion zinslose und innerhalb von 20 Jahren zu tilgende Darlehen in Höhe von 8 Mill. Dollar im Jahre 1934 und 2 Mill Dollar im Jahre 1935 aufgenommen. Mit diesen Darlehen wurden die Textilkombinate in Kavseri und Nazilli gebaut. (64)

Obwohl die Regierung ausländische Direktanlagen und Kredite nicht grund. sätzlich ausschloß, hielten sich die imperialistischen Staaten hier zurück, da Direkt-

60) Vgl. Avcioglu, D., a.a.O., S. 156-178, vgl. Sertel, Y., a.a.O., S. 19-24, vgl. Cem, I., a.a.O., S. 207-218, vgl. Barthel, G., Zur Industrialisierung der Türkei, Leipzig, 1966, S.64-68, vgl. Steinhaus, K., a.a.O., S. 124-125

61) Atatürk, M.K., Söylev ve Demecler, I, Ankara 1922, S. 228-229,zit, n. Naci, F., Atatük ü Temel Görüsleri, Istanbul,1968, S. 34

62) Atatürk, M.K, "Izmir Iktisat Kongresi Acis Nutku",Atatürk ün Söylev ve Demecleri II, Ankara 1952, S. 110-111, zit. n. Sertel, Y., a.a.O., S. 20-21

63) Vgl. Bulutoglu, K., a.a.O., S. 111

64) Barthel, G., a.a.O., S. 78-79 
investitionen nur unter umfangreichen gesetzlichen Einschränkungen möglich wa* ren und Kredite nur auf Kompensionsgeschâfte angenommen wurden.

Der Grund für diese Zuruickhaltung liegt darin, daß die imperialistischen Sta. ten auf einen Geschäftspartner stießen, der sich ihrem Diktat nicht unterwarf. In der Außenpolitik verfuhr Atatük nach dem Motto: "Kauft ein Land tiirkische Waren, kaufen wir auch seine Waren. ${ }^{99}$ Dem stand aber vorläufig noch die der Türkeí im Lausanner Vertrag aufgezwungene Abmachung entgegen, die türkischen $\mathbb{Z} \ddot{0} l l e$ bis 1929 auf dem Niveau von 1916 zu halten, (65) was sich sehr nachteilig auf die Außenhandelsbilanz auswirkte, da die Zölle von 1916 extrem niedrig lagen.

Tabelle 1 Die turische AuRenhande

\begin{tabular}{cccc} 
Jahr & $\begin{array}{l}\text { Einfuhr } \\
\text { (in Willionen TL) }\end{array}$ & Ausfuhr & Differenz \\
\hline 1923 & 144,8 & 84,7 & $-60,1$ \\
1924 & 193,6 & 158,9 & $-34,7$ \\
1925 & 241,6 & 192,4 & $-49,2$ \\
1926 & 234,7 & 186,4 & $-48,3$ \\
1927 & 211,4 & 158,4 & $-53,0$ \\
1928 & 233,5 & 173,5 & $-50,0$ \\
1929 & 256,3 & 155,2 & $-101,1$ \\
\hline
\end{tabular}

1927 wurde die erste umfassende statistische Enhebung in der Geschichte der Türkei durchgeführt. Sie erbrachte einige aufschlußisreiche Resuitate. Danach erhöhte sich die Zahl der Beschäftigten in gewerblichen Be trieben von $76.216 \mathrm{im}$ Jahre 1921 auf 256.000 in 65.265 Betrieben, die sich verteilten auf die verschiedenen 2 weige, wie folgt: $(67)$

Tabelle 2

\begin{tabular}{lrrrrr}
\hline & $\begin{array}{c}\text { Anteil am Produk- } \\
\text { tionswert in } \%\end{array}$ & \multicolumn{2}{c}{$\begin{array}{c}\text { Zahl der Betriebe ritit } \\
1.3\end{array}$} \\
& & $\begin{array}{c}4-10 \\
\text { Beschäfigten }\end{array}$ & 51 u.mehr \\
\hline Nahrungsmittel & 61,1 & 22.184 & 5.421 & 736 & 98 \\
Textilien & 17,6 & 6.894 & 2.024 & 339 & 96 \\
Chemie & 4,0 & 500 & 143 & 51 & 3 \\
Holz & 3,5 & 6.544 & 1.142 & 181 & 29 \\
Metall & 3,3 & 13.181 & 1.418 & 130 & 16 \\
Bergbau & 2,9 & 217 & 187 & 101 & 51 \\
Sonstiges & 3,6 & 2.035 & 1.288 & 201 & 28 \\
\hline Insgesamt & 100,0 & 51.56211 .623 & 1.739 & 321
\end{tabular}

65) Vgl. Bulutoglu, K, a.a.O., S. 109, Avcioglu, D., a.a.O. S.178, Sertel, Y., a.a.0., S.24

66) Vgl. Quelle, Siatistisches Jahrbuch, zit. n. Bulutoglu, K., a.a.0., S. 113

67) Vgi. Quelle: "T. C. Istatistik Yilligi, 1929", Ankara, 1929, S.137,0gü, A., "Wirtschaftslenkung", \$. 61, zit. n. Steinhaus, K., a.a.O., \$. $127-128$ 
Es zeigt sich, daß von einer Industrialisierung noch kaum die Rede sein kann. $79 \%$ der Betriebe beschäftigen zwischen 4 und 10 Personen, und nur 321 Unternehmen haben mehr als 50 Beschäftigte.

2.822 Betriebe hatten Antriebsmaschinen mit durchschnittlich 58 PS. Fast $80 \%$ des Produktionswerts wurde von der Land- und Forstwirtschaft erwirtschaftet. (68)

Die Weltwirtschaftskrise, das Ausbleiben des gewünschten wirtschaftlichen Erfolgs, vor allem aber die Erfahrung, daß die durch den Staat unterstiitzte nationale Bourgeoisie doch nicht die in sie gesetzten Erwartungen erfullen konte, fihren zu der zweiten ("etatistischen") Phase der Ara Atatïk.

\subsection{Erfolge durch den Etatismus}

Der Staat sollte nun in allen Zweigen der Wirtschaft intervenieren und die Kontrolle ubernehmen. Die Skepsis der Regierung gegenuber dem Systern des ${ }^{6}$ laisser faire" wachs angesichts der katastrophalen Folgen der Weltwirtschaftekrise in der kapitalistischen Welt. Hinzu kam die Tatsache der wachsenden wirtschaftlichen Erfolge der Sowjetunion, des bis dahin einzigen sozialistischen Staates, der seine anfänglichen Schwierigkeiten uberwunden hatte. 1928 begann die Regienug mit der Ruckzahlung der "osmanischen Schulden", was eine große Belastung darstellte. Ein Jahr später konnten endlich die Zollsätze von 1916 aufgehoben werden, so daß man nun den Außenhandel nach eigenem Emessen dirigieren und kontrollieren konnte.

Das etatistische Programm wurde ab 1930 in der neuen Zeitschrift "Kadro" (Programm) auch theoretisch entwickelt und verbreitet. Obwohl der Etatismus nach 1930 an Bedeutung gewann, gewährte die Regierung privaten Unternehmem weiter. hin finanzielle Unterstuitzung und steuerliche Vorteile. Bis zum ersten Fünfjahresplan wurde die Politik der "Fördenung des Privatuntemehmers" beibehalten, aber gleich. zeitig wurde die Kontrolle des Staates über die ganze Wirtschaft ausgedehnt. Die er. zielten Erfolge in den staatlichen Sektoren der Wirtschaft verstärkten die Ủberzeu. gung, daß die Industrialisierung am ehesten durch staatliche Planung und Leitung ermöglicht würde. Beispielsweise wurden bei der Produktion von Textilien, Zement und Zucker durch staatliche Investitionen zwischen 1927 und 1933 Produktionssteigerungen von 300 bis $1.200 \%$ erzielt. (69)

Wie alle Länder der Dritten Welt, die auf die Ausfuhr von Nahrungsmitteln und/oder Rohstoffen angewiesen sind, mußte auch die Tükei durch die Verschlech terung der Weltpreisrelationen $32,4 \%$ Verluste hinnehmen. (70)

Dennoch verbesserte sich die Zahlungsbilanz der Türkei ab 1929 (nach der Erhöhung der Zollsätze), trotz der Schuldenzahungen, die z. B. $193014,6 \%$ des ge. samten Etats ausmachten. (71)

Die größten Erfolge wurden unter dem ersten Fünfahresplan (yon 1933 bis

68) Vgl. Gross, H., "Südosteuropa". Bau und Entwicklung der Wirtschaft, Leipzig, 1967, zit. n. Steinhaus, K., a.a.O., S. 128

69) Vgl. Kienitz, F. K., "Türkei, Anschluss an die moderne Wirtschaft unter Kemal Atatürk" Hamburg, 1959, S. 106, vgl. Oguz, A. "Dic Wirtschaftslenkung der Türkei unter besonderer Berücksichtigung des Bankwesens", Beriin, 1940, S. 70, zit. n. Steinhaus, K.,a.a.O., S. 129

70) Vgl. Okkar, A. E., Der Titkische Aubenhandel und die Aufenhandelspolitik der Türkei unter der Republik 1923 bis 1938, IstanbuI, 1943, \$. 82, Resat, N., "Die Industrialjierung der Türkei", 1937, zit. n. Steinhaus, K., a.a.O., S. 229

71) Vgl. Avcioglu, D., a.a.O., S. 179 , Bulutoglu, K., a.a.O., S. 113 
1937) und dem zweiten Fünfjahresplan (Der ganze Plan konnte wegen des Krieges nicht durchgeführt werden) bis 1939 erzielt.

In dieser Phase wurde das Fundament der modernen Türkei gelegt. Das Pro. gramm der von Atatürk 1925 gegründeten Volkspartei (CHP) enthielt folgende Prin. zipien:

1. Die Quelle des Kapitals ist die nationale Arbeit und Sparsamkeit.

2. Für das Ziel einer positiven Zahlungsbilanz gilt das Motto, nur die notwendigsten Produkte einzuführen und zwar von denjenigen Ländern, die türkische Erzeugnisse kaufen.

3. Durch Schutzzölle werden Industrie und Handel geschützt.

4. Die Industrialisierung des Landes, staatliche und private Investitionen erfolgen nach einem Grundplan.

5. Die Landesverteidigung ist heilig. (72)

Der Grundgedanke des ersten Fünfjahresplans war, zunächst die Projekte zu verwirklichen (durch Erschließung der eigenen Ressourcen), die erstrangig für die weitere Entwicklung des Landes waren. Dazu gehörten Unabhängigkeit von den Massenprodukten des Auslands, positive Zahlungsbilanz und beschleunigte Erhöhung der Produktivität der Landwirtschaft.

Von den verfügbaren Mitteln wurden $50 \%$ in der Textilindustrie, $26,8 \% \mathrm{im}$ Montanbereich, 10,9\% in der Papier- und Zellstoffindustrie, $4,7 \%$ in der Glas- und Keramikindustrie, 5,6\% in der chemischen Industrie investiert, $1,1 \%$ wurden für die Ausbildung des technischen Personals zur Verfügung gestellt. (73)

1937 bis 1939 wurde das Eisen- und Stahlwerk Karabuk mit einer jährlichen Kapazität von $350.000 \mathrm{t}$ Roheisen und $280.000 \mathrm{t}$ Stahl gebaut. (74)

Eine Landreform, die Atatürk spätestens seit 1935 anstrebte (1923 war davon auf dem alltürkischen ökonomischen Kongress noch nicht die Rede), blieb infolge des Widerstands der Großgrundbesitzer Projekt. Der Gesetzentwurf für Landverteilung und für die Begrenzung der Bodengröße je nach der Fruchtbarkeit des Bodens konnte weder von der Regierung Atatürk noch jemals von einer späteren Regierung in die Tat umgesetzt werden. Zu den ge planten Maßnahmen fürte Atatürk im Parlament aus: "Zum ersten soll es keine landlosen Bauem geben. Noch wichtiger ist es aber, daß . . die Landgröße der Großbauern und die Farmgröße je nach den Provinzen, der Bevölkerungsdichte und der Landesfruchtbarkeit begrenzt wird." (75) Die veränderte Haltung der kemalistischen Führung hatte verschiedene Gründe:

1. 1923 sah Atatürk die Notwendigkeit für eine Landreform als nicht gegeben, da noch 1927 nur 5 bis $6,5 \%$ des gesamten Bodens bewirtschaftet wurden. (76)

2. Die Kräfteverhältnisse ließen es wahrscheinlich schon damals nicht zu, eine Landreform zu planen.

Statistiken in 35 Provinzen ergaben, daß 0,25\% der Bodenbesitzer $14 \%$ der landwirtschaftlichen Nutzflächen besaßen. (77)

Zwischen 1923 und 1934 wurden an Einwanderer, Austauschheimkehrer und landlose Bauern über 6 Mill.Döpüm staatlichen Bodens verteilt und von 1934 bis

72) Vgl. Programm đer Republikanischen Volkspartei, genehmigt vom IV. Großen Parteitag, Ankara, 1935, Teil II, Abschnitt D, S. 6-7, zit. n. Barthel, G., a.a.O., S. $72-73$

73) Vgl. Kienitz, F.K., a.a.O., S. 111, Mahoudji, A.E., a.a.O.s. 121-122, zit. n. Barthel,G. S. 75

74) Vgl. Barthe1, G.. a.a.O.. S. 76

75) Atatürkün Söylev ve Demecleri, I, Istanbul 1945, S. 379

76) Aksoy, S., Türkiyede Toprak Meselesi, S. 54

77) Aksoy, S., a.a.O., S. 58-59 
19383 Mill-Döpüm. Die Kredite für die Bauern wurden von 8 Mill.TL im Jahre 1923 auf 35 Mill.TL im Jahre 1936 erhöht, wobei die Hauptnutznießer die Großgrundbesitzer waren.

Es wurden staatliche Musterfarmen gegründet, landwirtschaftliche Schulen und Stationen eingerichtet. Die Bauern, die für die Modernisierung der Landwirtschaft Maschinen und Traktoren kaufen wollten, erhielten staatliche Subventionen. (78)

Die Weizenerzeugung erhöhte sich von 1,5 Millot im Jahre 1928 auf 2,5 Millot im Jahre 1935. Die Türkei, die vorher Weizen einführen mußte, konnte nun Weizen exportieren (1934 87.000 t) (79). Die Getreideernte stieg von 5,3 Mill.t (1930) auf 8,4 Mill.t (1938). (80)

Auch das Verkehrswesen verbesserte sich beachtlich. Eisenbahn und Schifffahrt wurden verstaatlicht, das Eisenbahnnetz fast verdoppelt $(19234.010 \mathrm{~km}$; $19397.324 \mathrm{~km}$ ) und neue Straßen angelegt. (81) dehnt.

Das Bankwesen wurde verbessert und durch Griindung neuer Banken ausge-

Die folgenden Tabellen veranschaulichen die Entwicklung der Wirtschaft zwischen 1923 und 1939:

Tabelle 3 Die türkische Zahlungsbilanz 1923 - 1939 (in Millionen TL) (82)

\begin{tabular}{llrl}
\hline Jahr & Importe & Exporte & Saldo \\
\hline 1923 & 144,8 & 84,7 & $-60,1$ \\
1924 & 193,6 & 158,9 & $-34,7$ \\
1925 & 241,6 & 192,4 & $-49,2$ \\
1926 & 234,7 & 186,4 & $-48,3$ \\
1927 & 211,4 & 158,4 & $-53,0$ \\
1928 & 223,5 & 173,5 & $-50,0$ \\
1929 & 256,3 & 155,2 & $-101,1$ \\
1930 & 174,6 & 151,5 & $+3,9$ \\
1931 & 126,7 & 127,3 & $+0,6$ \\
1932 & 86,0 & 101,3 & $+15,3$ \\
1933 & 47,7 & 96,2 & $+21,5$ \\
1934 & 86,8 & 92,1 & $+5,3$ \\
1935 & 88,8 & 96,0 & $+7,2$ \\
1936 & 92,5 & 117,7 & $+25,2$ \\
1937 & 114,4 & 138,0 & $+23,6$ \\
1938 & 149,8 & 144,9 & - \\
1939 & 118,2 & 127,4 & $+9,9$ \\
\hline
\end{tabular}

Wie zu sehen ist, wurde ab 1930 (nachdem 1929 die niedrigen Zollsätze von 1916 aufgehoben waren) ein aktiver Saldo crzielt.

78) Vg1. Avcioglu, D., a.a.O., S. 229

79) Vgl. Sertel, Y., a.a.O., S. 48

80) Vgl. Istatistik Yilligi 1934, Ankara-Istanbul S. 331

81) Vgl.Sertel, Y., a.a.O., S. 44

82) Vgl. Bulutoglu., a.a.O., S. 113

5 Probleme des Klassenkampis Nr. 5 


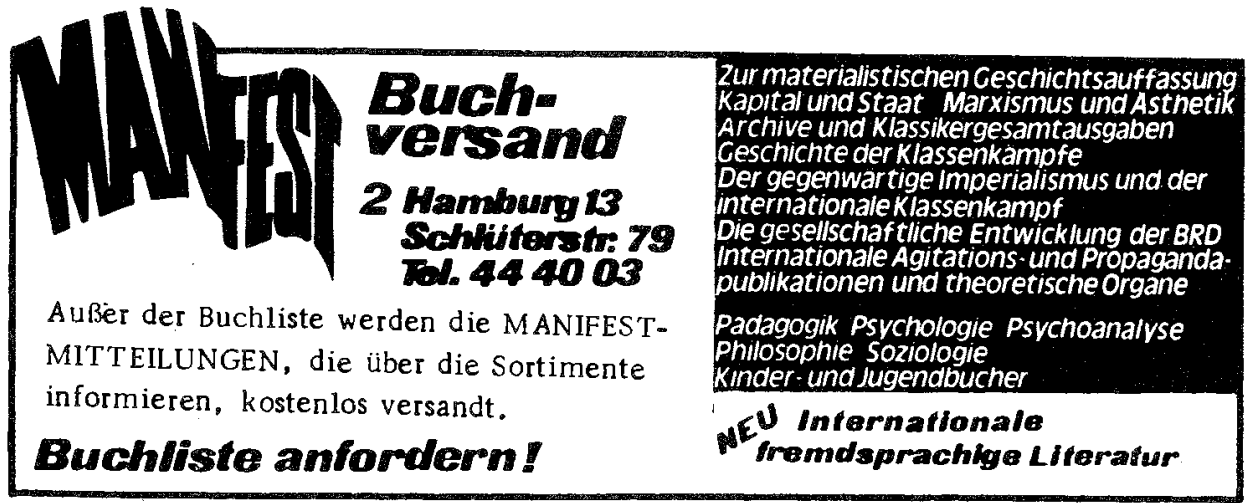

Diese Tabelle spiegelt den wirtschaftlichen Aufschwung wider: Rückgang des Imports von Agrar- und Textilprodukten, die nun im Lande produziert wurden und die Steigerung des Imports von Maschinen, Eisen und Stahl für die einsetzende Industrialisierung.

Tabelle 4 (83) Anteil am Einfuhrwert in v.H.

\begin{tabular}{lrr}
\hline & 1923 & 1938 \\
\hline Nahrungsmittel & 16,8 & 2,8 \\
Woll- und Baumwolltuche & 39,2 & 13,9 \\
Woll- und Baumwollgarne & 4,2 & 6,0 \\
Maschinen & 0,9 & 15,3 \\
Eisenund Stahl & 5,4 & 18,8
\end{tabular}

Tabelle 5 (84) Ausgewählte ökonomische Kennziffern im Vergleich

\begin{tabular}{lrcc}
\hline & 1929 & 1939 & Zunahme in \% \\
\hline $\begin{array}{l}\text { Eisen bahnnetz (in km) } \\
\text { Eisenbahngüterverkehr }\end{array}$ & 5.144 & 7.326 & 42 \\
$\quad$ (in Mio t km) & 356 & 1.564 & 339 \\
Straßennetz (in km) & $29.636(\mathrm{a})$ & $41.600(\mathrm{c})$ & 41 \\
$\begin{array}{l}\text { Elektrizitätse rzeugung } \\
\quad(\text { in Mio kWh) }\end{array}$ & $106(\mathrm{a})$ & 253 & 233 \\
Steinkohleförderung & & & \\
$\quad$ (in 1000 t) & 1.451 & 2.696 & 86 \\
Chromföderung (in 1000 t) & 16 & 183 & 1.044 \\
Zementproduktion (in 1000 t) & 65 & 284 & 337 \\
Zuckerproduktion (in 1000 t) & 8 & 95 & 1.008 \\
Garnproduktion (in 100 t) & 23 & $90(\mathrm{~b})$ & 291 \\
\hline
\end{tabular}
(a) 1930
(b) 1938
(c) 1940

83) Vgl. Quelle: T.C. Istatistik Yilligi 1938-1939, S. 231-262, zit. n. Steinhaus, K. a.a.o.,S.133

84) Vgl. Quelle: T.C. Istatistik Yilligi 1940-41, Ankara, S. 223 
Diese Tabelle zeigt, daß trotz der Weltwirtschaftskrise und trotz der "Schuldenriickzahlungen" die türkische Regierung beachtliche Erfolge in fast allen Zweigen der Wirtschaft aufweisen konnte.

Auch im Sozial- und Kulturwesen unternahm Atatürk große Anstrengungen. Welche Bedeutung er dem Aus- und Aufbau des Bildungswesens beimaß, wird an der Rede deutlich, die er vor dem Lehrerverein in Bursa 1922 hielt: "Lehrer! Der Sieg unserer Armee bereitete Euch und Euren Armeen nur die Basis. Der tatsächliche Sieg wird durch Euch errungen. Ich und meine Freunde werden mit einer unsterblichen Überzeugung hinter Euch stehen. Wir werden alle auf dem Wege stehenden Barrikaden zerbrechen." (85)

Außer der Verstaatlichung des Großgrundbesitzes konnte ein weiteres, kühnes Projekt aus dem Jahre 1923 bis zum heutigen Tage nicht verwirklicht werden. Atatürk wollte die kleinen, in unzugänglichen Gebirgsgegenden verstreuten Dörfer $\mathrm{zu}$ größeren Einheiten zusammenfassen, um Ausgaben für das Schulwesen, für StraBen und die Trinkwasserversorgung einzusparen. (86)

Gegen erbitterten Widerstand wurder zahlreiche Reformen durchgesetzt, die die "Westernisierung und Säkularisierung der Kultur" (Steinhaus) einleiteten: "Bereits 1925 wurde die islamische Zeitrechnung durch den international üblichen Kalender ersetzt, das Recht zum Tragen religiöser Kleidungsstücke allein auf Geistliche beschränkt und die traditionelle Kopfbedeckung - der Fes - verboten." (87) 1928 wurde die arabische Schrift durch das lateinische Alphabet ersetzt. Die türkische Sprache, die unter dem Einfluß des Islam viele arabische und farsische (altpersische) Elemente angenommen hatte, wurde "türkisiert".

Die Rechtsreformen lösten das vom Islam abstammende "Seriat" durch den Schweizer Code Civil ab. Auf dem Gebiet des Strafrechts dienten das italienische Strafgesetzbuch und die deutsche Strafprozeßordnung als Vorbilder. 1934 erhielten die Frauen das aktive und passive Wahlrecht. Auch die Monogamie, die Zivilehe und die Gleichberechtigung von Mann und Frau wurden Verfassungsnorm.

Diese Reformen unter Atatürk legten das Fundament des neuen türkischen Staates. Sie wiesen den Weg für eine erfolgreiche antiimperialistische, blockfreie Außenpolitik und für den Nelaufbau im Innern des Landes. Eine kritische Würdigung der Verdienste Atatürks darf aber nicht seine Fehler übersehen, die in erster Linie aus einer Fehleinschätzung der sozialen Lage der Türkei resultie rte. Er glaubte, in der Türkei gebe es keine Klassen, da die Kluft zwischen Reich und Arm gering sei. Durch Reichwerden der Armen würden die vorhandenen Differenzen beseitigt. Damit näherte er sich, wenn auch ohne tiefere Kenntnisse der marxistischen Klassiker, der Haltung Bernsteins. Er sah nicht den Widerspruch, der in seiner (stark vereinfacht dargestellten) theoretischen Position und der staatlichen Unterstützung der Privatunternehmen lag, die die Klassengegensätze zwangs" "ufig vergrößern mußte.

Dennoch können wir mit Bestimntheit sagen: hätten Atatürks Nachfolger seine Politik - auch mit ihren Fehlern und Widerspriichen im Sinne seiner sechs Postulate weitergeführt, würde sich uns heute nicht das Bild eines unterentwickelt gehaltenen Landes bieten, über das die neoimperialistischen Staaten weitgehend dic Oberhand gewonnen haben.

85) Cumhurbaskanlari, Basbakanlar ve Milli Egitim Bakanlarinin Milli Egitimle ilgili Söylev ve Demecleri, Ankara 1946, zit. n. Basgöz, I. - Wilson, E.H., Türkiye Cumhuriyetinde Egitim ve A tatürk, Istánbul, 1968, S. 77

86) Vgl. ebenda, S.97

87) Steinhaus, K., a.a.O., S. 110 


\section{Die Integration der Türkei in das westliche Bündnissystem}

Nach dem Tod Atatürks (1938) wurde die erfolgreiche blockfreie und antiimperialistische Außenpolitik aufgegeben. Wir müssen hier auf eine tiefergehende Analyse dieser Kursänderung verzichten und können nur einen knappen Überblick der wichtigsten Gründe hierfür geben.

Der Neuaufbau der Türkei war im wesentlichen das Werk Atatürks. Da nach dessen Ausscheiden keine ihm kongeniale Persönlichkeit seinen Platz einneh. men konnte, erhielten die Versäumnisse seiner Politik, die meist in der Rückständigkeit der Türkei gründeten, Relevanz. Die Masse der Bevölkerung war nicht in der Lage, bestimmend auf die Politik einzuwirken, und die Schicht der ehrlichen progressiven Intellektuellen zu dünn, um die Kontinuität der kemalistischen Politik gemeinsam mit einer "gebändigten" Bourgeoisie zu wahren.

Die Geschichte lehrt, daß ein unterentwickeltes Land (wie es auch die Türkei trotz aller unter Atatürk erzielten Fortschritte blieb) sich schwerlich dem imperialistischen Druck entziehen kann. Obwohl die Türkei zu ihrem großen Nachbarstaat Sowjetunion sehr gute Beziehungen unterhielt, befürchtete sie dennoch nach dem Einmarsch Hitler-Deutschlands in die Tschechoslowakei und des faschistischen Italiens in Abessinien einen Einfall dieser Staaten. Daher versuchte sie ihre Beziehungen zu Großbritannien und Frankreich zu verbessern. Dies war natürlich ein günstiger Moment für diese Staaten, ihren Einfluß in der Türkei auszudehnen, und sie nutzten skrupellos die ihnen gebotene Chance, die antiimperialistische Politik Atatürks zu unterminieren. Am 12. Mai 1939 unterzeichnete die Türkei jeweils getrennt mit Frankreich und Großbritannien sogenannte "Gegenseitige Hilfe- und Beistandsverträge."

Nach dem Abschluß des Nichtangriffspakts zwischen Deutschland und der Sowjetunion und der Kriegserklärung Großbritanniens und Frankreichs an Deutschland nach dessen Einmarsch in Polen war die türkische Regierung bestrebt, ihr Verhältnis zur Sowjetunion zu klären. Am 25. September fuhr der türkische Außenminister nach Moskau. Stalin verlangte von der Türkei die gemeinsame Verteidigung des Bosporus und der Dardanellen, was die Türkei jedoch nicht akzeptieren konnte. In der Folge gestaltete die Türkei ihre Beziehungen zu Großbritannien und Frankreich durch den Abschluß einer Dreierallianz noch enger (19. Oktober 1939). (88)

Damit hatte sich die außenpolitische Situation entscheidend geändert: Die Beziehungen zur Sowjetunion kühlten sich ab, und die Beziehungen zu Großbritannien und Frankreich wurden intensiver. Die Alliierten drängten die Türkei während des Krieges immer wieder, in den Krieg einzutreten, was die türkische Regierung unter Inönü aber verhindern konnte.

Trotz dieses unbestreitbaren Erfolges ist der neuen Regierung vorzuwerfen, daß sie besonders durch die allmähliche Aufgabe der sehr vorsichtigen und zurück: haltenden Wirtschaftspolitik Atatürks gegenüber den imperialistischen Staaten und der Umstellung eines großen Teils der Volkswirtschaft von der Friedenswirtschaft auf Kriegswirtschaft den Weg für die Rückkehr der imperialistischen Mächte ebnete.

1939 nahm die Türkei einen Kredit in Höhe von 25 Mill.Pfund Sterling von Großbritannicn auf, um damit Waffen kaufen zu können. Weitere zwei Millionen

88) Vgl. Celik, E., Türkiyenin Dis Politika Tarihi, Istanbul, 1969, S. 103-104

Avcioglu, D., a.a.O., S. 256-265 
folgten. Darüber hinaus gewährten Großbritannien und Frankreich im selben Jahr noch einmal 15.Mill Pfund Sterling. (89)

Am 2. Oktober 1941 wurde mit Deutschland ein Abkommen über den Warenund Zahlungsverkehr abgeschlossen.

Die USA lieferten während des Krieges für 95 Mill.Dollar Kriegsmaterial, welches nach dem Kriege zurückgegeben werden sollte. (90) Die während des Krieges aufgenommenen Kredite fallen jedoch noch nicht so sehr ins Gewicht, Erst nach dem Krieg öffnete die Türkei den imperialistischen Staaten, an erster Stelle den USA, wieder Tor und Tür. Seit 1946 begann die Türkei die kemalistischen Grundprinzipien preiszugeben und ein Staat im westlichen Bündnissystem zu werden.

Bei der Annäherung der Türkei an den Westen spielte die Haltung Stalins eine entscheidende Rolle. Er verhinderte die Verlängerung des "Freundschafts- und Nichtangriffspakts" zwischen der Türkei und der Sowjetunion aus dem Jahre 1925, da er an eine Verlängerung folgende Bedingungen knüpfte:

1. Die Grenzen von 1921 zwischen der Sowjetunion und der Türkei, die Lenin noch akzeptierte, sollten zugunsten der Sowjetunion geändert werden.

2. Die Dardanellen und der Bosporus sollten von der Türkei und der Sowjetunion gemeinsam verteidigt werden. Deshalb sollte die Sowjetunion die Erlaubnis zur Errichtung von Militärbasen in der Türkei erhalten.

3. Über die Revision des Vertrages von Montreux, wonach der Türkei die Kontrolle über die Meerengen wieder zugesichert wurde, sollte zwischen der Sowjetunion und de r Türkei eine prinzipielle Vereinbarung getroffen werden. (91) Die türkische Regierung konnte diese Forderungen nicht annehmen und wurde dadurch gezwungen, Rückhalt im kapitalistischen Lager zu suchen.

Die Haltung Stalins gab sowohl dem rechten Flügel der Republikanischen Volkspartei (die Partei Inönüs), als auch der 1946 gegründeten "Demokratischen Partei", die schon von sich aus gewillt war, die Beziehungen zum Westen zu verbessern, Anlaß zu einer bis heute andauernden antisowjetischen und antisozialistischen Propaganda. Die inkonsequente Haltung der türkischen Führung gegenüber der Sowjetunion während des Krieges und die Weigerung, die Meerengen (Datdanellen und Bosporus) freizugeben, ist nach unserer Meinung kein hinreichender Grund für Stalins Vorgehen. ${ }^{6}$ Wir wissen nicht, ob Stalin die blockfĩeie Außenpolitik und die innenpolitische Entwicklung der Türkei hätte beeinflussen können, wenn er wie vor dem Krieg die türkische Entwicklung unterstützt hätte, statt Land und Militärbasen zu verlangen. Aber sicher ist, daß die Haltung Stalins die Außen- und Innenpolitik der Türkei beeinflußt hat." ( $(92)$

\subsection{Truman-Doktrin}

Die türkische herrschende Klasse wandte sich trotz der jahrhundertelangen (schlechten) Erfahrungen mit dem Imperialismus und trotz der von Atatürk vorgezeichneten Praxis wieder jenen Staaten zu, die seine wirtschaftliche Entwicklung blockie ren würden.

Die Verkündung der Truman-Doktrin im Jahre 1945 und die Einbeziehung

89) Vgl. Sertel Y., a.a.O., S. 62

90) Vgl. Bilge, S., Olaylarla Türk dis Politikasi, Istanbul, 1970, S. 225-226

91 Vgl. Celik, E., a.a.O., S. 121-122, Avcioglu, D., a.a.O., S. 256-65

92) Avcioglu, D., a.a.O., S. 263-264 
der Türkei in ihren Geltungsbereich markiert den entscheidenden Wendepunkt in der Geschichte der Türkei, denn von nun an stand sie wieder unter dem Einfluß der imperialistischen Staaten. Die Truman-Doktrin entsprach in ihren Auswirkungen der "Düyun-u Umimiye", die die Industrialisierung des Osmanischen Reiches verhinderte und seinen Untergang besiegelte.

Nach dem Inkrafttreten der Truman-Doktrin am 22. Mai 1947 erhielten die Türkei und Griechenland 400 Mill.Dollar als "Hilfe" in Form von Krediten.

Gleichzeitig kamen militärische und zivile amerikanische Berater und Beobachter ins Land, und ausgewählte Griechen und Türken wurden in den USA ausge: bildet.

Die Beobachter hatten die Aufgabe, die Erfüllung der an die US- "Hilfe" geknüpften Forderungen zu kontrollieren. Bei der Ausübung ihrer Aufsicht mußsten ihnen alle gewünschten Informationen zugänglich gemacht werden. Sie wurden durch amerikanische Presse- und Rundfunkuntemehmen unterstiutzt, die ungehinderte Bewegungsfreiheit genossen. (93)

Der Kolumnist Walter Lippmann schrieb in der New York Herald Tribune am 1. April 1947: "Wir haben die Türkei und Griechenland nicht etwa als Hilfsobjekte gewählt, weil sie Hilfe brauchen oder weil sie Demokratien sind, sondern wir haben sie gewählt, weil sie das Tor zum Herzen der Sowjetunion und zum Schwarzen Meer öffnen." (94) Die Truman-Doktrin bezweckt, daß jene Länder, die ihrem Einfluß unterliegen, die Verteidigungsaufgaben der USA übernehmen. Da die USA ihre Sicherheit von der sicheren Kontrolle der Länder der Dritten Welt abhängig sehen, brauchen sie entweder eine sehr große eigene Armee, die jederzeit diese potentiellen Grenzen der USA schützen kann, oder aber, was weitaus günstiger ist, von den USA abhängige einheimische Armeen. Die Truman-Doktrin bevorzugt letzteres, weil einheimische Soldaten wesentlich billiger als amerikanische sind. Die Ausgaben für einen US-Soldaten betragen jährlich 4.500 Dollar, während die Ausgaben für Soldaten der Länder, denen militärische Hilfe gewährt wird, nur 540 Dollar betragen. (95) Die Türkei stellt für die westliche Verteidigung 18 Divisionen. Die Kosten dafür würden sich in den USA auf etwa 9 Mrd. Dollar belaufen, betragen in der Türkei hingegen nur ein Achtel dieser Summe. (96)

"Die Truman-Doktrin wurde zu keiner Hilfe für die Türkei und Griechenland, sondern sie ist," schreibt Ataoy, "dic neae Form des langiärig erfahrenen US-Impe. rialismus. Da die Engländer im Nahen Osten nicht mehr als die erstrangigen Wächter des Imperialismus fungieren komnten, ibergaben sie ihre alte Rolle den USA, die das Atommonopol innehaben und als größter kapitalistischer Staat aus dem letzten Krieg hervorgingen." (97)

Mit dem Marshall-Plan schufen die USA ein Instrument, das sich in hervor. ragender Weise eignete, die Zielsetzung der Truman.Doktrin noch wirksamer zu realisieren. Er war dazu geschaffen, sozialistische Bewegungen in den. Ländern, denen Hilfe gewährt wurde, im Keim zu ersticken, um die für den Bestand des Kapitalismus unerlässliche "kapitalistische Umwelt" zil erhalten und um diese gegenüber dem sozialistischen Lager zusammenzuhalten.

93) Vgl. Tunckanat, H., Ikill antlasmalarm Icyizi, Ankara, 1970, S. 189-193, Celik, Eّ, a.a.O., S, $129-134$

94) Zit. n. Aveioglu, D., a.a.0., S. 249

95) Avcioglu, D.; a.a.O., S. 267

96) Vgl. Fahri, M. Amerikan Harp Doktrinleri, lstanbul 1966, Onsöz, zit, n. Avioglu, D. a.a.O., S. 267

97) Ataöv, ', , a.a.O., Ankara, 1969, S. 117 
Nach anfänglicher Ablehnung (da die Türkei durch den Krieg keine Verluste erlitten hatte) kam auch die Türkei in den "Genuß" des Marshallplans. Mit diesen Mitteln sollte sie die Landwirtschaft und den extraktiven Bereich entwickeln, um als Nahrungsmittel- und Rohstofflieferant für die imperialistischen Staaten zu fungieren. Bei der Vergabe dieser Hilfe spielten strategische Überlegungen eine große Rolle.

\subsection{Teure Zusammenarbeit mit dem Westen}

Am 8. Juli 1948 ratifizierte das türkische Parlament den US-Türkischen "Vertrag über die ökonomische Zusammenarbeit." Bis Ende des Rechnungsjahres 1949/ 50 erhielt die Türkei 180 Mill-Dollar. (98)

Der Vertrag machte der Türkei zur Auflage, alle staatlichen oder privaten Hindernisse im Außenhandel zu beseitigen. (99) Bereits 1947 war ein "Gesetz zur Förderung des ausländischen Kapitals" verabschiedet worden, wonach Erleichterungen für ausländische Investoren Gesetzeskraft erhielten. (100) Nach Hershlag wurde diese Liberalisierung durch zunehmenden Druck von außen in Gang gesetzt. (101)

Die ausländischen Berater forderten und erreichten schließlich die Liberalisierung der Wirtschaft und Abkehr von der staatlichen Planung und dem Etatismus Atatürks zugunsten des privaten Unternehmertums und des ausländischen Kapitals. Beispielhaft ist die einflußreiche Wirtschaftskommission unter M. W. Thornburg, die einen Bericht mit dem Titel "Kritik der heutigen Wirtschaftslage der Türkei" veröffentlichte, in der die Frage abgehandelt wird, ob, wie und unter welchen Bedingungen der Türkei "Hilfe" geleistet werden solle. Es werden die genannten Forderungen erhoben, darüberhinaus empfiehlt sie z. B., die Eisen- und Stahlfabrik in Karabük zu liquidieren. Wörtlich: "Es ist ein Prüfstein für die US-Hilfe, ob die zuständigen Behörden der Türkei den Mut zeigen und bereit sind, die notwendigen Änderungen zu machen; ob sie Karabük für die wahren Interessen des türkischen Volkes hingeben wollen oder nicht." (102)

Projekte, für die die Türkei Kredite beantragte, wie der Bau einer Lokomotivfabrik und einer Maschinen- und Motorenfabrik lehnte Thornburg entschicden ab. Die Türkei sei ein Agrarstaat und brauche deshalb nur einfache Werkzeuge für die Landwirtschaft, kompliziertere Maschinen könnten ja montiert werden und brauchten deshalb nicht im Lande produziert zu werden. (103) An anderer Stelle spricht er sich auch gegen die Herstellung von Düngemitteln in der Türkei aus. (104) Die Türkei brauche auch keine eigene Handelsflotte. Die ausländischen Investoren sollten die gleichen Rechte wie die inländischen Investoren erhalten. Ein Kommentar zu diesen Feststellungen und Empfehlungen, die noch nicht einmal vollständig aufgezählt worden sind, erübrigt sich. Die mit all diesen Bedingungen verbundene US"Hilfe" bewirkte, daß die unter Atatürk begonnene Industrialisierung gebremst wurde.

98) Avcioglu, D., a.a.O., S. 270

99) Vgl.: Agreement between the U.S.A. Government and tha Government of the Turkish Re public on AID to Turkey, Washington, 1947, S. 2, zit. n. Sertel, Y., a.a.O., S. 74

100) Sertel, Y., a.a.O., S. 74

101) Hershlag, Z. Y., "Turkey, an Economy in Transition", The Hagve, 1958, S. 184, zit. n. Sertel, Y., a.a.O., S. 74-75

102) Thornburg, M. V., Türkiyenin Bugünkü Ekonomik Duru munun Tenkidi, Ankara, 1950 S. 119

103) Vgl. ibid., S. 92

104) Vgl. ibid., S. 137 
Diese den Interessen des türkischen Volkes diametral entgegengesetzten Vorschläge fanden jedoch in der Öffentlichkeit große Beachtung. Die Zeitung "Vatan" (Heimat) bezeichnete Thornburg als "großen Freund der Türkei".

Die Türkei verschwendete 6 Jahre lang (1939-1945) über die Hälfte ihres Budgets (durchschnittlich 53,56 \%) für Verteidigungsausgaben. Die vorhandene Industrie wurde auf Rüstungsbedarf umgestellt. Eine Armee von 500.000 Mann (bei einer Einwohnerzahl von 18 Mill!) mußte unterhalten werden. Da der größte Teil der Soldaten bäuerlicher Herkunft war, fehlten in der Landwirtschaft Arbeitskräfte - die landwirtschaftliche Produktion ging zurück. Die Emteerträge verminderten sich fast um die Hälfte und die Türkei, die vor dem Krieg Weizen exportiert hatte, mußte jetzt wieder Weizen importieren. (Außerdem mußten die Bauern ca. 10 - 12\% ihrer Erzeugnisse als Steuern abgeben.) (105) Die Folge war eine Hungersnot und die Rationalisierung der Lebensmittel.

Die Industrie erhöhte ihre Produktion zwischen 1939 und 1945 um 15,4\%, orientiert an Kriegswirtschaft mit Schwergewicht im Bergbau und in der verarbeitenden Industrie auf Kosten der gesamtindustriellen Entwicklung. Die staatlichen Investitionen sanken von $18,62 \%$ des Etats im Jahre 1939 auf $13,75 \%$ im Jahre 1945. (106) Durchschnittlich stieg die industrielle Produktion von $1939-1945$ jahrlich um 2,5\%. (107) Nachstehend die Entwicklung des türkischen Außenhandels von $1939 \cdot 1950 \cdot(108)$

Tabelle 6 Außenhandel in Millionen $T L$

\begin{tabular}{crrr}
\hline Iahr & Import & Export & Saldo \\
\hline 1939 & 118,2 & 127,4 & $+9,2$ \\
1940 & 68,9 & 111,4 & $+42,5$ \\
1941 & 74,8 & 123,1 & $+48,5$ \\
1942 & 147,7 & 165,0 & $+17,3$ \\
1943 & 203,0 & 257,2 & $+54,2$ \\
1944 & 169,9 & 232,5 & $+67,6$ \\
1945 & 126,2 & 218,9 & $+92,7$ \\
1946 & 223,9 & 432,1 & $+208,2$ \\
1947 & 685,0 & 625,2 & $-59,8$ \\
1948 & 770,1 & 551,0 & $-219,1$ \\
1949 & 812,3 & 693,9 & $-118,4$ \\
1950 & 799,9 & 737,6 & $-62,3$
\end{tabular}

105) Vyl. Sertel, Y., a.a.O., S. 59, Cem, 1., a.a.O., S. 236

106) Vgl. Barthel, G., Jahrbuch, a.a.O., S. $178-179$

107) Vgl. Sertel, Y., a.a.O., S. 61, v. Bulutoglu, K, a.a.O., S. 113, "Istatistik Yilligi"

108) Vgl. Steinhaus, K., a.a.O., S. 153 
Der schrittweise Abbau der Warenkontingentierung nach 1946 ließ Importe unkontrolliert ins Land fließen. Selbst die Abwertung (108a) der Türkischen Lira im Jahre 1946 um über $100 \%$ konnte die Verschlechterung der Zahlungsbilanz nicht aufhalten. (108 a)Die Preis- und Steuerpolitik der Regierung während des Krieges und nach jener $A b$ wertung war am wenigsten erfolgreich. Vor allem die Arbeiter und Bauern hatten unter den schnell steigenden Preisen zu leiden, die zwischen 1938 und 1946 um über $320 \%$ stiegen. (109)

Tabelle 7

\begin{tabular}{|c|c|c|c|}
\hline \multirow{2}{*}{ Jahr } & \multirow{2}{*}{$\begin{array}{l}\text { Genereller Preis- } \\
\text { index }\end{array}$} & \multicolumn{2}{|c|}{ Lebenshaltungskostenindex } \\
\hline & & Istanbul & Ankara \\
\hline 1938 & 100 & 100 & 100 \\
\hline 1942 & 339,6 & 232,5 & 220,9 \\
\hline 1943 & 590,1 & 347,3 & 322,9 \\
\hline 1946 & 427,3 & 342,5 & 320,6 \\
\hline
\end{tabular}

Die Versuche einer progressiven Besteuerung der einkommensstarken Schichten scheiterten, Hauptsteuerzahler blieben die Lohnabhängigen und die armen Baum. Durch die inflationistische und unüberschaubare Steuerpolitik verarmte die groBe Masse der Bevölkerung, einige wenige wurden immer reicher. Die Zahl der sogenannten "Kriegsgewinnler" wird auf ca. $30.000-40.000$ geschätzt. (110)

Steinhaus schildert die Situation folgendermaßen: "Während die Lebenshaltungskosten wesentlich schneller anstiegen als die kontraktbestimmten Einkommen, war das Bürgertum weiterhin in der Lage, beträchtliche Kapitalien zu akkumulieren. Gleichzeitig wurden die Goldreserven binnen kurzem ohne jeden nennenswerten gesamtwirtschaftlichen Nutzeffekt buchstäblich verschleudert. Die Regierung versuchte daraufhin das Problem der passiven Zahlungsbilanz durch Kapitalimporte zu lösen. und ging zur Aufnahme von Auslandsanleihen über." (111)

"Die Nationalreserven, die zwischen 1938 und 1945 von 29 auf 240 Mill.Dollar angewachsen waren, betrugen zwar 1949 und 1950 nominell noch über 200 Mill. Dollar, waren jedoch größtenteils an das Ausiand verpfändet. Die Auslandsanleihen machten 1950 bereits 775 Mill.türkische Lira aus, was bei Zugrundelegung eines Kurses von 4 zu 1 fast 190 Mill Dollar entsprach." (112)

108a) 1 Dollar $=2,80 \mathrm{TL}$ stat bis dahin 1,30

109) Kücük Istatistik Yilligi, Ankara 1947, S. 409, zit。n. Sertel, Y, a.a.O, S. 60

110) Vgl. Sertel, Y., a.a.O., S. 54-56

$111)$ Steinhaus, K., a.a.O., S. 153-154

112) Wolf,G., "Türkei. Entwicklungsländer zwischen Inflation und Stagnation",Hamburg,1962, S. 55, Bismark-Osten-Ferdinand, Struktur, Wandlungen und Nachkriegsprobleme der Türkischen Volks-Wirtschaft, Kiel, 1951, S. 82, Hershiag, Z.Y., a.a.O., S. 154, zit. n. Stein haus, K., a.a.O., S. 154 
Es zeichnete sich der Sieg der wirtschaftspolitischen Theorien eines Thornburg und ähnlicher Leute ab. Deutlich wird das in den Wirtschaftsplänen, die nach dem Kriege verwirklicht wurden und in denen eine Industrialisierung durch staatliche Investitionstätigkeit gebremst und viel mehr die privaten Unternehmer vom Staat gefördert wurden. (113)

\subsection{Der U̇bergang zum Mehrparteiensystem}

Das Parteienwesen mußte auf Betreiben der imperialistischen Staaten von Grund auf reformiert werden. Sie mißtrauten trotz der erfolgten Zusammenarbeit der einzigen Partei, der Partei Atatürks (Republikanische Partei, CHP), die ihren "demokratischen Ansprüchen" nicht genuigte. Nur "demokratische" Staaten erhielten "Hilfe". Der Nachfolger Atatürks, Inönü, sah sich daraufhin genötigt, der Gründung anderer Parteien zuzustimmen. 1946 wurde die zweite große Partei, die Demokratische Partei,gegründet. Der Chefredakteur der einflußreichen türkischen Zeitung Cumhuriyet, Nadir Nadi, bemerkt dazu, daß die durch Inönü unternommene "Demokratisierung von Oben" auf den Druck des Auslandes zurückzuführen sei. "Ich bin so davon überzeugt, als ob ich es mit eigenen Augen gesehen hätte.” (114)

Von 1938 bis 1950 wurden hauptsächlich auf dem Bildungssektor nennenswerte Erfolge erzielt. Die Analphabetenrate konnte um 11,2\% gedrückt werden. In dieser Zeit stieg die Anzahl der Volksschulen von 9418 auf 17600 und verdoppelte sich damit nahezu. Die Zahl der Volksschullehrer stieg von 19047 auf 34800 . Die Zahl der Mittelschulen, Gymnasien und Hochschulen wuchs ziemlich schnell. (115)

Vorbildlich sollte vor allem das Projekt Dorfinstitute (Köy Enstitüleri) werden. Bis 1942 verabschiedete das Parlament das Gesetz für Dorf-Institute und das "Gesetz für Organisation der Institute." (116) Dieses Projekt wandte sich vor allem an die dörfliche Bevölkerung, die in Dorfgenossenschaften und Dorfkombinaten organisiert und für die Landreform gerïstet werden sollte. Das Ziel dieses Projekts wird in einer Veröffentlichung von 1970 wie folgt dargestellt: "Als ganzes war dieses System der Dorfinstitute nicht nur ein Projekt, um Lesen und Schreiben zu lernen, um Lehrer auszubilden und Schulen aufzubauen und um die Entwicklung des Dorfes voranzutreiben. Das Hauptziel dieser Institute war, die Bevölkerung nach Möglichkeit an der Führung des Landes zu beteiligen, die Werktätigen aufzuklären und den Revolutionsproze B vorzubereiten." (117)

Deshalb wurde dieses Projekt von Anfang an von der Bourgeoisie angegriffen und als kommunistisch diffamiert.

Nach 1946 konnte Inönü stolz behaupten, daß er dem türkischen Volk zwei Werke hinterlassen werde, die Dorfinstitute und das Mehrparteiensystem. Doch bereits 1948 stimmte er der Schließung der Oberen Dorfinstitute zu, die Avcioglu zufolge das Gehirn des ganzen Projekts waren. Nach der Machtübernahme durch die Demokratische Partei wurde das ganze System der Dorfinstitute aufgelöst. Auch die 1945 beschlossene Landre form wurde endguiltig begraben.

Man kann wohl annehmen, daß die Verwirklichung des oben skizzierten Projekts die Türkei aus der Unterentwicklung geführt hätte. Abschlie ßend sei noch ein.

113) Vgl. Avcioglu, D., a.a.0., \$. 175 178

114) Nadir, Nadi., Perde Araligindan, zit. n. Avcioglu, D., a.a.0., S. 247

$115)$ Vgl. Basgöz, I., Wilson, H.E., a.a.O., S. 245-247

116) Vgl. Tonuc, E., Devrim Acisindan Köy Innstituiteri, Istanbul, 1971, S. 222

117) Ibid., a.a.O., \$. 270 
mal Inönü zitiert. 1942 sagte er: "Die betrügerischen Großgrundbesitzer, die von diesen schlechten Zeiten profitieren wollen und die unersättlichen wucherischen Kaufleute, die, stünde es in ihrer Macht, sogar aus der Atemluft eine Ware machen würden, und ein paar Politiker, die die schwierige Situation zu ihren Gunsten ausnutzen, wobei man nicht weiß, für Interessen welcher Nation sie tätig sind, wollen die Existenz einer großen Nation auf unverschämte Weise aufs Spiel setzen. Es gibt sicherlich Möglichkeiten, diese Menschen, von denen es mehr als 500 gibt, aus dem Weg zu räumen." (118)

Wie wir gesehen haben, war dies nicht möglich, da diese par Hundert Menschen mächtige Verbündete, die imperialistischen Staaten, hinter sich wußten.

\section{Die Türkei unter dem Einfluß des Neoimperialismus}

W. H. Arnold, Chef der amerikanischen Militärmission sagte bezogen auf die Türkei 1950: "Ich weiß kein Land in Mittelost, wo die amerikanische Dollarhilfe besser angelegt wäre." (119)

1950 übernahm die Demokratische Partei (DP), als Reaktion auf die Verab. schiedung der Landreform von Großgrundbesitzern (wie Adnan Menderes, Carit Oral), Vertretern der Handels- und Bankbourgeoisie (wie Celat Bayar, Ziya Önis) und anderen Vertretem der Großbourgeoisie gegründet, die Regierung. Diese Vertreter der Großbourgeoisie hatten seit 1946 die enge Zusammenarbeit mit den imperialistischen Staaten proklamiert, vor allem mit dem "besten Freund der Türkei den USA". Die Schlagworte der neuen Regierung waren dementsprechend:

1. Liquidierung des Etatismus zugunsten des Privatunternehmertums.

2. Enge Zusammenarbeit des einheimischen mit dem Fremdkapital.

3. Liquidierung der Landreform von 1945, d.h. Sanktionierung der Interessen der Großgrundbesitzer.

Die neue Regierung vertrat die Auffassung, der Staat solle die Lenkung der Wirtschaft der Initiative der Privatunternehmer überlassen, die die nötigen Investitionen mit finanzieller Unterstützung veranlassen und durchfühıren würden. Nur für Bildung, Verkehr und Post sei der Staat zuständig (hier sind nämlich die Profitchancen geringer). Die Funktion des Staates beschränke sich darauf, die Freiheit der Privatunternehmer zu schiitzen. Staatspräsident Bayer nannte als Vorbild Friedrich

118) Cem, I., a.a.O., S. 237

119) New York Herald Tribune, v. 1.12.1950, zit. n. Krüger, K. "Die Türkei" Berlin, 1951, S. 167 
II., der mit staatlichen Mitteln Fabriken errichten ließ und sie anschließend Privatunternehmern weiterverkauft habe. (120) Auch türkische staatliche Fabriken wurden reprivatisiert. Menderes, der bei dem manipulierten und unaufgeklärten Teil des Volkes sehr beliebt war, faßte einige Jahre später den Inhalt dieser neuen Politik in einem Satz zusammen: "In jedem Wohnviertel soll es einen Millionär geben."

Die Landwirtschaft sollte entsprechend den US-Plänen auf Kosten einer leistungsfähigen Industrie bevorzugt gefördert werden. In den ersten fünf Jahren der Regierung Menderes wurde die landwirtschaftliche Produktion durch Vergrößerung der landwirtschaftlichen Nutzfläche und Mechanisierung und durch die günstige Witterung der Iahre 1950 bis 1953 erhöht.

Die Mechanisierung der Landwirtschaft und die Erhöhung der öffentlichen Subventionen und Kredite kam hauptsächlich den Großbauem zugute. Untersuchungen von W. H. Nicholls ergaben, daß nur knapp über ein Prozent der Bauem von der Mechanisierung Gebrauch machen konnten, eine Folge der ungleichen Einfluß- und Landverteilung. (121) 1952 verfügten ca. 1,5\% der Grundbesitzer über $25 \%$ der landwirtschaftlichen Nutzfläche, während 62,1 \% der Bauern nur $18,6 \%$ besaßen. (122) Exaktere Zahlen würden für die Klein- und Mittelbauern, vor allem in Ostanatolien, ein noch ungünstigeres Verhältnis ergeben. Ein erheblicher Teil der Bauern besaß entweder kein eigenes Land oder so wenig, daß sie unter quasi-feudalen Bedingungen für die Großgrundbesitzer arbeiten mußten. Außerdem hatten Großgrundbesitzer meistens die fruchtbarsten Teile der landwirtschaftlichen Nutzflächen besetzt. In Cukurova (Amik, Ceyhan, Berdan und Asi), wo die fruchtbarsten Gebiete der Türkei liegen, verfügen $2 \%$ der Bodenbesitzer über $59 \%$ des Ackerlandes, $17 \%$ der Bauern besitzen kein Land und $56 \%$ der Bauern besitzen $11 \%$ der landwirtschaftlichen Nutzfläche. (123)

$60 \%$ der Bauern der Türkei besitzen unter 5 ha Land. (124) Das 1945 verabschie dete Gesetz, wonach das private Eigentum an Grund und Boden auf 500 ha be. grenzt werden sollte, wurde nie praktiziert und schließlich von der neuen Regierung aufgehoben.

Die Industrialisierungspolitik der neuen Regierung war von der Abhängigkeit von den kapitalistischen Staaten bestimmt. Die Politik der staatlichen Lenkung wurde aufgehoben, freie Marktwirtschaft war nun die Losung. Trotz der vorrangigen Förderung der privaten Unternehmen sah sich die Regie rung genötigt, die staatlichen Unternehmen weiterzuführen, da die türkische Bourgeoisie für die Übernahme der ganzen Investitionen unfähig war.

1950 existierten lediglich drei Aktiengesellschaften mit einem Grundkapital von 1,4 Mill. TL, 1954 waren es bereits 56 mit einem Grundkapital von 167 Mill.TL. (125)

Die Zahl der staatlichen Betriebe stieg von 103 im Jahre 1950 auf 149 im Jahre 1953, das investierte Kapital erhöhte sich um 42,6 Mill TL. Die Zahl der in staat-

120) Vgl. Sertel, Y., a.a.O., S. 65-67, Barthe1, G., Jahrbuch, a.a.O., S. 179-182

121) Vgl. Nichols, W.H., Investment in Agriculture in underdeveloped Countries, American Economic Review, Mayn, 1955 , zit. n. Karpat, K., Türk Demokrasisi Tarihi, Istanbul, 1967 , S. 261, Avcioglu, D., a.a.O., S. 285

122) Vgl. Steinhaus, K., a.a.O., S. 157, Aksoy, S., a.a.O., S. 103

123) Vgl. Avcioglu, D., a.a.O., S. 286

124) Vgl. Holm, H. M.; Turkey's Agricultural Economy in Brief, 1964, Economic Research Service, US. Department of Agriculture, Washington, zit. n. Sertel, Y., a.a.O., S. 81

125) Vgl. Stcinhaus, K., a.a.O., S. 161 
lichen Betrieben Beschäftigten stieg von 76033 auf 86331. (126)

Die folgende Tabelle zeigt, daß trotz der Subventionen durch öffentliche Mittel (die großen Banken werden vom Staat kontrolliert) sich der private Anteil an der Industrieerzeugung nicht wesentlich erhöhte, obwohl die Beschäftigtenzahl, die Investitionssumme und die Kredite enorm angestiegen sind.

Tabelle 8 (127) Anteil des privaten Sektors in v.H.

\begin{tabular}{lll}
\hline & 1950 & 1960 \\
\hline Zahl der Betriebe & 96,1 & 96,0 \\
Zahl der Arbeite r & 52,7 & 58,6 \\
Produktionswert & 53,6 & 55,6 \\
Investitionen & 45,9 & 63,5 \\
Bankkredite & 67,3 & 88,4
\end{tabular}

An dieser Stelle ist ein Vergleich der Perioden von 1929-1939 und 1950-1960 angebracht. Dabei ist zu berücksichtigen, daß zwischen 1929 und 1939 jährlich die "Schulden" des Osmanischen Reiches zurückgezahlt wurden, die ausländischen Firmen gegen Bezahlung nationalisiert wurden und die Weltwirtschaftskrise sich ver. heerend auswirkte. Dagegen wurden in der Zeit von 1950 - 1960 Auslandsanleihen aufgenommen und das Fremdkapital konnte fast schrankenlos in der Türkei investieren.

Tabelle 9 (128) Vergleich der Perioden von 1929-39 und 1950-60

\begin{tabular}{|c|c|c|c|c|}
\hline & & & $\begin{array}{l}\text { Zunahme in \% } \\
1950-1960\end{array}$ & $\begin{array}{c}\text { Zunahme in \% } \\
1929-1939\end{array}$ \\
\hline Eisenbahnnetz (in km) & 7.671 & 7.895 & 3 & 42 \\
\hline Eisenbahngüterverkehr & & & & \\
\hline (in Mio $\mathrm{t} \mathrm{km}$ ) & 2.503 & 4.325 & 73 & 339 \\
\hline Straßennetz (in km) & 47.100 & 61.500 & 31 & 41 \\
\hline $\begin{array}{l}\text { Elektrizitätserzeugung } \\
\text { (in Mio kWh) }\end{array}$ & 700 & 22015 & 256 & 233 \\
\hline Steinkohleförderung & ט & 20.010 & 250 & 253 \\
\hline (in $1000 \mathrm{t})$ & 2.939 & 3.907 & 33 & 86 \\
\hline Chromförderung (in 1000 t) & 202 & 221 & 9 & 1.044 \\
\hline Zementförde rung (in $1000 t$ ) & 395 & 2.038 & 416 & 337 \\
\hline Zuckerproduktion (in $1000 \mathrm{t}$ ) & 153 & 618 & 300 & 1.088 \\
\hline Gamproduktion (in $100 \mathrm{t}$ ) & 377 & 785 & 109 & 291 \\
\hline
\end{tabular}

126) Vgl. Uhrenbach, W., Türkei-Länderhandbuch, Berlin 1957, zir. n. Barthel, G., Jahrbuch ..., a.a.O., S. 185

127) Vgl. Erbas, I., "Strukturanalyse der Wirtschaftsentwicklung in der Türkei." Berlin 1963, (Diss.) S. 130, vgl. Peters, L., Die Entwicklung des Geldwertes in der Türkei, Frankfurt, 1963 , S.159, zit. n. Steinhaus, K., a.a.O., S. 161

128) Vgl. Development Plan, S. 8 und 16, vgl. T.C. Istatistik Yilligi 1960-1962, S. 319 und 515, Statistical Yearbook, 1952, New York 1952, S. 121, 160, 175, 180, 187, Statistical Yearbook 1965, New York, 1966, S. 190, 245, 261, 267, 426, und unsere Tabelle 11, S. 47 
In fast allen Bereichen, außer Elektrizitätserzeugung und Zementproduktion war die Zunahme unter Atatürk bedeutend größer als unter den von der Demokratischen Partei gestellten Regierungen. Selbst in der sogenannten "Boomperiode" 1950 -1955 stieg das Pro-Kopf-Produkt nicht schneller als in den Jahren 1935-1940. (129)

Nachstehende Aufstellung gibt Aufschluß über die Verteilung der arbeitsfähigen Bevölkerung (ab 15 Jahre) auf die verschiedenen Wirtschaftszweige im Jahre 1960. (130)

Tabelle 10

Wirtschaftszweige
$\begin{gathered}\text { Anteil der arbeitenden } \\ \text { absolut }\end{gathered}$

Landwirtschaft, Forstwirtschaft, Jagd

Industrie

Bauwesen

Elektrizität, Gas und Wasser

Handel, Banken und Versicherungen

Verkehrswesen, Post

Dienstleistungen

Sonstige

9.737 .489

961.988

74,09

290.088

7,41

15.484

2,23

403.764

0,12

246.839

3,12

676.838

1,94

660.759

5,21

5,08

Insgesamt

12.993 .249

100,00

Annähernd drei Viertel der arbeitsfähigen Bevölkerung ist in der Landwirtschaft beschäftigt, und nur 7,41 \% in der Industrie. Der relative Anteil der Landwirtschaft am Nationaleinkommen (Preisbasis 1948) sank von $50 \%$ im Jahre 1950 auf 43,9 \% im Jahre 1960, aber nicht zu Gunsten der Industrie, sondern des Verkehrsund Dienstleistungswesens. Der Anteil der Industrie am Nationaleinkommen veränderte sich kaum. (1950: 16,1\%;1960: 16,8\%) (131)

In der Sozialpolitik versagte die Regierung Menderes vollkommen. Die Diskrepanz zwischen den verschiedenen Regionen des Landes vergrößerte sich ständig, die Kluft zwischen Reich und Arm wurde immer tiefer. Unter den schnell steigenden Preisen bei stagnierenden Iöhnen hatten Arbeiter, Bauern und Beamte gleicher maßen zu leiden. Die Lebenshaltungskosten stiegen in den Jahren 1948-1960 um $200 \%$, die Preise (Preisbasis 1938) um das zehnfache, während die Löhne der Arbeiter und Angestellten nur um das zweieinhalbfache angehoben wurden. (132) Zwischen 1927 und 1938 stieg das Pro-Kopf-Einkommen durchschnittlich jährlich um $6 \%$, zwischen 1950 und 1961 nur noch um $2 \%$. (133)

129) Vgl. Steinhaus, K., a.a.O., S. 163

130) Vgl. "Türkiye Istatistik Yilligi 1963" S. 69 (Auszug)

131) Vgl. Türkiye Milli Geliri (1948-1958) Ankara, Nr. 391, vgl, ibid., Ankara, Nr. 420, beide zit. n. Kazgan, G., Türkiye Ekonomisinde Strukturel Degisme, Ikt. Fak. Mecmuasi, Nr. 5-4/1963, S. 199

132) Vgl. Aylik Istatistik Bülteni, 1962, Istanbul, 1962, S. 39, vgl. Sertel, Y., a.a.O., S. 102, vgl. Fisek, K., a.a.O., S. 88-91

133) Vgl. I. Bes Yillik Kalkinma Plani S. 8, zit. n. Özkol,S., a.a.O., S. 73 
Die Bildungspolitik der Regierung Menderes war schlechthin ein einziges Fiasko. Der Aufbau des Schulwesens blieb hinter dem Wachstum der Bevölkerung zurück. Zwischen 1955 und 1960 ist sogar eine Zunahme der Analphabetenrate festzustellen. (134) Der Aufbau von Schulen auf dem Lande ging sehr schleppend voran.

Nach unserer Meinung war es ein schwerer Fehler Atatürks, die durch das Verbot der alten Religionsschulen entstandene Lücke nicht durch neue, weltliche Schulen zu schließen. Der durch das Verbot beabsichtigte Effekt, den Einfluß des Klerus auszuschalten, verkehrte sich ins Gegenteil, denn die bei der Bevölkerung beliebten Schulen setzten ihre Tätigkeit illegal fort, mit schiecht ausgebildeten, unqualifizierten geistlichen Lehrern, die keine Gelegenheit ausließen, gegen die fortschrittliche Regierung Atatürks und später selbst Inönüs Sturm zu laufen. Bei den Wahlen nutzten sie ihren Einfluß aus, möglichst viele Stimmen für die reaktionäre Demokratische Partei zu mobilisieren. Konsequent erlaubte die Regierung Menderes nach ihrem Wahlsieg die Wiedereröffnung der Religionsschulen und ließ mehr neue Moscheen als Schulen bauen.

Die Religiosität eines großen Teils der Bevölkerung wird für die Manipulationen der Demokratischen Partei und ihrer Nachfolgepartei, der Gerechtigkeitspartei ausgenutzt, was ihre große Beliebtheit bei der Bevölkerung erklärt. Fortschrittliche Reformen werden sehr erfolgreich als kommunistisch und atheistisch diffamiert.

Atatürk und Inönü ist der Vorwurf zu machen, daß sie die tiefverwurzelte Gläubigkeit des Volkes nicht in Rechnung stellten und die Religionsschulen zum größten Teil schlossen, anstatt sie zu reformieren.

\subsection{Dollarpolitik und Nato-Mitgliedschaft}

Wenden wir uns nun der Außenpolitik und deren Auswirkungen auf die Türkei zu. Die Periode von 1950 - 1960 ist für die Türkei von großer Bedeutung, da sie nach drei Jahrzehnten voller Souveränität endgültig in den Bannkreis des Neoimperialismus geriet. Avcioglu bezeichnete den neuen Führungsstil als "Dollar-Diplomatie": "Die neue Führung ist bereit, die militärischen, wirtschaftlichen und politischen Wünsche der USA ohne Einwände zu akzeptieren. Sie erwartet dafür Dollars und immer mehr Doilars." (135)

Dieses Vorgehen išt typisch für die neoimperialistische Politik in den Ländern der Dritten Welt, die von hervorragender wirtschaftlicher (Absatzmärkte, natürliche Ressourcen etc.) und/oder strategischer Bedeutung sind. Nach dem 2. Weltkrieg, als in vielen Ländern die Bewegungen gegen Unterdrückung und Abhängigkeit anschwollen, verstanden es die neoimperialistischen Staaten durch Korrumpierung einheimischer Politiker, diese Bewegungen in eine ihnen genehme Richtung zu lenken.

Die in den fünfziger Jahren äußerst labile Lage im Nahen Osten (Israel, SuezKrise) und der "Drang der Sowjetunion" in den Mittelmeerraum verstärkten den Ruf der USA nach zuverlässigen Bündnispartnem, die in Griechenland und der Türkei gewonnen wurden. Mit militärischen und wirtschaftlichen Abkommen wurden diese Länder fest in das westliche Bündnissystem integriert.

Die Regierung Menderes zeigte sich diesen Bemühungen sehr aufgeschlossen, sie stellte sogar von sich aus den Antrag, in die NATO einzutreten. Die Beteiligung

134) Vgl. Kodamanoglu, M. N., Türkiye'de Egitim, Ankara, 1964, zit. n. Steinhaus, K.,a.a.O., S. 73

135) Avcioglu, D., a.a.O., S. 279 
türkischer Soldaten räumte alle Bedenken bei den NATO-Staaten aus, die zunächst abwartend oder ablehnend reagierten. Über diese Frage kam es zu Differenzen zwischen Großbritannien und den USA, die für den sofortigen Eintritt der Türkei in die NATO plädierten, während Großbritannien, da es seine Nah-Ost-Interessen gefährdet sah, mit der Türkei und anderen Staaten im Nahen Osten ein separates Abkommen abschließen wollte, (136) (was es schließlich mit dem Bagdad-Pakt erreichte, der nach dem Austritt des Irak unter der Bezeichnung CENTO weiter existierte).

Im Frühjahr 1951 betonte das Pentagon die militärisch-strategische Bedeutung der Türkei und verlangte die volle Mitgliedschaft Griechenlands und der Türkei, (137) und bereits am 15. Mai 1951 unterbreiteten die USA den übrigen Natopartnern einen entsprechenden Vorschlag. Der englische Außenminister erklärte vor dem Unterhaus, Großbritannien sei bereit, die Mitgliedschaft der Türkei zu unterstützen, aber von ihr erwarte sie, daß sie mit Großbritannien einem Nah-Ost-Abkommen beitrete. (138) Der US-Außenminister erklärte 1951, daß der Eintritt der Türkei in die Nato für die kapitalistische Welt von großer Bedeutung sei. (139)

Am 29. Februar 1952 wurde die volle Mitgliedschaft der Türkei und Griechenlands einstimmig angenommen. Dem Natoeintritt folgten geheime bilate rale Verträge zwischen den USA und der Türkei, von denen das Parlament und die türkische Öffentlichkeit erst nach dem berühmt gewordenen Brief Johnsons an die türkische Regierung während der Zypernkrise 1964 erfuhr.In dem Brief mahnte er die türkische Regierung, daß Waffen, Flugzeuge etc. nur im Rahmen der Nato eingesetzt werden dürfen. Erst in den letzten Jahren wurden Einzelheiten dieser bilateralen Verträge bekannt. Der pensionierte Admiral Sezai Orkunt, der als Experte für NatoFragen gilt, sagte aus, daß in den Jahren 1947-1966 zwischen der Türkei und den USA 58 Verträge unterschrieben worden seien. (140)

Die aus der Nato-Mitgliedschaft resultierenden Probleme für die Türkei faßt Ihan Selcuk, einer der einflußreichsten Kolumnisten der Türkei, in folgenden Punkten zusammen: (141)

1. Die Verteidigungskräfte der Türkei sind vollkommen von den USA abhängig, insbesondere weil alle Waffen US-amerikanischer Herkunft sind.

2. $99 \%$ der türkischen Streitkräfte stehen unter Natokommando.

3. Die nationale Verteidigung der Türkei ist durch bilaterale Verträge von den USA abhängig.

4. Wichtige Waffen, die von der türkischen Armee bedient werden, können im Ennstfall erst mit Genehmigung des US-Präsidenten eingesetzt werden.

5. Da es in der Türkei über 100 Militärbasen gibt und da in der Türkei Nuklearwaffen gelagert sind, wird im Falle eines Krieges die Türkei eines der ersten Ziele eines Nuklearschlages werden.

6. Eine eigene Kriegsindustrie wurde durch Einfluß von außen verhindert.

7. Die nationale Verteidigung der Türkei wird von der Nato-Strategie bestimmt.

8. Ein Vertrag vom 8. Mai 1966 legalisiert eine militärische Intervention der USA

136) Vgl. Ataöv, T. "Amerika, Nato ve Türkiye", Ankara, 1969, S. 207-210, detaillierte Informationen: S. 175-210

137) Vgl. US, Congress, Senate, 82nd Congress. 2nd Session, S. Exec, E., zit. n. ibid.. S. 208

138) Vgl. Great Britain, Hansard's Parliamentary Debates (Commons) C. 490 , Spalte 1227. 1228 , zit. n. ibid., S. 209

139) Vgl. US Senate., 82 nd Congress, 2nd Session, S. Exec, E., zit. n. ibid., S. 210

$140)$ Vgl. Orkunt, S., "Ikili Antlasmalar", Cumhuriyet, 29.5.1969, S. 2

141) Vgl. Selcuk, I., "Silahli Kuvvetler Problemi", Cumburiyet, 3.2.1969 
in der Türkei. (141a)

General Bradley unterstrich die Bedeutung der US-Militärbasen in den überseeischen Ländern. "Es ist notwendig, daß wir in Ủbersee Militärbasen haben. Alle Amerikaner missen begreifen, von welcher Wichtigkeit es ist, daß wir den Feind außerhalb unserer Grenzen angreifen und von diesen Basen aus die ersten Angriffe starten. Es wird sonst unmöglich, glaube ich, daß die USA und ihre Streitkräfte in einem neuen Krieg mit geringsten Verlusten auskommen. Die Basen, die das Herz des Feindes treffen sollen, missen in den Ländem aufgebaut werden, die dem feind. lichen Land am nächsten sind." (142)

General Reinhardt präzisierte diese Überlegungen: "Das geeignetste Gebiet, wo die Angriffskräfte konzentriert werden soliten, ist der Nahe Osten. Es ist für die Sowjetunion ein kritischer und neuralgischer Raum. Heer, Luftwaffe und Marinestreitkräfte können aus diesem Raum in kürzester Frist bis tief ins Innere der Sowjetunion eindringen und strategisch wichtige Orte erreichen und zerstören ... Für eine solche Operation sollten die USA sich bei den Staaten im Nahen Osten, insbesondere in Persien und der Türkei, um eine Erlaubnis für Militärbasen bemühen." (143)

Durch die Nato-Mitgliedschaft erwachsen der Türkei niesige wirtschaftliche, soziale und kulturelle Probleme. Ein unterentwickeltes Land kann es sich auf die Dauer nicht leisten, ein Drittel seines Etats für militärische Zwecke zu vergeuden. Die Nato-Mitgliedschaft lie $B$ die Verteidigungsausgaben von $30,1 \%$ des Etats im Jahre 1950 auf 35,1 \% im Jahre 1955 anschwellen. (144) Die folgende Tabelle zeigt die Verteidigungsausgaben und die Zahl der Soldaten im Vergleich mit einigen ausgewählten Natostaaten. (145)

\section{Tabelle 11}

\begin{tabular}{llccc}
\hline Land & $\begin{array}{l}\text { Einwohner- } \\
\text { zahl } \\
\text { (in 1000) }\end{array}$ & $\begin{array}{l}\text { Zahl der } \\
\text { Soldaten } \\
\text { (in 1000) }\end{array}$ & $\begin{array}{l}\text { Verteidigungs- } \\
\text { etat } \\
\text { (in Mrd. Dollar) }\end{array}$ & $\begin{array}{l}\text { Verteidigungsausgaben } \\
\text { zu Volkseinkommen } \\
\text { (in \%) }\end{array}$ \\
\hline Frankreich & 50.400 & 505 & 6,1 & 4,3 \\
England & 55.297 & 427 & 5,5 & 5,7 \\
BRD & 55.700 & 456 & 5,11 & 4,3 \\
Türkei & 32.894 & 514 & 0,439 & 4,6
\end{tabular}

Die Türkei unterhält innerhalb der Nato gemessen an der Einwohnerzahl die größte Armee. Nach Aussagen des tükischen Stabchefs sollte die Zahl der Solda. ten 1970 auf 650.000 und 1980 auf cine Million erhöht werden. (146) Die Ver-

141a) Die Prawda berichtete in diesem Zusammenhang, daß die USA ein "direktes Interventionsrecht in der Türkei" hätten. "Die USA können in dem FalI von diesem Recht Gebrauch machen, wenn sie glauben, daß die politische Lage nicht mehr pro-westlich ist" (Cumhuriyet, 22. April 1969).

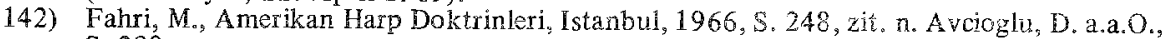
S. 280 .

143) Avcioglu, D., a.2. O.,$\$ .280$

144) Vgl. Barthel, G., Jahrbuch a.a.0., S. 189

145) Vgl. Orkunt, S., "Dünyada ve bizde Savunma Sorunlari" u. "Milli Gelir ve Insan Gücü Illiskileri," Cumhuriyet, S. 2 u. 18, 19.9.69.

146) Vgl, ibid., S.2 
teidigungsausgaben sind mit 439 Mill. Dollar niedriger als diejenigen der in der Tabelle angefürten Länder, gemessen am Volkseinkommen aber höher als in Frankreich oder in der Bundesrepublik.

T. Halman berechnete nach Angaben der UNESCO, daß mit dem Geld für ein Bombenflugzeug, das die Türkei kauft, 75 Krankenhäuser mit je 100 Betten oder eine Universität für 30.000 Studenten gebaut werden könnte. (147)

\subsection{Offene Tuir und Tor für das Fremdkapital}

Betrachten wir nun den Einfluß des Fremdkapitals. Die Regierung Menderes setzte die in ihrem Programm angekündigte enge Kooperation mit ausländischem Kapital sogleich nach ihrem Machtantritt in die Tat um. Am 1. August 1951 wurde das "Gesetz zur Förderung des ausländischen Kapitals" verabschiedet. Da dieses Gesetz dern Fremdkapital bestimmte Beschränkungen auferlegte (z. B. konnten Reinvestitionen nur begrenzt getätigt werden, und nur in bestimmten Branchen konnte das Fremdkapital investieren) kam kaum nennenswertes Kapital in die Türkei. Finanzielle Schwierigkeiten, verursacht durch eine plan- und ziellose Wirtschaftspolitik und Druck von außen zwangen die Regierung, die letzten Hindernisse für das Eindringen des Fremdkapitals zu beseitigen.Aus den USA angereiste Spezialisten arbeiteten ein neues "Gesetz zur Förderung des ausländischen Kapitals" und ein "Erdölgesetz" aus. Diese Anfang 1954 verabschiedeten Gesetze legalisierten sämtliche Aktionen des Fremdkapitals.

1. Es darf in allen Branchen investieren.

2. Die Profite und das Stammkapital könnten jederzeit rücktransferiert werden.

3. Alle Vorteile, die die einheimischen Privatunternehmen genießen, erhalten die ausländischen investoren in gleicher Weise.

4. Die ausländischen Untemehmen können eigene qualifizierte Kiäfte beschäftigen. Diese Personen genießen besondere Zollerleichterungen. (148)

Die Erklärung Staatspräsidents Bayers, die er in einer Pressekonferenz in Washington eine Woche nach Verabschiedung des Gesetzes zur Förderung des Fremdkapitals abgab, belegt die Übereinstimmung der türkischen herrschenden Klasse mit den neoimperialistischen Plänen: "Durch die Erhöhung der Kaufkraft des türkischen Volkes und durch die Erhöhung seines Lebensstandards wird die Türkei zu einem großen Absatzmarkt für Fertigwaren und Konsumwaren werden. Durch das unlängst angenommene Gesetz wird Fremdkapital unter sehr günstigen Bedingungen in die Türkei fließen können. Kurz, es kann gesagt werden, jeder Dollar, der in der Türkei investiert wird, gleicht in fruchtbarsten Boden gesäten Samen." (149)

Vor allem das auf 80 Jahre befristete Erdölgesetz machte den ausländischen Monopolen (Caltex, Shell), die sich weigerten das $_{3}$ einheimische Erdöl zu verrarbeiten, große Konzessionen.

Sie brauchten das Erdöl nicht zu Weltmarktpreisen importieren, sondern konnten die Preise nach eigenem Ermessen festsetzen, durchschnittlich 30-35\% über dem Weltmarktpreis. Erst nach längeren Auseinandersetzungen in der Öffentlichkeit erklärten sich die Monopole bereit, die Erdölpreise herabzusetzen, aber keineswegs auf Weltmarktniveau.

14.7) Vgl. Halman, T., "Sefalet Ordusu", Miliyet, 14.12 .1969

148) Tunces, B., Türkiyede Yabanci Sermaye Sorunu, Ankara, 1968, S. 74-75, vg1. Bulutoglu, K., a.a.O., S. 124-125, vgl. Sertel, Y., a.a.O., S. 83-84

149) Nadir, Nadi., "Igneyi Kendine..." Cumhuriyet, 20.4 .1969 
Oppositionsführer Inönï verglich das Erdölgesetz mit den Kapitulationen des Osmanischen Reichs. "Durch dieses Gesetz sieht das Land einer ungewissen $\mathrm{Zu}$ kunft entgegen." (150) Und über das "Gesetz zur Förderung des ausländischen Kapitals": "Dieses Gesetz hat unserem Handel, unserer Industrie und unserer Wirtschaft tiefe Wunden geschlagen." (151)

Von 1950 bis 1960 erhielt die Türkei insgesamt 758,9 Mill Dollar Anleihen, an denen sich, um die wichtigsten Staaten und Institutionen zu nennen, die USA, BRD, OECD, IMF, IBRD, IDA und EPU beteiligten. (152) $62,8 \%$ der Anleihen wurden für den Import von Fertigprodukten verwendet. 19,8\% für US-Nahrungsmittel, 2,5\% als Finanzausgleich für die in der Türkei tätigen ausländischen Spezialisten. Nur 14,9\% kamen der industriellen Entwicklung zugute. (153) Y. Sertel beziffert den Anteil der Kredite und Schenkungen, mit denen Rüstungsgüter (die in den USA keine Verwendung mehr fanden) gekauft wurden, auf $50 \%$. (154)

Der Grund für die große Summe der Anleihen lag in dem jährlich größer werdenen Zahlungsbilanzdefizit.

Tabelle $12(155)$

\begin{tabular}{lccc}
\hline & 1950 & 1955 & 1960 \\
\hline Haushaltsdefizit (in Mio TL) & 156,3 & 699,6 & $1.298,5$ \\
Außenhandelsdefizit (in Mio TL) & 22,3 & 184,4 & 147,5 \\
Großhandelsindex & 100 & 131 & 263
\end{tabular}

Durch die unkontrollierte Einfuhr wurde die Lage derart prekär, daß sich die Regierung schließlich am 4. August 1958 gezwungen sah, den Kurswert des türkischen Lira erneut drastisch um $220 \%$ zu senken. (156)

Die ausländischen Investoren hielten sich in dieser Periode auffallend zurück. Nach B. Tuncer betrug der Gesantwert aller Investitionen ca. 533,1 Mill.Dollar. Die ausländischen Untemehmen irvestierten hauptsächlich in der Eisen und Stahl erzeugenden Industrie und in der Erdölbranche in enger Zusammenarbeit mit den cinheimischen Privat- und staatlichen Untemehmen, die sie durch ihre technische Überlegenheit bei geringer prozentualer Kapitalbeteiligung weitgehend in der Hand hatten. Beispielhaft ist die Eisen und Stahl erzeugende Fabrik in Eregli. Der Staat übernahm von den Investitionen im Wert von 600 Mill. TL 306 Mill.TL, der Rest verteilte sich auf die drei US-Unternehmen Koppers Corp. Inc., Westinghouse Elec. tric Int. Comp. und Blow Knox und zwei türkische Unternehmen. Der Staat übernahm die Bürgschaft für über $1 \mathrm{Mrd}$ TL Kredite. Dennoch ist das Unternehmen der staatlichen Kontrolle entzogen. Die Anlagen wurden unter der Leitung von US-Un

150) Yeni Ulus Gazetesi., "Nigcie Konusmasi", zit. n. Avcioglu, D. a.a.O., S. 324

151) Yeni Ulus Gazetesi., "Balikesir Konusmasi", zit. n. ibid, 16.4.1954

152) Vgl. Bulutoglu, $K$," "Bütce Gerekceleri", a.a.O., \$. 118

153) Vgl. Economics and Finance

154) Vgl. Sertel, Y., a.a.O., S. 100

155) Development Plan, S. 16-20, zit. n. Steinhaus, K., a.a.O., S. 160

156) Vgl. Bulutoglu, K., a.a.O., S. 123, Barthel, G., a.a.O., S. 190 
ternehmen aus den USA besorgt. Ingenieure hatten die Kosten für das Werk auf maximal 1,5 Mrd TL veranschlagt, ohne allerdings die überhöhten Preise für die Anlagen aus den USA miteinzukalkulieren. Es kosiete schließlich 3 Mrd TL. (157)

Dieses Reispiel ist nur eines von vielen, das die Verschwendung und gleichguil. tige Vergabe öfentlicher Mittel demonstriert.

Diese Politik der Regierung, durch öffentliche Mittel "in jedem Stadtviertel einen Millionär zu zuichten," war in der Tat für die Privatunternehmer und für die führenden Politiker äußerst profitabel, für die Masse der Bevölkerung dagegen gab es keine Chance der Partizipation an diesem Reichtum.

Die gemeinsamen Interessen der nationalen und internationalen Bourgeoisie verhalfen dem Neoimperialismus und seinen Verbündeten zu einem Sieg auf der ganzen Linie. Im Staatsapparat blïhte die Korruption, auf dem Boden der wachsenden Auslandsschulden (1960 betrugen sie bereits mit Zinsen $20 \mathrm{Mrd} \mathrm{TL}$ ) (158) und der Haushaltsdefizite gedieh Inflation. Das Chaos war perfekt. Dennoch lehnten sich die ungenügend organisierten Arbeiter und Bauern gegen die unerträglichen Mißstände nicht auf, und wo sie es doch einmal wagten, gegen die Regierung zu demonstrieren, wurden sie mit Terror unterdruickt. Die Mitglieder der Oppositionspartei und ihr Führer, der ehemalige Staatspräsident Inönü, wurden in ihrer Freizügigkeit beschnitten, die Presse wurde zensiert.

Dies forderte den Widerstand der progressiven Kräfte,der Offiziere, Intellektuellen und Studenten heraus. Studenten in den großen Städten wie Ankara, Istanbul und Izmir revoltierten gegen die antidemokratischen und terroristischen Methoden der Regierung und gegen die chaotische wirtschaftliche Lage.

Avcioglu schildert die Situation: "Das bedrückende und kummervolle Leben der Mehrheit auf der einen und das luxuriöse Leben der Klassen, die mühelos reich werden konnten, auf der anderen Seite schürte die Unzufriedenheit. Der Begriff "glückliche Minderheit" ist das Produkt dieser Jahre und bringt den Zorn auf diejenigen zum Ausdruck, die auf Kosten der Masse reich werden konnten. Beamte, Offiziere und die Jugendlichen verspürten diese Unzufriedenheit am tiefsten." (159)

Am 27. Mai 1960 setzte die türkische Armee, nachdem die Studentenunruhen bedrohliche Ausmaße angenommen hatten, die Regierung ab. Menderes (Ministerpräsident), F.R. Zorlu (Außenminister) und H. Polatkan (Finanzminister) wurden nach einem langen Prozeß zum Tode verurteilt und hingerichtet. Viele andere Politiker entgingen wegen ihres Alters der Todesstrafe. Sie wurden zu lebenslänglich oder zu mehreren Jahren Zuchthaus verurteilt, nach einigen Jahren jedoch durch eine Amnestie wieder freigelassen.

157) Vgl. Avcioglu, D. a.a.O., S. $331-332$

158) Vgl. Sertel, Y., a.a.O., S. 102

159) Vgl. Avcioglu, D., a.a.O., S. 348 


\section{Eine neue Etappe in der Geschichte der Türkei}

Einer der Führer der Bewegung vom 27. Mai 1960, General Madanoglu, der jetzt Senator im türkischen Parlament ist, hielt anläßlich des 10. Jahrestags eine über Rundfunk und Fernsehen ausgestrahlte Rede über Sinn und Charakter der Bewegung. "Der 27. Mai symbolisiert das Sehnen nach Atatürk. Atatürk war ein Gegner des Kapitalismus, Imperialismus und Konservatismus. Es genügte nicht, die Imperialisten ins Meer zu jagen, es mußte auch mit der Ausbeutung Schluß gemacht werden ... Nach Atatürk basierten der Nationalismus (159a), Populismus, Etatismus und die revolutionären Prinzipien nicht mehr auf den sozioökonomischen Grundlagen, und das Land geriet in das Joch des Kapitalismus und Imperialismus. Nun wollen die Ausbeuter, die Profitsüchtigen und die Fanatiker gemeinsam diese Unterjochung zementieren ... Die Jugend und die Armee führten aus Überzeugung die Bewegung des 27. Mai, weil sie Anhänger Atatürks sind, weil sie in ihm ihr Vor* bild sehen." (160)

Madanoglu gibt in einem Interview mit der Wochenzeitung Deyrim zu, daß die Führer der Bewegung kein Programm hatten. "Als Revolutionäre waren wir alle ohne Ausnahme Kemalisten. Aber unser Kemalismus entsprang einer Überzeugung, einem Sehnen und der Sympathie mit dem Kemalismus, ohne daß wir gewußt hätten, wie das Ziel Atatürks, eine unabhängige, zivilisierte und demokratische Türkei, zu verwirklichen sei." (161)

B. Savci beschrieb die Bewegung als eine Reaktion gegen diejenigen, die von der Bahn der national-demokratischen Revolution abgekommen seien und die Türkei dem Joch des Imperialismus überantwortet hätten. "Die Türkei wurde (zwischen 1950 und $1960-H . K_{\text {. }}$ ) zu einem klassischen Ausbeutungsobjekt gemacht. Dies führte die Abkehr von Mustafa Kemal herbei, denn Kemalismus bedeutet Antiimperialismus. Das Ziel der Bewegung war es deshalb, Schluß mit den unerträglichen Zuständen zu machen." (162)

Kubali schließt sich Madanoglu und Savci an. Die Regierung Menderes habe nicht nur das Land wieder zu einem klassischen Ausbeutungsobjekt degradiert und die kemaiistischen Prinzipien mit Füßen getreten, sondern auch die Veríassung zerstört und unmäßige Korruption und Vetternwirtschaft geculdaet. (163)

Der inzwischen pensionierte General R. Tulga, einer der Führer der Bewegung, bezeichnete es als falsch, sie als einen militärischen Putsch aufzufassen, sie sei vielmehr das Werk aller derjenigen gewesen, die die kemalistischen Prinzipien achteten und Freiheit und Gleichheit nicht als leere Phrasen im Munde fuhrten. Sie sei eine Revolution nicht gegen die Herrschaft des Staates, sondern gegen die Partei, die die Macht des Staates usurpiert und das Erbe Atatüks verraten habe. (164)

Y. Sertel, die Tochter eines namhaften türkischen Sozialisten, faßt in folgenden Punkten die Prinzipien der Bewegung zusammen:

1. Der Etatismus sollte unter den neuen Bedingungen wieder praktiziert werden, das hieß, das Privateigentum anzuerkennen, aber dessen Machtmißbrauch durch staatliche Kontrolle zu verhindern.

159a) Nationalismus im kemalistischen Sinne heißt, die Gewährung der vollen nationalen Souveränität.

60) Madanoglu, C., Devrim Ankara, 26.5.1970, Nr. 32, S. 8

1) Madanoglu, C., ibid., S. 8

(6) Savci, B., "Thtilal Ne Getirdi?", Cumhuriyet, 31.5.1969, S. 2

3) Kubali, H. N., "27 Mayis'in 9. Yilinda", 4.6.1969, S. 2

164) Tulga, R., "27 Mayis Felsefesi", Cumhuriyet, 26.5.1970, S. 2 
2. Durch zentrale Planung und Leitung die natürlichen Ressourcen des Landes für die Volkswirtschaft, vor allem für die Entwicklung der Industrie zu erschließen.

3. Durch Gesetze und Reformen soziale Gerechtigkeit zu verwirklichen.

4. Durchführung der Landreform.

5. Kontrolle der Bourgeoisie.

6. Gewährung bürgerlich-demokratischer Rechte und Freiheiten.

7. In der Außenpolitik nach dem Prinzip Kemal Atatürks - "Friede in der Heimat, Friede in der Welt" - zu handeln. (165)

Diese Vorsätze leiteten die Bewegung. Mit großer Einsatzfreude und tief̂em Idealismus wollte man die verfahrene Situation meistern. Umso dringender erhebt sich die Frage, warum die Bewegung letztlich scheiterte, bzw. was nach 11 Jahren von ihr übrig geblieben ist? Madanoglu und andere führende Köpfe der Bewegung gestehen ein, daß man ohne klare Konzeption, ohne eigentlich recht zu wisser, was zu tun sei, sich in den Kampf gestüzt habe. Gewißheit habe nur darüber besancen, daß die Regierung gestüzt werden müsse, aber nicht, wie es danach weitergehen solle.

Der berühmte Schriftsteller der Türkei, S. S. Aydemir, einer der geistigen Weg. bereiter des Kemalismus, kritisiert in seinem noch nicht veröffentlichen Buch "Die Philosophie der Revolution" diese überstirzte Aktion. Seme Hauptvorwürfe gegen die Bewegung sind:

1. Mangelnde Organisation

2. Fiihrungslosigkeit

3. Fehlender Kontakt zur Bevölkerung

4. Konzeptionslosigkeit während und nach der Bewegung (166)

Aydemirs Kritik legt die wunden Punkte der Bewegung blob; dennoch genugt sie uns nicht, da Aydemir dariber hinausgreifende Fragen gar nicht stelit.

1. Wäre mit den oben genannten Zielen eine Rückkehr zum Kemalismus überhaupt möglich gewesen, und

2. waren die objektiver. und subjektiven Bedingungen für die Erfülung dieser Ziele gegeben?

Ad1)Die Führer der Bewegurg hatten nicht erkannt,daß ihre Postulate wenig mit den kemalistischen Prinzipien gemein hatten. Vergegenwärtigen wir uns:A tatürk kämpfte für die uneingeschränkte Sonveränität der Türkei, was ohne ökonomische Selbständigkeit ewig ein Wunschtraum bleiben mußte. Deshalb versuchte er die Bindungen an die imperialistischen Mächte auf ein Minimum zu reduzieren. Schulden wurden regelmäßig zurïckgezahlt, ausiändische Unternehmen nationalisiert und nur in Ausnahmefällen Auslandsschulden gemacht, obwohl Geld dringend benötigi wurde.

Davon war bei den Verantwortlichen des 27. Mai nicht die Rede, der Austritt aus der Nato, der CENTO oder die Kindigung der bilateralen Verträge mit den USA standen nicht zur Debatte, ganz im Gegenteil, man erklärte von Anfang an, alle Ver. träge und Abkommen srfuilen zu wollen.

Unter diesen Voraussetzungen werpuffe die Stoßkraft der Bewegung, und sie mußte schlieblich im Sand zeraufen. Die nationale und internationale Bourgeoisie hatte nichts zu befuchten, solargs ihr beherrschender Einfluß nicht angetastet wurde.

165) Sertei, $Y_{0}$, a.a.0., S. $118+118$

166) Tükel, S., zit. n. "Sevket Süreyya Aydemir", Aksam, 5.1.1971 
Der Kemalismus ist seinem Wesen nach dynamisch. Es wäre daher falsch, die Bewegung des 27. Mai an den Prinzipien Atatürks zu messen, seine Prinzipien mechanisch auf den Zeitabschnitt nach der Mai-Revolte zu übertragen. Die Klassenwidersprüche in der Türkei hatten sich verschärft, die Welt war in zwei Lager gespalten. Dieser neuen Entwicklung muß der Kemalismus gerecht werden, will er nicht blindem Pragmatismus verfallen. Eine der vorrangigsten Aufgaben wäre die Beseitigung der extremsten Klassenwidersprüche und Privilegien einer dünnen Oberschicht gewesen.

Ad 2) Die Frage nach dem Vorhandensein der objektiven und subjektiven Bedingungen ist nicht eindeutig zu bejahen oder zu verneinen. Die Führung der Bewegung lag in den Händen des progressiven Teils der Armee, der mit dem progressiven Teil der Intelligenz kooperierte. Eine antiimperialistische Politik und Liquidierung der Privilegien der Bourgeoisie wäre objektiv im Bereich des möglichen gelegen.

Soweit reichte aber die Vorstellungskraft und das Denkvermögen der pro. gressiven Führung nicht, und von der Masse der apathischen Bevölkerung waren Anregungen mit diesen Intentionen schon gar nicht zu erwarten. Die Politik Mienderes hatte jegliche Initiative, die von der Masse zur Verbesserung ihrer Lebenslage ausging, im Keim erstickt. "Die Gesellschaft war für radikale Umwälzungen nicht reif, da es keine ausreichenden geistigen Potenzen gab." (167) schreibt Avcioglu in "Gedanken über den 27. Mai", dennoch habe die Führung das unter den damaligen Umständen mögliche erreicht. Unseres Erachtens trifft dies nicht zu, denn schon geplante und ausgearbeitete Reformen wurden zur Durchführung den Kräften überlassen, die an diesen Reformen kein Interesse haben konnten. Eine radikale Landreform, durchgeführt mit maßgeblicher Beteiligung von Großgrundbesitzern käme einem Wunder gleich und widerspricht sämtlichen geschichtlichen Erfahrungen.

\subsection{Demokratisierung im Überbau}

Fragen wir nun nach den Erfolgen der Bewegung.

Es kann nicht geleugnet werden, daß ihr einige fortschrittliche Neuerungen zu verdanken sind. Erstmals in der Geschichte der Türkeß werden die Werktätigen als eigenständige Kraft anerkannt, Möglichkeiten für deren Aufklärung und Organisierung können legal diskutiert und in die Praxis umgesetzt werden. Dieses veränderte Bewußtsein fand seinen Niederschlag in der neuen türkischen Verfassung von 1961, die die sozialen, ökonomischen und kulturellen Rechte der Werktätigen ausdrücklich anerkennt. Artikel 1 und 2 bestimmen den türkischen Staat als demokratische Republik und laizistischen, sozialen, auf den Menschenrechten basierenden Rechtsstaat.

In der Verfassung sind das Streikrecht der Werktägigen, das Recht auf Gründung ihrer eigenen Parteien und Gewerkschaften, das Koalitionsrecht und das Recht auf Arbeit, die Pflicht des Staates zur Beseitigung der wirtschaftlichen und sozialen Probleme verankert. (Art. 10)

Die neue Verfassung wird vielerorts als eine der fortschrittlichsten bürgerlichen Verfassungen anerkannt. Doch bleibt die beste Verfassung hohle Phrase, wenn die elementarsten Bedingungen fehlen, sie zu praktizieren. Was niitzt das Recht auf Bildung, wenn es in den Dörfern keine Schulen gibt, wenn jährlich zehntausende von biturienten keinen Platz in den Universitäten finden, was nützt das Recht auf Ar-

267) Avcioglu, D., “27 Mayis Uzerine Düsünceler”, Devrim, Nr. 32, 26.5.1970, S. 1 
beit bei chronischer Arbeitslosigkeit, was nützt das Recht auf soziale und medizinische Betreuung, wenn Krankenhäuser überbelegt sind, wenn die Arztkosten nicht bezahlt werden können?

Dennoch markiert die Verabschiedung der Verfassung einen neuen Abschnitt in der Geschichte der Türkei. In den 10 Jahren seit ihrer Verabschiedung kam langsam bei Arbeitern und Bauern, progressiven Intellektuellen und Studenten ein ProzeB des "nationalen BewuBtwerdens" in Gang. Die Intellektuellen und Studenten besannen sich endlich auf ihre eigene nationale Kultur und setzten der Imitation Europas ein Ende. So konstatiert M. Ozyörük in einem Rückblick zum zehnjährigen Jahrestag des 27. Mai: "Was ist vom 27. Mai übrig geblieben? Eine revolutionäre, sich bewußte, überzeugte, energiegeladene Jugend, wie sie die türkische Geschichte nie gekannt hat." (168) 1961 wurde die türkische Arbeiterpartei (TIP) gegrüdet, und nach der Verabschiedung des Gewerkschaftsgesetzes breitete sich die Gewerkschaftsbewegung aus. Es dauerte jedoch nicht lange, bis ein Teil der Gewerkschaftsinnktionäre von der türkischen Großbourgeoisie bestochen war. 1967 schlossen sisch die progressivsten Gewerkschaftler in der "Revolutionären Arbeiterkonföderấion" (DISK) zusammen. Die Organisation der Arbeiterklasse brachte große Erfolge. Streiks und Protestaktionen führten ihre Macht vor Augen. Von 1963-1966 wurden 83 Streiks durchgefuhrt.

In der Volkspartei, die nach dem Tod Atatirks sich immer mehr vom Volke löste, und die Interessen der Großgrundbesitzer und wohlhabenden Bürger wahrnahm, setzite eine neue Entwicklung ein. Unter ihrem Generalsekretär B. Ecevit sagte der linke Fligel dem rechten den Kampf an, der daraufhin eine neue Partei, die "Vertrauenspartei" grüdete. Die Volkspartei proklamierte ihren Standort nun "links vont ter Mitte".

Die Mitglieder der nach dem 27. Mai verbotenen Demokratischen Partei gründeten die "Gerechtigkeitspartei".

Ene der ersten Maßnahmen der Militärs nach der Machtübemahme war die Einberufung des "Komitee der nationalen Einheit". Seine Mitglieder waren sich über die Notwendigkeit einer neuen Verfassung als Grundlage der weiteren Entwicklung einig. Am 6. Januar 1961 beriefen sie ein "Aufbauparlament" ein, das über den von wissenschafthichen Kommissionen vorbereiteten Verfassungsentwurf beriet, der nach AbschluB der Beratungen am 9. Juli 1961 der Bevölkerung zur Abstimmung vorgelegt und angenommen wurde. Wenig später wurden Parlamentswahlen durchgeführt, die jedoch keiner Partei die absolute Mehrheit brachten, so daß sich eine Koalitions. regierung unter Ministerpräsident Inönii konstituierte.

1964 ibernahm die Gerechtigkeitspartei nach ihrem absoluten Wahlsieg die Regierung. Der lediglich in den USA und der türkischen Bourgeoisie bekannte Demirel wurde Miristerpräsident. (168a) Die Gerechtigkeitspartei konnte ihren Wahlsieg stets wiede holen und regierte das Land bis zum 12. März 1971, als Demirel nach Intervention der türkischen Armee abdanken mußte.

168) Özyürik, M., "27 Mayisin 10. Vildonumandä", Cumburiyet, 28.5.1970, \$.2

168a) Bevor Demirel Vorsitzender der Gerechtigkeitsparte wurde, stellte thn die bereits von ihm kontrollerte Zeitung Adalet mit den Worten der Öffentlichkeit vor: "Demirel ist zwar bei breiten Teilen des Volkes nicht als eine politische Persönlichkeit bekannt. Aber er ist der türkischen Geschäftswalt im Ausland, insbesondere in den USA U. selbst bei Präsident Johnson und den groken nternchmen der USA, wo er nach seinem Studium seine be. rits vorhandenen konale crwerem konnte, uls eine erfolgreiche, kenntnisreiche $u$.

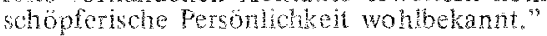




\subsection{Die Fünfjahrespläne}

"Das Komitee der nationalen Einheit gründete das 'Staatliche Planungsamt'. . dessen Zielsetzungen in einer grïndlichen Bestandsaufnahme der wirtschaftlichen Lage und in der Ausarbeitung eines Entwicklungs- und Perspektivplans für den Zeitraum von 15 Jahren bestanden." (169)

Der erste Fünfjahresplan für den Zeitraum von 1963 bis 1967 enthielt folgende Forderungen:

1. Beendigung der inflationistischen Politik.

2. Durch schuelles Entwicklungstempo Erhöhung des Nationaleinkommens um jährlich $7 \%$.

3. Gerechtere Verteilung des Nationaleinkommens.

4. Beschleunigung der Industrialisierung.

5. Gleichmäßige Entwicklung des staatlichen und privaten Sektors der Wirtschaft.

6. Beseitigung des Zahlungsbilanz- und Haushaltsdefizits.

Das Gesetz zur Förderung des ausländischen Kapitals wurde nicht angetastet. Es sollte mehr ausländisches Kapital ins Land fließen. 4 \% der Investitionen sollten durch ausländisches Kapital ermöglicht werden. Dieser dem Fremdkapital sehr freundliche Plan fand auch den Beifall des US-Botschafters. (170)

Inönü sagte, der erste Fünfjahresplan sei mit der Absicht vorbereitet worden, die wirtschaftliche, soziale und kulturelle Entwicklung des Landes auf demokratischem Wege zu verwirklichen. Er fügte hinzu "In unserem Land beginnt mit der Annahme des ersten Fünfjahresplans eine neue wirtschaftspolitische Ordnung." (171)

Der 2. Fünfjahresplan unterscheidet sich nicht wesentlich von dem ersten. Wir werden deshalb beide zusammen analysieren, auf einige Unterschiede jedoch kurz eingehen. Der 2. Fünfjahresplan bevorzugt wieder - wie die Regierung Menderes die Privatwirtschaft. Privatunternehmen sind angehalten, in allen $\mathbb{Z}$ weigen der Wirtschaft zu investieren, während der Staat in den Bereichen investieren soll, wo die Privatunternehmen trotz staatlicher Subventionen nicht in der Lage sind.

Das Fremdkapital wird als Devisenquelle und Inhaber überlegener Technologie gefördert. "Die Verwirklichung der geplanten Investitionen und Entwicklungsziele wird davon abhängen, daß im geplanten Umfang Auslandsanleihen aufgenommen werden können." (172)

Als eines der wichtigsten Vorhaben war geplant, daß die Investitionen unter dem 1. Fünfjahresplan 18,3\% und unter dem 2. Fünfjahresplan 21,3\% des Bruttonationaleinkommens erreichen sollten.

In keinem Jahr wurde das Planziel erreicht. Fast jedes Jahr lagen die Investitionen unter dem Plansoll, 1968 wurde noch nicht einmal das Planziel von 1963 erreicht. Der Anteil der Investitionen der öffentlichen Hand mußte trotz der Vergünstigun. gen zugunsten des privaten Sektors von 1963 bis 1968 zunehmen. Im Wirtschaftsbericht der "Handels- und Industriekammer und Börsen" wird diese Entwicklung attackiert. Es sei zwar verständlich, daß die Investitionen, die kurzfristig keine Profite bringen und eine umfangreiche Organisation und ein großes Kapital erforderm, durch die offentliche Hand erfolgen, aber wenn man bedenke, daß in den entwickel-

169) Barthel, G., Jahrbuch, a.a.O., S. 199

170) Vgl.Avcioglu, D., "A merikan Büyükelcisinin Türkiye'ye Yardim Konusundaki Raporunun Tam Metni", Yön Dergisi, N $\mathbf{1}$. 4 (S. 355, Türkiyenin Düzeni)

171) Inönü, I., Kalkinma Plani, 1. Bes Yil, Ankara, 1963 67, S. 3-4

172) Ikinci Kalkinma Plani, S. 122 , vgl. auch S. 9.122 
Tabelle 13 Anteil der Gesamtinvestitionen am

Bruttonationaleinkommen (in \%) (173)

\begin{tabular}{lccc}
\hline Jahr & $\begin{array}{c}\text { Gesamt- } \\
\text { investitionen* }\end{array}$ & $\begin{array}{c}\text { Anteil der Privatinvesti- } \\
\text { tionen an den Gesamt- } \\
\text { investitionen }\end{array}$ & $\begin{array}{l}\text { Anteil der staalichen In- } \\
\text { vestitionen an den Gesamt- } \\
\text { investitionen }\end{array}$ \\
\hline 1963 & 14,6 & 48,53 & 51,57 \\
1964 & 14,2 & 45,49 & 54,61 \\
1965 & 14,6 & 44,33 & 55,67 \\
1966 & 16,2 & 46,53 & 53,47 \\
$1967 * *$ & 16,6 & 47,29 & 57,71 \\
1968 & 18,2 & 43,23 & 56,72 \\
\hline
\end{tabular}

*o hne Lageränderungen

**1963-1967: Zeitraum des 1.Fünfjahresplanes

ten Industriestaaten $80 \%$ der Investitionen auf Privatinitiative erfolgten, sei die Entwicklung in der Türkei zu bedauem. (174)

Es ist nur zu deutlich, was diese Forderungen bezwecken. Der Staat soll die ungezügelte Profitgier der Bourgeoisie durch immer mehr Subventionen begünstigen, die in den Wirtschaftszweigen investiert werden, wo in kürzester Frist große Profite herauszuschlagen sind, wie z. B. im Wohnungsbau. 1963 wurden von den Investitionen des Privatsektors 16,1 \%, 1968 19,4\% im Wohnungsbau investiert. (Staatliche Investitionen: $2 \%$ bzw. 0,9 \%) (175). Mit dem größten Teil dieser Wohnungsbauinvestitionen werden vor allem Villen und Luxusappartements gebaut. Auf diese Weise werden enorme Summen der Industrialisierung eines unterentwickelt gehaltenen Landes entzogen.

Tabelle 14 Verteilung der Investitionen auf die verschiedenen

Wirtschaftszweige (176) Investitionen 1963-66

$\begin{array}{lrlr}\text { Landwirtschaft } & 15,5 & \text { Wohnungsbau } & 21,1 \\ \text { Bergbau } & 5,5 & \text { Bildungswesen } & 6,6 \\ \text { Industrielle Produktion } & 18,3 & \text { Gesundlheitswesen } & 1,8 \\ \text { Energie } & 7,0 & \text { Tourismus } & 1,9 \\ \text { Verkehrswesen } & 14,6 & \text { Dienstleistungswesen } & 7,6\end{array}$

$21,1 \%$ der Gesamtinvestitionen erfolgten im Wohnungsbau. Die zweite Stelle nehmen zwar die Investitionen für die industrielle Produktion ein, der größere Teil davon ist aber für die extraktive Industrie bestimmt. Vergegenwärtigt man sich, daß z. B. 1967 noch $76 \%$ der notwendigen Maschinen und Ausrïstungen importiert werden mußten, und $32 \%$ der einheimischen Maschinenproduktion nur durch ausländische Importe fertiggestellt werden konnten, (177) so wird deutlich, daß die industri-

173) Zit. n. Türkiye Ticaret Odalari ve Ticaret Borsalari Birligi, "Iktisadi Rapor", S. 41, Tabelle 19 und S. 45 , Tabelle 22

174) Vgl. ibid., S. 46-47

175) Vgl. ibid., S. 49

176) Özkol, Sedat., Geri Birakilmis Türkiye, Istanbul, 1969, S. 83

177) Vgl. "Türkiyede Makina Yapan Makinalar Sanayiinin Gelecegi", Devrim, Nr。9, 16.12.1969 S. 8 
ellen Investitionen vor allem in der Schwerindustrie sehr viel höher sein müßten, als es tatsächlich der Fall ist.

Beide Pläne beabsichtigen, den Anteil der Landwirtschaft zugunsten des industriellen Wachstums am Bruttonationaleinkommen zu senken.

Tabelle 15 Entwicklung des Anteils der verschiedenen Wirtschaftssektoren am Bruttonationaleinkommen (178)

(in \%)

Sektoren

19621963196419651966196719681969

Landwirtschaft: 1. Fünfjahresplan-

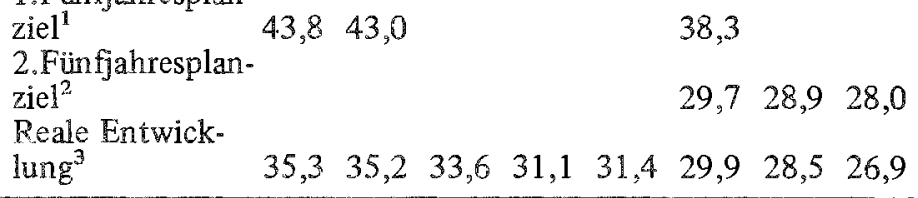

Industrie: 1 .Fünfjahresplan-

ziel $^{1} \quad 16,8 \quad 21,4$

2.Fünfjahresplan-

$\begin{array}{llll}\text { ziel }^{2} & 16,3 \quad 17,2 & 18,0\end{array}$

Reale Entwick-

$\begin{array}{llllllllll}\text { lung }^{3} & 14,2 & 14,2 & 14,7 & 15,3 & 15,4 & 16,3 & 16,8 & 17,6\end{array}$

Sonstiges: 1.Fünfjahresplan-

ziel $^{1} \quad 39,4 \quad 40,3$

2.Fünfjahresplan-

ziel ${ }^{2}$

$54,0 \quad 53,9 \quad 54,7$

Reale Entwick-

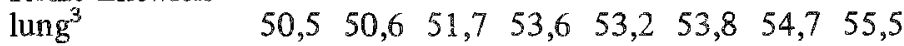

In den Preisen von 1961, DPT, 1. Plan, Tablo: $53 / 2$

2 In den Preisen von 1965, DPT, II. Plan, Tablo: 36

In den Preisen von 1961, DIE

Der Anteil der Landwirtschaft am Bruttonationaleinkommen ist zwar schneller zurückgegangen als geplant, aber nicht zugunsten der Industrie, die um $5,1 \%$ hinter den Planzielen zurïckblieb. Dagegen erhöhte sich der Anteil des Dienstleistungswesens, des Wohnungsbaus etc. unerwartet schnell von 50,5\% im Jahre 1962 auf $55,5 \%$ im Jahre 1969. Diese Entwicklung zeigt einen eindeutigen Mißerfolg der Planungen im Bereich der Investitionen. Selbst die türkische Industrie- und Handelskammer be zeichnet diese Entwicklung als gefährlich und bemängelt die Unproduktivität der Investitionen. (179)

Die Bemühungen, durch eine gewisse regionale Verteilung der Konzentration von Investitionen in den drei großen Städten Istanbul, Ankara und Izmir entgegenzuwirken, schlugen fehl. Die krasse Diskrepanz dieser Städte zu den ïbrigen Teilen des Landes nahm noch zu.

178) Iktisadi Rapor, a.2.O., S. 11, Tabelle 1.

179) Iktisadi Rapor, a. 3.O., S. 13 
Tabelle 16 Regionale Ansiedlung neuer Firmen (1960-1967) (180)

\begin{tabular}{lrrrr}
\hline Städte & $\begin{array}{l}\text { Neugegrüde- } \\
\text { te Firmen }\end{array}$ & $\%$ & Gesamtkapital (in TL) & $\%$ \\
\hline Istanbul & 3.441 & 37,1 & 1.670 .229 & 43,7 \\
Ankara & 960 & 10,3 & 993.543 & 26,2 \\
Izmir & 736 & 7,9 & 228.206 & 6,5 \\
Sonstige & 4.447 & 44,7 & 636.611 & 18,0 \\
\hline Insgesamt & 9.284 & 100,0 & 3.528 .589 & 98,0
\end{tabular}

Über $80 \%$ der gesamten Investitionen erfolgten erneut in den genannten Städten, was nicht nur zu einer ungleichen Verteilung des Volkseinkommens zwischen den Regionen führte, sondern zusätzlich viele neue Probleme mit sich bringt. Der Bau von Wohnungen hält mit dem wachsenden Zustrom neuer Einwohner nicht Schritt, Slums schießen wie die Pilze aus dem Boden und umgeben die Städte wie ein fester Kordon. (180a) zu ziehen:

Versuchen wir die Bilanz der Fünfjahrespläne hinsichtlich der Investitionen

1. Der geplante Umfang der Investitionen wurde nicht erreicht.

2. Mißerfolg in der sektoralen Planung.

3. Mißerfolg in der Regionalplanung.

Statistiken des türkischen Planungsamtes weisen aus, daß 1968 der von der Landwirtschaft produzierte Neuwert um 1,9\% stieg (in den Preisen von 1961), 1969 nur um 0,8 \%, während der Plan $4 \%$ vorsah.

Allein in den Branchen Bauwesen, Handel und Verkehr, wo großzügige staatliche Kredite und Vergünstigungen vergeben wurden, konnten die Planziele um durchschnittlich $2 \%$ iberschritten werden. (181)

Ein anderes wichtiges Ziel war die Bekämpfung der Inflation. Die Preissteigerungen sollten gedrosselt werden, der Auftrieb der Lebenserhaltungskosten gebremst und das Einkommensgefälle gemildert werden. Demirel und die Gerechtigkeitspartei wurden nicht müde, diese Ziele zu proklamieren, die ständige Wiederholung allein brachte diese Vorhaben aber keinen Schritt weiter in Richtung auf ihre Realisierung.

180) Türkiye Istatistik Yilligi, Ankara, 1968, S. 306, (Auszug)

180a) Diese Behausungen werden bei uns "Gece Kondu" genannt, d.h.: in einer Nacht erbaut. Baut sich jemand in einer Nacht ein primitives Haus, so darf es von der Regierung nicht onne weiteres eingerissen werden.

181) Vgl. Iktisadi Rapor, 1970, a.a.O., S. 17-18, Kücük, S., "Politik bunalimin temelindeki Ekonomik Bunalim, Egemen Siniflarin Kalkinma Cikmazi," Devrim, Nr. 69, 16.2.1971,
S. 8 
Tabelle 17 Allgemeiner Preisindex der Jahre 1960-1967 (182)

(Basisjahr 1958 $=100$ )

\begin{tabular}{lccccc}
\hline & 1960 & 1963 & 1965 & 1967 & $1960 / 67$ in \% \\
\hline Allgemeiner Index & 126,0 & 143 & 154 & 170 & 34,9 \\
Nahrungsmittel & 123,6 & 148,5 & 150,1 & 168,1 & 36,7 \\
Landwirtschaft u. Getreide & 129,0 & 155,0 & 164,5 & 187,7 & 45,5 \\
Obst & 135,1 & 157,6 & 155,6 & 157,3 & 16,4 \\
Tierische Lebensmittel & 148,2 & 169,8 & 186,6 & 224,5 & 58,2 \\
Textilien & 131,1 & 121,6 & 130,5 & 153,4 & 35,6 \\
Brennstoff und Erdgas & 136,7 & 147,8 & 151,5 & 174,8 & 73,7
\end{tabular}

Die Handelskammer von Istanbul errechnete einen Preisanstieg wichtiger Grundnahrungsmittel zwischen 1959 und 1968 von über 200\%. (183)

Tabelle 18 Preissteigerungen wich tiger Lebensmittẻl zwischen 1959 und 1968 (184)

\begin{tabular}{lccc}
\hline & $\begin{array}{c}\text { Durchschnitts- } \\
\text { preise in Kurus* } \\
1959\end{array}$ & $\begin{array}{c}\text { Durchschnitts- } \\
\text { preise in Kurus* } \\
1968\end{array}$ & $\begin{array}{c}1959 \text { bis } 1968 \\
\text { in \% }\end{array}$ \\
\hline Brot (kilo) & 52,5 & 115 & 119 \\
Schaffleisch & 500,0 & 1.484 & 196,5 \\
Rindfleisch & 415 & 1.269 & 206 \\
Gemüse & 110 & 169 & 53,6 \\
Olivenöl & 464 & 1.092 & 135 \\
Reis & 175 & 323 & 84,7 \\
Zwiebeln & 52 & 110 & 115,5 \\
Radio & 322 & 495 & 53,7 \\
Arztvisite & 15 & 40 & 166,5 \\
Bücher & 4,50 & 8,00 & 77,7 \\
\hline
\end{tabular}

$* 100$ Kurus $=1 \mathrm{TL}$

182) Ticaret Bakanligi Konjuktür ve Yayin Müdürlügü-Istanbul, Ticaret Odalari., zit. n. Türkiye Istatistik Yilligi, 1968, S. 402

183) Cumhuriyet, 20.6.1969

184) Ibid. "1 TL - 100 Kurus" 
Nach 1968 stiegen die Preise sogar noch schneller. Allein 1968/69 verteuerten sich die Gemüse um $50 \%$. (185) Auch die Mieten erhöhten sich sehr rasch; 1960 . 1967 um $73,7 \%$. (186)

$\mathrm{Zu}$ obenstehender Tabelle ist anzumerken, daß nach Angaben des türkischen staatlichen statịstischen Amtes 52,9\% der Dorfbewohner im Jahr nur einmal (zum Opferfest) Fleisch essen. (187)

Tabelle 19 Die Entwicklung der Löhne (1962-1968) (188)

\begin{tabular}{lrrr}
\hline & 1962 & 1968 & \multicolumn{1}{c}{ in \% } \\
\hline Industrie & 15,73 & 27,06 & 72,0 \\
Bergbau & 13,35 & 27,09 & 102,9 \\
Bauwesen & 16,94 & 29,03 & 71,3 \\
Verkehrswesen, Post & 19,42 & 33,72 & 73,6
\end{tabular}

Die angezeigten Lohnsteigerungen können nicht darïber hinwegtäuschen, daß sie vollständig von den Preissteigerungen absorbiert bzw, von ihnen ibertroffen werden, d.h. die Lage der Arbeiter verschlechtert sich.

Die meisten Bauern sind noch schlechter gestellt als die Arbeiter. Mustata Ok, Abgeordneter der Volkspartei,machte im türkischen Parlament eine detaillierteRechnung auf, wonach der Tageslohn der Familie eines Tabakpflanzers 59 (!) Kurus (etwa 20 Pfennig) ergab. (189) (Es ist nun nicht weiter erstaunlich, warum $52 \%$ der Bauern nur einmal im Jahr Fleisch essen).

Die Untätigkeit der Regierung bei der Bekämpfung der anhaltenden Verteuerung der Lebenshaltungskosten, und das ausufernde Zahlungsbilanzdefizit ließen der Inflation freien Lauf. Anfang 1971 mußte die türkische Lira um $66 \%$ abgewer. tet werden.

Untersuchen wir abschließend eines der wichtigsten Ziele der Fünfjahrespläne, für soziale Gerechtigkeit Sorge zu tragen und das Einkommerssefälle zwischenReich und Arm zu mildern. (189a) Die Handhabung der Steuer- und Kreditpolitik sprach diesen proklamierten Zielen geradezu Hohn. Sie ist für die herrschende Klasse ein bequemes Instrument, sich ungehindert auf Kosten der einkommensschwachen Schichten des türkischen Volkes zu bereichern.

Die Steuerpolitik hatte sich seit bestehender Republik nachteilig für die Werktätigen ausgewirkt, da der Großteil der Steuern als Verbrauchssteuem indirekt erhoben wird.

185) Cumhuriyet, 14.7.1969

186) Istanbul Ticaret Odalari, zit. n. Türkiye Istatistik Yilligi, 1968, S. 403

187) Gümüstas, Y., Cumhuriyet, 16.3.1970

188) Vgl. IKA Günlük Bülkeni, 5.11.1969, Nr. 481, zit. n. Iktisadi Rapor 1970, a.a.0., S. 68

189) Ok, M., "Haklar Dengesi ve Aci Gercek", Cumhuriyet, 9.8.1969, S. 2

189a) 1963 bezogen $20 \%$ der Bevölkerung $61 \%$ des Gesamteinkommens, $40 \%$ der Bevölkerung dagegen nur $10,6 \%$. 
Tabelle 20 Anteil der direkten und indirekten Steuern am Gesamtsteueraufkommen (190)

\begin{tabular}{lcccc} 
Jahr & $\begin{array}{l}\text { Direkte Steuern } \\
\text { in Mrd. TL }\end{array}$ & in \% & $\begin{array}{l}\text { Indirekte Steuern } \\
\text { in Mrd. TL }\end{array}$ & in \% \\
\hline 1965 & 3,408 & 24,39 & 6,866 & 53,33 \\
1967 & 5,077 & 28,05 & 9,818 & 54,24 \\
1969 & 6,798 & 30,09 & 12,313 & 54,63
\end{tabular}

Seit Jahren verliert der Staat durch Steuerhinterziehung der Unternehmer und Großgrundbesitzer riesige Summen. Staatliche Steuerprüfer stellten bei $3 \%$ der Gewinnsteuerpflichtigen, die sie überprüft hatten, fest, daß sie 1,7 Mrd Steuern widerrechtlich einbehalten hatten. Der jährliche Verlust des Staates wird auf $10 \mathrm{Mrd}$. TL geschätzt. (190a)

Durch staatliche Kredite werden in ersten Linie Untemehmer und Großgrundbesitzer gefördert. Sie erhalten jährlich $70 \%$ der Bankkredite. (191)

1962 erhielt der Privatsektor der Wirtschaft $86 \%$ aller Bankkredite (ohne Zentralbankkredite), der staatliche Sektor nur $14 \% .1966$ erhöhte sich der Anteil des Privatsektors auf $87,3 \%$, der Anteil des öffentlichen Sektors sank auf 12,7\%. (192)

Am Beispiel des Tabakanbaus und des Tabakhandels erläuterte Mustafa $\mathrm{Ok}$ 1967 das Kreditvergabesystem. 82 Tabakexporteure erhielten 1967 von der staatlichen Zentralbank Kredite in Höhe von 366,6.Mill TL, durchschnittlich jeder also 4,5 Mill TL. Im selben Jahr erhielten 427.798 Tabakpflanzer Kredite in Höhe von 378 Mill.TL, pro Tabakpflanzer 885 TL. (193) Für die Tabakexporteure sind diese Kredite ein äußerst lohnendes Geschäft, denn sie gewähren den Tabakpflanzern Kredite zu höheren Zinsen als sie selbst zahlen.

Wuchergeschäfte dieser Art sind gang und gäbe, die Bauern verschulden und geraten in völlige Abhängigkeit von den Wucherern,denen es so ermöglicht wird, die Erzeugnisse der Bauem zu niedrigen Pauschalpreisen aufzukaufen. 1964 verdiente ein Tabakbauer an einem Kilo Tabak 56 Kurus, das gleiche Kilo Tabak brachte dem Tabakexporteur einen Reingewinn von 256 Kurus. (194)Die Tabakexporteure erhalten zusätzlich Exportvergünstigungen. Senator S. Kücük schätzt die durch Steuer-, Export- und Kreditverguinstigungen Kaufleuten und Privatunternehmern zugeflossene Summe (194a) auf 13 Mrd. TL. (195)

190) Vgl. Dikmener, B., "Beyannameli Mükellefler Az Vergi Veriyor", Cumhuriyet, 26.3.1971, S. 5, vgl. Aren, S., Ekonominin El Kitabi, Istanbul, 1968, S. 99-108, vgl. Ener, B., "Siyasi Bunalimin Ardindaki Gercek," Ant Dergisi, Nr. 168, 17.3.1970, S. 9

190a) 25,6 \% der Gewinnsteuerzahler gaben 1970 ein durchschnittliches Monatseinkommen von lächerlichen $176 \mathrm{TL}$ an und zahlten eine monatliche Durchschnittssteuer von $25 \mathrm{TL}$.

191) Vgl. Selcuk, I. "Pencere", Cumhuriyet, 29.5.1970

192) Vgl. Özkol, S., Geri Biräkilmis Türkiye, a.a.O., S. $82-83$

193) Vgl. Ok, M., Cumhuriyet, 9.9 .1969$, S. 2

194) Vgl. Avcioglu, D., a.a.O., S. 312

194a) An diesen Manipulationen partizipieren auch führende Politiker. Seit Demirel Ministerpräsident ist, wurde seine Familie zur zweitreichsten der Türkei.

195) Vgl. Kücük, S., a.a.O., (Devrim) 
Wir haben einen Eindruck gewonnen, was die herrschenden Klassen unter "sozialer Gerechtigkeit und gerechter Einkommenspolitik" verstehen. B. Ecevit, bis zum 22. März Generalsekretär der Volkspartei, beschrieb diese Politik mit einem passenden Vergleich: "Im Vertrauen auf das Profitstreben und die Schöpfungskraft wurde das Privatunternehmertum als Lokomotive der wirtschaftlichen Entwicklung und Industrialisierung eingesetzt. Für die Lokomotive wurden Schienen gelegt, ihre Depots mit Brennstoff aufgefüllt, Tunnels und Brïcken errichtet, damit sie schneller fahren kann. Dies ailes wurde in der Türkei mehrmals ausprobiert: Im Osmanischen Reich - das Reich ging zugrunde; in den Anfängen der Republik - nach ein paar Jahren stand die junge Türkei am Rande des Ruins, der Staat mußte die Lenkung der Lokomotive übernehmen - er wurde gerettet. Nach 1950 machte man denselben Versuch - der Staat wurde der Diener des Privateigentums, und nach wenigen scheinbar erfolgreichen $J$ ahren war unsere Wirtschaft bankrott . . .

Als ob das nicht gereicht hätte, wurde von der einheimischen und ausländischen Unternehmerschaft ein junger Mann an die Spitze lanciert, der wiederum und noch bewußter den alten Versuch wiederholen will."

Ecevit fragt sich, was die Regierung in dem Chaos zu machen gedenke, und gibt die Antwort: "Sie macht gar nichts, und sie wird auch nichts machen können ... Offensichtlich wird sie von der Lawine, die auf uns zukommt, überrollt." (196)

\section{Die Herschaft der Bourgeoisie und ihre Verbündeten}

Die Analyse der Fünfjahrespläne hat ergeben, daß sie ein einziger Mißerfolg waren. Das nach offiziellen Angaben und meist unternehmerfreundlichen Berichten zusammengestellte Zahlenmaterial beweist, daß die Ziele des 1. Fünfjahresplans und bis jetzt auch des 2. Fünfjahresplans nicht annähernd verwirklicht wurden. Es erhebt sich die Frage, ob die Herrschaftsverhältnisse in der Türkei es überhaupt gestatten, die Planziele zu realisieren, die Industrialisierung voranzutreiben und die vielfältigen Probleme zu lösen?

Wir meinen, die Antwort kann nur ein klares Nein sein. Die Interessen der türkischen und internationalen Bourgeoisie stehen in zu engem Zusammenhang, als daß diese nicht versuchen würden, in enger Kooperation ihre Pfründe sich zu erhalten. Mit anderen Worten, das Ziel der Pläne ist nicht die Industrialisierung der Türkei und Überwindung ihrer Probleme, sondern die Perpetuierung der Herrschaft der türkischen Bourgeoisie und des Neoimperialismus. Wie kann es sonst erklärt werden, daß beispielsweise die Fünfjahrespläne mit maßgeblicher Beteiligung und unter Kontrolle von US-Spezialisten vorbereitet wurden, daß ein vollkommen unbekannter Mann (Demirel) plötzlich Ministerpräsident wurde, daß gerade die Partei, die mit den imperialistischen Staaten eng zusammenarbeitet, die Wahlen immer wieder gewann, und daß bei Wahlen Dollars eine große Rolle spielen? Die Innenpolitik der Türkei kann nicht isoliert betrachtet werden, sondern sie ist in en. gem Kontext mit der Politik des Fremdkapitals zu sehen.

196) Ecevit, B., "Bütce Tankidi Konusmasi", zit. n. Selcuk, I. Cumhuriyet, 16.2.1969 


\subsection{Gesetze im Dienste des Fremdkapitals}

Zur Förderung des Fremdkapitals wurden nach 1951 mehrere Gesetze erlassen, deren Einfluß auf den Umfang des Fremdkapitals wir zunächst jeweils einzeln analysieren werden.

\section{1. "Das Gesetz zur Förderung des ausländischen Kapitals"}

Nach diesem Gesetz war es für ausländische Investoren nicht bindend, entsprechend ihren Anträgen tatsächlich zu investieren. Das hatte für sie den Vorteil, nachdem ihnen die Durchführung eines Projekts zugestanden war,einerseits bis zur Durchführung andere Bewerber auszuschalten, und andererseits, in anderen Ländern etc. unter günstigeren Konditionen investieren zu können. Durch diese Politik entstehen den abhängigen Ländern große Schäden, da ihre Pläne ständig durchkreuzt werden.

Tabelle 21 Beantragte Investitionen und tatsächliche Investitionen in $1000 \mathrm{TL}$ (in 197)

\begin{tabular}{lccc}
\hline Jahr & $\begin{array}{l}\text { Beantragte } \\
\text { Investitionen (1) }\end{array}$ & $\begin{array}{l}\text { Tatsächliche } \\
\text { Investitionen (2) }\end{array}$ & $\begin{array}{l}\text { (2) in \% } \\
\text { von (1) }\end{array}$ \\
\hline 1951 & 4.800 & 3.410 & 69,89 \\
1952 & 26.993 & 2.993 & 20,09 \\
1953 & 18.197 & 1.148 & 15,08 \\
1954 & 108.440 & 2.598 & 6,41 \\
1955 & 48.968 & 8.002 & 8,75 \\
1956 & 66.954 & 21.655 & 14,51 \\
1957 & 42.895 & 10.531 & 15,89 \\
1958 & 57.693 & 15.068 & 17,44 \\
1959 & 69.474 & 19.825 & 19.18 \\
1960 & 48.926 & 18.711 & 21,07 \\
1961 & 88.055 & 43.056 & 25,28 \\
1962 & 136.604 & 87.246 & 32,76 \\
1963 & 243.849 & 91.386 & 33,96 \\
1964 & 125.281 & 69.885 & 36,48 \\
1965 & 193.320 & 95.598 & 41,71 \\
1966 & 229.933 & 69.580 & 30,26 \\
\hline Insgesamt & 1.407 .462 & 560.695 & 39,84
\end{tabular}

Nach Verabschiedung des "Gesetz zur Förderung des ausländischen Kapitals" im Jahre 1951 wurden bis Ende 1965 umgerechnet 68,6 Mill॰Dollar in der Türkei investiert, davon 57,8 \% (39,7 MillDollar) in Form von Sachwerten, 37,7\%(25,9 Mill。 Dollar) in Form von Geld und 4,5\% (3,1 Mill. Dollar) in Form von immateriellen Güterrechten wie Lizenzen, Patentrechten, Dienstleistungen und Warenzeichen. (198)

197) Toncer, B. a.a.O., S. 83

198) Ibid. (Vgl.), S. 85

7 Probleme des Klassenkampfs Nr, 5 
Tabelle 22 Herkunft des Fremdkapitals (1951-1965) (199)

\begin{tabular}{lcc}
\hline Länder & Fremdkapital in 1000 Dollar & in \% \\
\hline USA & 20.828 & 30,5 \\
Schweiz & 12.121 & 17,7 \\
Niederlande & 10.991 & 16,0 \\
BRD & 10.023 & 14,6 \\
Frankreich & 4.685 & 6,8 \\
England & 2.171 & 3,2 \\
Italien & 2.157 & 2,8 \\
Sonstige Länder & 3.564 & 5,3 \\
Gemeinschaftskredite & 1.899 & 3,1 \\
\hline Insgesamt & 68.618 & 100,00
\end{tabular}

Aus den USA stammte knapp ein Drittel des Fremdkapitals, gefolgt von der Schweiz, Holland und der BRD, die zusammen mit fast $80 \%$ am Fremdkapital beteiligt sind. Bis 1968 rückte die BRD auf den 2. Platz.

Die Investitionen wurden fast ausschließlich $(96,28 \%$ des Fremdkapitals) im Bereich der verarbeitenden Industrie vorgenommen, innerhalb der Industrie wurden folgende Zweige bevorzugt: (200)

Tabelle 23

Gummi und Kautschuk

$26,26 \%$

Chemie

$24,53 \%$

Elektrische Maschinen

$12,58 \%$

Nahrungs- und Genußmittel

$10,93 \%$

Mineralien

Maschinenbau

$6,60 \%$

$5,45 \%$

Bis Ende 1965 wurden $99 \%$ der Fremdkapitalinvestitionen in vier Großstädten (Istanbul, Ankara, Kocali und Izmir) getätigt, davon $80 \%$ allein in Istanbul. (201)

2. "Das Erdölgesetz"

Das Erdölgesetz, vorbereitet von dem US-Experten Max Ball wurde 1954 verabschiedet. Es gewährt den Ölmonopolen in besonderem Maße Sonderrechte. (202)

199) Vgl. Ibid., S. 86 (Auszug)

200) Vgl. Ibid., S. 88

201) Vgl. Ibid., S. 89

202) Vgl. Cerid, M., Petrol Emperyalizmi, Istanbul, 1965, S. 83-86 
Sachwerte Geldwerte immaterielle insgesamt in \% Güterrechte

\begin{tabular}{lrrrrr}
\hline $\begin{array}{l}\text { Erdölerschließung } \\
\text { Raffinerien }\end{array}$ & 238.062 & 245.145 & 414.823 & 898.031 & 59,2 \\
\hline Insgesamt & 477.103 & 325.427 & 149.987 & 951.516 & 40,8 \\
\hline
\end{tabular}

3. "Das Gesetz für die Eisen- und Stahlfabriken in Ereglis" (TAS)

Für die Errichtung dieser Fabriken wurden 163,8 Mill,Dollar (1,5 Mrd TL) investiert, deren Herkunft folgende Tabelle zeigt: (204)

Tabelle 25

\begin{tabular}{lr}
\hline & (in 1000 TL) \\
\hline Ausländische Gesellschaften & 110.385 \\
AID.Kredite & 1.131 .895 \\
OECD-Kredite & 187.025 \\
Chase-Kredite & 45.000 \\
\hline Insgesamt & 1.474 .305
\end{tabular}

4. Durch Vermittlung der türkischen Bank für industrielle Entwicklung erhielten inund ausländische Investoren von internationalen Organisationen insgesamt 64,5 Mill.Dollar (463,1 Mill.TL) langfristige Kredite. (205)

Tabelle 26

\begin{tabular}{lc}
\hline Organisation & Kredite in $1.000 \mathrm{TL}$ \\
\hline IBRD & 127.666 \\
DLF & 88.058 \\
IDA & 140.411 \\
AlD & 38.675 \\
EIB & 68.338 \\
\hline Insgesamt & 463.148
\end{tabular}

Nachstehend die Summe des gesamten Fremdkapitals von 1951 bis 1965 (in 1000 Dollar):

Tabelie 27

\begin{tabular}{lcc}
\hline & 1.000 Dollar & $\%$ \\
\hline Erdölgesetz & 236.227 & 44,3 \\
Gesetz für die Eisen- und Stahlfabriken & 163.812 & 30,8 \\
$\quad$ in Eriglis & 68.618 & 12,8 \\
Gesetz zur Förderung des ausländischen & 64.481 & 12,1 \\
$\quad$ Kapitals & 533.138 & 100,0 \\
Bank für industrielle Entwicklung &
\end{tabular}

203) Toncer, B., a.a.0., S. 80

204) Vgl. Ibid, a.a.O., S. 81

205) Vgl. Ibid., S. 81 
Eine fundierte Analyse des Fre mdkapitals in der Türkei steht leider noch aus. Deshalb müssen wir uns mit allgemeinen Angaben begnügen.

Cem schätzt das von 1951 bis Anfang 1971 in die Türkei transferierte private Kapital auf 575 Mill.Dollar (ohne das durch die Bank für industrielle Entwicklung in die Türkei vermittelte Kapital). In den 20 Jahren wurden 297 Mill Dollar Profite in die Mutterländer rücktransferiert. (206)

Tabelle 28

\begin{tabular}{lccc}
\hline & \multicolumn{2}{l}{$\begin{array}{l}\text { Investiertes Kapital } \\
\text { (Mio Dollar) }\end{array}$} & \multicolumn{2}{c}{ Rücktranferierte Profite } \\
in Mio Dollar & in \% \\
\hline $1951-1970$ & 575 & 297 & 51 \\
$1963-1970$ & 209 & 172 & 82 \\
$1968-1970$ & 95 & 97 & 101
\end{tabular}

Auffallend ist, daß die in den vier letzten Jahren rücktransferierten Profite das importierte Kapital übertreffen. Der neue stellvertretende Ministe rpräsident der Türkei, Karaosmanoglu, der für alle wirtschaftlichen Angelegenheiten zuständig ist, gab 1971 in seiner ersten Presseerklärung bekannt, daß dem von 1967 - 1970 importierten Fremdkapital von 112,9 Mill.Dollar rücktransferierte Profite in Höhe von 121,9 MilloDollar gegenüberstehen. (207)

Tabelle 29

\begin{tabular}{lcccc}
\hline Jahr & Geldmittel & Sachwerte & Insgesamt & Rücktransfer.Gewinne \\
\hline 1967 & 12,8 & 4,4 & 17,2 & 25,3 \\
1968 & 7,4 & 5,7 & 13,1 & 31,8 \\
1969 & 14,1 & 10,1 & 24,2 & 31,8 \\
1970 & 15,6 & 42,8 & 58,4 & 33,9 \\
\hline Insgesamt & 49,9 & 63,0 & 112,9 & 121,9
\end{tabular}

Karaosmanoglu crklärte: "Unter diesen Umständen kann von einem Beitrag des Fremdkapitals für die Entwicklung der türkischen Wirtschaft innerhalb der letzten vier Jahre nicht gesprochen werden." (208)

Selbstverstandlich werden nicht alle Profite rücktransferiert, ein Teil der Profite wird für Reinvestitionen verwendet.

Die Höhe der Profite kann nicht mit Sicherheit ermittelt we rden, da sowohl die türkischen als auch die ausländischen Unternehmen mit Angaben über ihre Profite schr "zurückhaltend" sind, um weniger Steuern zahlen zu mussen.

Nach Angaben des staatlichen Plan ungsamtes liegen die Profitraten der ausländischen Firmen (außer in der Erdöl- und erdölverarbeitenden 1ndustrie, wo sie noch höher sind) jährlich durchschnittlich bei $50 \%$,dic der einheinischen Privatunternehmen durchschnittlich bei $20 \%$. (209) Die Profite der Unternehmen, die cine Monopolstellung innehaben, liegen jährlich bei durchschnittlich $60 \%-80 \%$. (210)

206) Cem, I., "Yabanci Sermaye", Milliyet. 20.4.1971, S. 2

207) Cumhuriyet, 15.4.1971.S.1

208) Milliyet, 15.4.1971, S.7

209) Vgl. Toncer, a.a.O., S. 103

210) Vel. Ibid.. S. 104 
Von dem in Geldform von den Unternehmen der kapitalistischen Industriestaaten in die Türkei exportierten Kapital konnten von 1951 bis 1968 sogar $85 \%$ als Profite in die Mutterländer rücktransferiert werden. (211)

Die Vergünstigungen der Regierung erlauben den ausländischen Unternchmen, ihre Profite weiterhin zu maximieren. Die Wirtschaftlerin G. Kazan attackiert die türkische Regierung, daß sie von der Geschichte nichts gelernt hätte, weil sie die Privilegien des Fremdkapitals nicht abbaut. Sie führt als Beispiel an: "Trotz der Abwertung der türkischen Lira (Abwertung der TL um 66,6 \%) können die ausländischen Öluntemehmen ihre Profite zu einem Kurs von 1 Dollar $=9 \mathrm{TL}$, ja sogar zu einem Kurs von 1 Dollar $=2,80$ TL rücktransferieren." (212)

Auch bei der Zahlung von Steuern wurden die ausländischenUnternehmen bevorteilt. "Bis 1969 mußten sie nur $20 \%$ Gewinnsteuer entrichten, während die türkischen Unternehmen fast doppelt soviel zu zahlen hatten." (213)

Für die ausländischen Monopole bieten die Länder der Dritten Welt hervorragende Profitchancen, da ein aufnahmefähiger Absatzmarkt, die notwendigen Rohstoffe und billige Arbeitskräfte fast immer vorhanden sind. Welche Möglichkeiten das Fremdkapital in den unterentwickelt gehaltenen Ländern hat, erhıllt die Geschäftspolitik der Daimler-Benz-AG, die in Istanbul eine Tochtergesellschaft gegründet hat.

Die Herstellungskosten eines Autobusses betragen 175.000 TL, wegen des großen Bedarfs können sie für $300.000 \mathrm{TL}$ abgesetzt werden. (214) Ein türkischer Facharbeiter verdient in der Bundesrepublik bei der Daimler-Benz-AG durchschnittlich 6,- DM die Stunde, sein Kollege in der Türkei verdient davon höchstens ein Viertel. Würde die Daimler-Benz-AG die Autos in der BRD bauen und sie in die Türkei exportieren, müßte sie sehr hohe Zölle bezahlen und die Transportkosten tragen. Baut sie die Autos in der Türkei, fallen diese Kosten weg. Weitere Vorteile ergeben sich daraus, daß die notwendigen Rohstoffe in der Türkei billiger sind, daß wichtige Teile wie Motoren mit großzügigen Vergünstigungen importiert werden können, und schließlich, daß es kaum Absatzschwierigkeiten gibt.

Lenins Worte aus dem Jahr 1917 haben ihre volle Gültigkeit behalten: "In diesen rückständigen Ländern ist der Profit gewöhnlich hoch, denn es gibt dort wenig Kapital, die Bodenpreise sind verhältnismäßig nicht hoch, die Löhne niedrig und die Rohstoffe billig." (215)

\subsection{Die Türkei im Teufelskreis der Unterentwicklung und der Abhängigkeit}

Die Türkei ist nach 1946 in ökonomischer, militärischer und politischer Hinsicht so fest in die Gewalt des Neoimperialismus geraten wie kaum ein anderes Land.Die Verschuldung ge genüber den kapitalistischen Industriestaaten wuchs nicht nur durch das für Investitionen bestimmte Fremdkapital, sondern auch durch Anleihen der Nato-Staaten, die für militärische Zwecke bestimmt waren.

Die folgende Tabelle gibt einen Gesamtüberblick über die aufgənommenen Kredite und die rückerstatteten Schulden: (216)

211) Vgl. Yeni Gazete, 25.6.1969, zit. n. Bulutoglu, K., a.a.O., S. 164

212) Vgl. Kazgan, G., "Yabanci Sermayeye Imtiyazlar", Cumhuriyet, 11.9.1970, S. 5

13) Vgl. Bulutoglu, K., a.a.O., S. 175-176

214) Vgl. Sadin-Edip, M., "Oto-Montaj Sanayiinin Icyüzü', Devrim, Nr. 34, S. 8

5) Lenin, W. I., a.a.O., Band I, S. 816

216) Vgl. "1969 Devlet Borclari Bülteni", zit. n. Devrim, Nr. 61, S. 2, 15.12.1970 
Tabelle 30 (in Mio Dollar)

\begin{tabular}{lcrcr}
\hline Jahre & \multirow{2}{*}{$\begin{array}{c}\text { Aufgenommene } \\
\text { Kredite }\end{array}$} & \multicolumn{3}{c}{ Zurückgezahlte Schulden } \\
& & Kredite & Zinsen & Insgesamt \\
\hline $1947-1964$ & 1.623 & 953 & 287 & 1.240 \\
1965 & 251 & 155 & 28 & 183 \\
1966 & 268 & 118 & 28 & 146 \\
1967 & 212 & 100 & 29 & 129 \\
1968 & 283 & 98 & 30 & 128 \\
1969 & 285 & 107 & 39 & 146 \\
\hline
\end{tabular}

Unter Demirel stiegen die Schulden von 1965-1969 im Vergleich zum Zeitraum von 1947-1964 sehr viel schneller, und entsprechend weniger Schulden als im vorigen Zeitraum wurden zurückbezahit.

Bis Ende 1969 betrugen die Auslandsschulden der Türkei, die in Devisen zu zahlen waren, insgesamt über 3 Mrd Dollar. Die Schulden verteilten sich auf die folgenden Gläubigerländer und Organisationen: (217)

Tabelle 31 (in Mio Dollar)

\begin{tabular}{lrrc}
\hline $\begin{array}{l}\text { Läder und } \\
\text { Organisationen }\end{array}$ & Kredite & Zinsen & Insgesamt \\
\hline Internationale Organisationen & 543 & 203 & 746 \\
USA & 849 & 340 & 1.189 \\
BRD & 337 & 110 & 447 \\
England & 110 & 32 & 142 \\
Frankreich & 81 & 20 & 101 \\
Italien & 100 & 30 & 130 \\
Sonstige Länder & 112 & 46 & 158 \\
Ausländische Firmen & 41 & 16 & 57 \\
Konsolidierte Handelsschulenl & 37 & 1 & 38 \\
\hline Insgesamt & 2.210 & 798 & 3.008
\end{tabular}

Die Türkei ist den USA am tiefsten verschuldet, gefolgt von internationalen Organisationen und der BRD. Da selbst die intermationalen Organisationen von den USA abhängig sind, erhöheı: sich indirekt die Schulden gegenüber den USA und damit die Abhängigkeit von de: USA.

217) Vgl. Ibid., S. 2

102 
In einer Forumsdiskussion der türkischen Zeitung Milliyet über das Thema "Die US-Hilfe und die Türkei" vom 18. April 1971 erklärte Joseph S. Roner (USVertreter der AID in der Türkei) auf die Frage: Was ist die neue Form der USHilfe? "Die Form der US-Hilfe hat sich etwas geändert, die USA ziehen es nun vor, durch internationale Organisationen wie die Weltbank, den internationalen Währungsfond oder die Vereinten Nationen nicht unmittelbar, sondern mittelbar Hilfe zu leisten." (218)

Der Grund für die Bevorzugung des mittelbaren Weges liegt in der wachsenden Unzufriedenheit und Antipathie der Völker der Dritten Welt gegen die USA, deren "Hilfe" auf diese Art verschleiert werden soll.

Obige Tabelle zeigt außerdem, daß die Zinsen fast ein Drittel, manchmal sogar fast die Hälfte der empfangenen Kredite betragen. Die Zeitung Cumhuriyet schreibt: Die Schulden, die die Türkische Republik innerhalb von 41 Jahren gemacht hat, hat die AP (Gerechtigkeitspartei - H. K. ) innerhalb von 5 Jahren ge macht. Jeder Türke hat heute 2.200 TL Schulden. (219) Bis Ende September 1970 waren die Schulden gewaltig angewachsen: (220)

Tabelle 32 (in Mio Dollar)

\begin{tabular}{lccc}
\hline & Kredite & Zinse n & Insgesamt \\
\hline September 1965 & 1.370 & 376 & 1.746 \\
September 1970 & 2.359 & 868 & 3.227 \\
Erhöhung & 989 & 492 & 1.481
\end{tabular}

Tabelle 33 (in Mio TL)

\begin{tabular}{lrcc}
\hline & Kredite & Zinsen & Insgesamt \\
\hline September 1965 & 3.769 & 1.866 & 5.635 \\
September 1970 & 4.572 & 2.026 & 6.598 \\
Erhöhung & 803 & 160 & 963
\end{tabular}

Der Staat ist auch der einheimischen Wirtschaft stark verschuldet.

Tabelle 34 (in Mio TL)

\begin{tabular}{llll}
\hline & Kredite & Zinsen & Insgesamt \\
\hline Séptember 1965 & 10.025 & 4.267 & 14.292 \\
September 1970 & 17.386 & 6.607 & 23.993 \\
Erhöhung & 7.361 & 2.340 & 9.701
\end{tabular}

Die verheißungsvoll proklamierte Politik der Regierung Demirel, durch ausländisches Kapital die Entwicklung der Türkei voranzutreiben, mußte die Türkei notwendigerweise dahin bringen, wohin das Osmanische Reich durch die Verschuldung gegenuiber den imperialistischen Staaten geriet; es sah sich schließlich gezwungen, einen Staat im Staat in Form der Düyun-u Umimiye zu dulden.

Die derzeitige Situation der Türkei weist eine starke Ähnlichkeit mit der Situation des Osmanischen Reiches auf, wenn sich auch die Methoden und Taktiken des Neoimperialismus geändert haben, um seinen Einfluß nicht allzu sichtbar wer-

218) Toner, I., "ABD yardimi ve Türkiye", Milliyet, S. 7, 18.4.1971

.9) Cumhuriyet, 12.2.1971

220) Ibid. 
den zu lassen. Dic türkische Republik ist in einen Teufelskreis geraten, der schwer zu durchbrechen sein wird.

1. Die ausländischen Firmen entnehmen den in der Türkei gegründeten Tochtergesellschaften die erzielten Gewinne in Form von Devisen. In den letzten Jahren übertraf der Abfluß von Devisen den Zustrom an Devisen, so daß das neue ausländische Investitionskapital im Grunde nicht zusätzliches Kapital bedeutet, da mehr Kapital, als im Land akkumuliert wird, ins Ausland fließt.

2. Die Kre dite müssen nach einer gewissen Zeit zum größten Teil in Devisen zurückbezahlt werden. (220a) Nach Angaben von Cumhuriyet betragen die Zinsen für 3 Dollar durchschnittlich 2 Dollar. (221) Um die Kredite mitsamt den Zinsen zurückzahlen zu können, werden ständig neue Kredite erfordeılich, die die Schulden lawinenartig anschwellen lassen.

3. Die Zahlungsbilanzschwierigkeiten wachsen noch dadurch, daß die Rücktransfers größer sind als das Kapital, das ins Land kommt. Wie alle unterentwickelt gehaltenen Länder exportiert die Türkei hauptsächlich nur landwirtschaftliche Produkte oder Rohstoffe. Seit Jahren besteht der Export zu ca. $60 \%$ aus fünf Produkten: Baumwolle, Tabak, Weintrauben, Nüsse und Feigen. (222)

Tabelle 34a Anteil dieser 5 Produkte am Export der Türkei von 1961-68 in \%

\begin{tabular}{clllllllll}
\hline 1961 & 1962 & 1963 & 1964 & 1965 & 1966 & 1967 & 1968 & $1961-1968$ \\
\hline 59,8 & 62,0 & 60,0 & 61,0 & 59,7 & 64,6 & 68,7 & 67,4 & 62,9
\end{tabular}

19 landwirtschaftliche Produkte machten im selben Zeitraum durchschnittlich 74, $43 \%$ des gesamten Exports aus. In den letzten Jahren sanken die Preise wirtschaftlicher Produkte im Verhältnis zu Industrieprodukten im Weltmaßstab.

Tabelle $35(223) \quad$ (Preisbasis $1963=100)$

\begin{tabular}{lccrrrc}
\hline & 1961 & 1962 & 1963 & 1964 & 1965 & 1966 \\
\hline Exportpreise & 77 & 81 & 100 & 96,2 & 91 & 92 \\
Importpreise & 96 & 94 & 100 & 100,7 & 103,5 & 100,4 \\
Handelsrate & 80 & 86 & 100 & 95,5 & 87,9 & 91,6
\end{tabular}

Wie wir sehen, fielen dic Preise der türkischen Exportprodukte zwischen 1963 und 1966 um $8 \%$, in der gleichen Zeit stiegen die Importpreise um $0,4 \%$, d. h. die Handelsrate, (Terms of Trade) verschlechterte sich um $8,4 \%$ in nur 3 Jahren zuungunsten der Türkei. Zwischen 1956 und 1964 hat die Türkei auf diese Weise 939.5 Mill. Dollar an Verlusten hinnehmen müssen. (224)

220a) Wie in fast allen unterentwickelt gehaltenen Ländern ist cin yrofier Teil der Kredite für militärische Zwecke bestimmt oder an Projekte gebunden, die für die Kreditgeber von größerer Bedeutung sind als für die Türkei.

221) Ibid.

222) Vgl. Ticaret Bakanligi, Disticaret dairesi., "Devlet Planlama Teskilati Dergisi 9", zit, n. Tayanc, T., S. 47

223) Alper, M., Dis Ticaret Indeksleri, Ankara, 1968, S. 22, zit. n. ibid.

224) Vgl. Ibid., S. 53 
Diese Tatsache ist wichtig, versucht man die Rolle der imperialistischen Staaten für die Entwicklung der Türkei, wie auch der übrigen unterentwickelt gehaltenen Länder zutreffend einzuschätzen: Die Türkei nahm von 1947-1964 953,1 Mill。 Dollar Kredite auf; der durch die Terms of Trade zwischen 1956 und 1964 erlittene Verlust betrug 939,5 Mill.Dollar, d.h. ohne die Preisverluste hätte die Türkei auf die ausländischen Kredite verzichten können! Unter diesen Umständen nimmt es nicht wunder, daß das Ziel der beiden Fünfjahrespläne, das Außenhandelsdefizit auszugleichen, nicht einmal annähernd erreicht wurde.

Tabelle 36 (225)Entwicklung des Außenhandels $1961-1968$ (in 1.000 TL)

\begin{tabular}{lrrr}
\hline Jahr & Import & Export & Differenz \\
\hline 1961 & 4.585 .129 & 3.120 .659 & -1.464 .470 \\
1962 & 5.599 .802 & 3.430 .777 & -2.169 .025 \\
1963 & 6.216 .051 & 3.312 .781 & -2.903 .270 \\
1964 & 4.878 .041 & 3.696 .942 & -1.181 .099 \\
1965 & 5.193 .332 & 4.173 .643 & -1.019 .689 \\
1966 & 6.521 .885 & 4.414 .570 & -2.107 .315 \\
1967 & 6.216 .794 & 4.701 .007 & -1.516 .787 \\
$1968(226)$ & 6.934 .000 & 4.467 .000 & -2.467 .000
\end{tabular}

1969 betrug das Außenhandelsdefizit 2,4 Mrd TL, 197028 Mrd TL. Ohne die Devisen der türkischen Arbeiter im Ausland würde das Zahlungsbilanzdefizit katastrophale Ausmaße annehmen, da sie von 1965 - 1970 Devisen in Höhe von 785 Mill.Dollar (7,1 Mrd TL) in die Türkei überwiesen. (227)

Es ist nicht abzusehen, wann und wie das Außenhandelsdefizit jemals ausgeglichen werden kann, solange die Industrialisierung der Türkei keine Fortschritte macht, solange sie auf den Export landwirtschaftlicher Produkte angewiesen bleibt. (228)

4. Die inflationäre Ausgabenpolitik führte zu einer immer größer werdenden Dekkungslücke im Haushaltsplan

Tabelle 37 Entwicklung des Haushaltsdefizits 1963 - 1969 (in Mic TL) (229)

\begin{tabular}{ccccccc}
\hline 1963 & 1964 & 1965 & 1966 & 1967 & & \\
\hline 1963 & 1964 & 1965 & 1966 & 1967 & 1968 & 1969 \\
\hline$+5,2$ & $-613,4$ & $-900,0$ & $-690,8$ & $-98,6$ & $-965,6$ & $-1.887,7$
\end{tabular}

Diese sich gegenseitig beeinflussenden Komponenten ergänzen sich zu einem Ganzen als ein Problem, das wir als Teufelskreis bezeichnet haben. Da die tïrkische

225) Statistical Yearbook of Turkey 1968, S. 309

226) Monthiy Foreign Trade Statistics, 1968, S. 12

227) Kücük, S., ebd. (Devrim)

228) Im Aulkenhandel der Türkei nimmt die BRD den ersten Platz ein; dic türkischen Importe stiegen von 17.1\% (1962) auf 19.5\% (1967), während dic Exporte von 17,7\% (1962) auf $16,1 \%$ (1967) fielen. Auch hier ist ein zunchmendes Defizit der Türkei crkennbar. Statistical Ycar Book of Turkey 1968, S. 310-311

229) Vgl. Iktisadi Rapor, 1970, a.a.O., S, 241 
herrschende Klasse und ihre Verbündeten keinen Ausweg aus dem Dilemma sahen, griffen sie auf Kosten des Volkes zu harten Maßnahmen. Die Steuern wurden angehoben, bei langsam ansteigenden Löhnen und Gehältem die Preise erhöht und die Türkische Lira draștisch abgewertet.

1. Abwertung der TL um $115 \%$ im Jahre 1946

1 Dollar $=2,80 \mathrm{TL}$ (bis dahin $=1,30 \mathrm{TL}$ )

2. Abwertung der TL um $321 \%$ im Jahre 1958

1 Dollar $=9,00 \mathrm{TL}$

3. Abwertung der TL um $66,6 \%$ im Jahre 1970

1 Dollar $=15,00 \mathrm{TL}$

\subsection{Das Ende der Regierung Demirel}

Wir haben an Hand von Fakten zu zeigen versucht, daß die Machthaber in der Türkei die von ihnen aufgestellten Planziele nicht erreichen konnten. Die vorhandenen Probleme haben zugenommen. Die Unterschiede zwischen der wohlhabenden, "glücklichen Minderheit" und der seit Jahren unterdrückten, ausgebeuteten großen Mehrheit des türkischen Volkes wurden noch unerträglicher, die Widersprüche verschärften sich. Als Folge dieser Entwicklung verstärkte sich der Klassenkampf in dem Maße, wie bei der ausgebeuteten Klasse sich das Bewußtsein ihrer Unterdruickung herausbildete, indem sie die Ursachen ihrer Verelendung erkannte. Kurz zusammengefaßt sind die Hauptprobleme des türkischen Volkes: Analphabetismus, unerträgliche Daseinsbedingungen, die Diskrepanz zwischen der West- und Osttürkei, die unwürdige Abhängigkeit vom Neoimperialismus.

Nach einer Mitteilung des statistischen Amtes konnten $196952 \%$ der Bevölkerung weder schreiben noch lesen. (230) Nur ein Fünftel der studierwilligen Abiturienten fand einen Studienplatz. Eine Untersuchung des amerikanischen Soziologen Fray ergab, daß 34 \% der Landbevölkerung den Namen keiner einzigen Partei kanute. Bei den Frauen lag dieser Prozentsatz sogar bei $54 \%$, in den Dörfern, in denen die bis vor kurzem regierende Gerechtigkeitspartei bei einer Wahlbeteiligung von $80 \%$ mit absoluter Mehrheit die Wahlen gewonnen hatte, kannten nur $45 \%$ der Wahlberechtigten den Namen dieser Partei. (231)

Das Hauptproblem der Türkei, Ursache aller anderen Probleme ist die mangelnde Industrialisierung. Da die Industrialisierung mit dem Wachstum der Bevölkerung nicht Schritt hält, und da die Landflucht gewaltige Ausmaße annimmt, erhöht sich jährlich die Arbeitslosigkeit. Nach dem 1. Fünfjahresplan sollten 2,1 Mill. neue Arbeitsplätze geschaffen werden, tatsächlich wurden aber nur 1,2 Mill ${ }^{\circ}$ neue Arbeitsplätze geschaffen. (232) In der Landwirtschaft konnten $196753,5 \%$ der Arbeitsfähigen nicht beschäftigt werden. In den anderen Sektoren betrug die Arbeitslosenquote 1967 jeweils $9,5 \%$. Insgesamt waren 1967 von 14,1 Mill.Arbeits. fähigen 5,6 Millarbeitslos $(=39,6 \%)$. (233) Die Zahl der Arbeitslosen nahm in den folgenden Jahren noch $\mathrm{zu}$.

230) Vgl. Cetiner, 1, Cumhuriyet, 24.2 .1969

231) Vgl. Selcuk, l., Cumhuriyet, 16.10.1970

232) Vgl. Kalkinma Plani (lkinci Bes yil), zit. n. Özkol, S., a.a.O., S. 86

233) Vgl. ibid, S.87

234) entfallt 
$90 \%$ der im Ausland beschäftigten tükischen Arbeiter sind in der BRD und in Westberlin beschäftigt. (235)

Die Landflucht in der Türkei bewirkt eine rasche Vergrößerung der Slumviertel um die großen Städte. 1965 lebten $45 \%$ der Einwohner Istanbuls in Slums, (236) ähnliche Zustände herrschen in Ankara und Izmir. Die meisten dieser Behau. sungen sind ohne fließendes Wasser, ohne Küche, Bad und Toilette. 46,5\% der Slumbewohner trinken Brunnenwasser, $(240)$, Tausende von Kindern sterben vor ihrem 14. Lebensjahr. (237)

Die Wohnmöglichkeiten der verarmten Bauem in den Dörfern sind noch. schlechter, und vor allem in Ost-, Süd- und Nordostanatolien herrschen verheerende Zustände.

Solange die Abhängigkeit von den imperialistischen Staaten andauert, besteht keine Aussicht auf lösung der überhandnehmenden Probleme. Diese Abhängigkeit charakterisierte ein Politiker, der sich zur linken Mitte bekennt, mit den Worten: "Wir begegnen einer Türkei, deren Reichtümer unter und über dem Boden, de. ren Industrie und Landwirtschaft, deren privater und staatlicher Sektor unter Ausländern vertellt ist. Somit wird der Traum (der imperialistischen Mächte - H.K.) in einer Weise verwirklicht, wie es selbst in der osmanischen Ara nicht der Fall war." (238)

Die türkischen Arbeiter und Bauem, die progressiven Intellektuellen, Studenten und Beamten sind nicht länger gewillt, die unerträglichen Verhältnisse zu ertragen. "Die Basis der türkischen Gesellschaft geht seit zweieinhalb Jahren mit stei. gendem Schwung und steigender Heftigkeit gegen diese politische Ordnung an. Ihre Aktionen sind Seismographen der wachsenden Erbitterung" (239) beschreibt T. $\mathbb{Z}$. Tunaya die angespannte lage. Er konstatiert vom 8. Juni 1968 bis zum 12. Februar 1971 insgesamt 440 wichtige Aktionen, denen die ersten Seiten der Zeitungen gewidmet waren. "Fast alle Tage gab es entweder einen Strcik, eine Besetzung oder eine Demonstration." (240) Am 7. Mai 1969 gingen selbst hohe Richter in Ankara auf die Straße, ein Novum in der tiurkischen Geschichte. Am 15, und 16. Juni 1969 fancen die bisher machtvollsten De monstrationen in Istanbul und Kocacli gegen das geplante reaktionäre Gewerkschaftsgesetz statt, an denen 80.000 - 100.000 Arbeiter teilnahmen. Tunaya bezeichnet diese Ereignisse als Erdbeben an der Basis. Er wirft der Regierung vor, daß sie Mittel und Wege sucht, um die Mündigen mund tot zu machen, um die verdorbene politische Ordnung, die an unserer Unterentwicklung schuld ist, weiter bestehen zu lassen. Die Regierung suchte ihr Heil in terroristischen MaRnahmen, um das tïrkische Volk, das sich seiner Probleme bewuBt zu werden be.

235) Vgl. Ausländische Atbeitnehmer 1969, Bundesanstalt hür Arbeit, Nünberg, 1970, S. 94 1960 gab es erst 2.495 türkische Arbeiter in der BRD und Westberlin. Anfang 1971 waren es bereits 373.000 Arbeiter. Bie türkischen Arbeiter bilden die zweitgröbte Gruppe der ausiändischen Arbeiter in der BRD und Westberlin. Sie werden in ihren Heimatländern forgfaltig nach beruflicher Qualifikation und "charakterlicher" Eignung ausgesucht. In" nerhalb der ausländischen Arbeiter haben die tïrkischen Arbeiter mit 28,2\% den höchsten Anteil an Facharbeitern.

Nach einer Unfrage von B. Meistemann schicken $9 \%$ der tïkischen Arbeiter kein Geld in die Türkei, $17 \%$ bis $200 \mathrm{DM}, 35 \% 200-300 \mathrm{DM}$ und $39 \%$ mehr als $300 \mathrm{DM}$.

236) Vgl. Selcuk, 1., Cumhuriyet, 20.10.1970

237) Vgl. Atabek, E., "Gecekondu Cocuklari", Cumhuriyet, 20.8.1970

238) Selcuk, 1., "Bilent Ecevit'in Konusmasi", Cumhuriyet, 15.2.1970

239) Tunaya, T.Z." "Tabandaki Deprem", Cumhuriyet, 21.2 .1971

240) bid., S.2 
ginnt, zu unterdrücken. Allein 23 Studenten wurden seit Juni 1968 von Terrorkommandos, die von der Regierung heimlich unterstützt werden, getötet. Mehrere Arbeiter kamen bei Straßenschlachten mit der Polizei, während Streiks und Protestdemonstrationen, ums Leben. Mehrere fortschrittliche Lehrer wurden mit mittelalterlichen Methoden gefoltert. (241) Ofmals werden fanatisierte Gläubige gegen die progressiven Kräfte aufgeputscht. (241a)

Am 12. März mußte Demirel abdanken, nachdem die türkische Armee andernfalls mit einer direkten Machtïbernahme gedroht hatte. Das türkische Militär gab der Öffentlichkeit drei Hauptmotive für ihr Eingreifen an:

1. Das Parlament und die Regierung haben das Land in Anarchie, Brude rkampf und soziales und wirtschaftliches Chaos geführt, den kemalistischen Weg verlassen und in der Verfassung vorgesehene Reformen nicht durchgeführt. Dadurch geriet die $\mathrm{Zu}$ kunft der türkischen Republik in ernste Gefahr.

2. Die Verteidigungskräfte verlangen daher eine glaubhafte Regierung, die auf kemalistischem Wege die Reformen, die die Verfassung vorschreibt, ausführt.

3. Werden diese Forderungen nicht schnellstmöglich erfüllt, wird die türkische Armee die Macht uibernehmen. (242)

Es wurde unter Ministerpräsident Evrim (242a) eine neue Regierung gebildet, der grundsätzlich nur Technokraten und Fachleute angehören. Die Regierung verkündete in ihrem Programm, der Anarchie bald Herr zu werden, die längst fälligen Land-, Steuer-, Schul- und Sozialreformen in Angriff zu nehmen und die Industrialisie rung der Türkei zu beschleunigen.

Die türkische Armee unterscheidet sich grundlegend von den reaktionären Militärs der lateinamerikanischen Länder (mit Ausnahme Chiles), Griechenlands und Spaniens. Sie hat sich bisher immer als Hüterin der kemalistischen Prinzipien verstanden und bildete daher für die Imperialisten und die herrschende Klasse in der Türkei ständig eine latente Gefahr.

Die Mehrheit der türkischen Offiziere rekrutiert sich aus den unteren sozialen Schichten. Durch staatliche Stipendien (schon von der 6. Klasse an) erhalten sie die Möglichke it, die Militärschulen und Akademien zu besuchen.

Seit einigen Jahren wird nun versucht, die kemalistische Struktur, offensichtlich unter dem Einfluß der Nato, zu verändern. Die Militärschulen wurden außer einem Militärgymnasium in Istanbul und einer Militärakademie in Ankara aufgelöst.

Die Gehälter der bis vor wenigen Jahren finanziell schlecht gestellten Offiziere wurden stark erhöht. Durch die Einrichtung einer "Armee-Hilfsorganisation", in die ein Teil der Offizierseinkommen fliefst, werden die Offiziere an Investitionen betciligt. Die Offiziere verdienen inzwischen innerhalb der Beamtenhierarchie am meisten.

241) Vgl. Kestin, H., Studentenbewegung und Staatskrise in der Türkei, FU-Information, Nr. 2/71, Berlin, 19.2.1971

241a) Diese fanatischen und reaktionären Aktionen werden von der herrschenden Klasse geschickt inszeniert. Z. B. werden immer wieder Bomben in oder in der Nähe von Moscheen geworfen, wenn Tausende in ihre Andacht vertieft sind, um hinterher behaupten zu können, "Kommunisten haben die Bomben geworfen." Anschließend gibt es meistens wüste Ausschreitungen und manchmal Plünderungen.

242) Vgl. Cumhuriyet, 13.3.1971, S. 1

242a) Evrim, der zum rechten ['lügel der Republikanischen Volkspartei (CHP) bis zu seinem Amt als Ministerpräsident gehörte, mußte aus der Partei austreten, weil er gemä́s dem Ultimatum der Armee überparteilich scin sollte. 
Viele Offiziere erhalten eine Ausbildung in den USA, durch die sie pro-amerikanisch orientiert werden sollen. Diese und andere Versuche, den Kemalismus in der türkischen Armee zu untergraben, müssen bei der Beurteilung der jüngsten Ereignisse in Betracht gezogen werden. Nach Meinung der Monatszeitschrift ANT (243) war das Ultimatum der Armee vom 12. März 1971 ein taktischer Vorwand, um die linksorientierten Offiziere zu eliminieren. Progressive Offiziere hatten seit einiger Zeit geplant, das reaktionäre Parlament aufzulösen, die Regierung abzuset. zen und nach einer kurzen Interimszeit die staatliche Führung einem aus linksorientierten Zivilisten gebildeten Volkskomitee zu übergeben. Die ursprünglichen Pläne sahen ein noch radikaleres Vorgehen als am 27. Mai 1960 vor.

Nach bisher unbestätigten Berichten soll ein hoher Offizier die Pläne der progressiven Offiziere an Regierungskreise weitergeleitet haben. Nach einer Beratung in der US-Botschaft, an der jener erwähnte Offizier, der Sohn des Staatspräsidenten Sunay und englische und amerikanische Botschaftsangehörige teilnahmen, soll man sich darauf gecinigt haben, die progressiven Offizic re kaltzustellen und eine überparteiliche Regierung zu bilden. Nach dem Ultimatum vom 12. März 1971 wurden mehrere hohe Offiziere pensioniert, andere auf bedeutungslose Posten außerhalb der Großstädte versetzt.

Wie kürzlich gemeldet wurde, ist in 11 großen, hauptsächlich in Arbeiterregionen, der Ausnahmezustand verhängt worden. Das jetzige Vorgchen der türkischen Armee verstärkt die Zweifel, ob das Militär bereit ist, auch diesmal gegen eine korrupte und reaktionäre Regierung vorzugehen, oder ob es nicht viclmehr den Nato-bzw. US-Plänen entsprechend das kapitalistische System retten will,das durch die sich ihrer Lage bewußst werdenden Arbeiter, Bauern, Studenten und Lehrer gefährdet ist. Eine richtige Einschätzung der letzten Entwicklung müßte von einer Klassenanalyse ausgehen, was im Rahmen dieser Arbeit nicht möglich ist. Wir haben in unseren bisherigen Ausführungen gesehen,daß die Türkei, wic alle anderen Länder der dritten Welt vor sehr schwierigen Problemen steht. Unter den vorhandenen Problemen in der Türkei leiden nicht mehr die Armeeangchörigen, sondern die breite Masse der Werktätigen.

Nicht nur die Geschichte der türkischen Republik, sondern die jahrhundertelangen Erfahrungen aller unterdrückten Völker haben bewiesen, daß keine andere Klasse bereit ist, die Interessen der breiten Masse đer Bauern und der Arbeiterklasse wahrzunchmen. Mit anderen Worten: Die Industrialisierung der unterentwickelt gehaltenen Länder, die Lösung der sich zuspitzenden Probleme und die volle Unabhängigkeit dieser Länder wird und kann nur das Werk der ausgebeuteten und unterdrïckten Menschen, d.h. aller Werktätigen sein.

"In den letzten 10 Jahren", schreibt das Organ der türkischen Arbeiterpartei (TIP), "hat die Arbeiterklasse ihre Einheit und Solidarität entwickelt, das Niveau ihres Kampfes und ihrer Organisation verbessert und sich als ein unabhängiger politischer Machtfaktor erwiesen. In der türkischen Arbeiterklasse vollzieht sich die Weiterentwicklung von der 'Klasse an sich' zur 'Klasse für sich'." (244)

243) Vgl. Ant, Yorum; Reform ve huzur pluninin icyürü, Nr. 13, Istanbul, Mai 1971, S. 6-7

244) Emek, 12 Mart Muhtirasi ve sonrasi, Nr. 11, Ankura, April 1971, S. 5 


\section{Die Türkei unter Kriegsrecht}

Seit über 20 Monaten wird die Türkei mit Hilfe des Kriegsrechtes regiert,durch das die unmittelbare Macht vom Militär ausgeht.

Die Militärgouverneure sind ermächtigt, ohne rechtlichen Beschluß Menschen bis zu 30 Tagen festzunehmen, Häuser durchsuchen zu lassen, das Post- und Femmeldegeheimnis aufzuheben, Streiks zu verbieten, Ausgangssperren zu verhängen. jegliche Versammlungen zu verbieten, Vereine aufzulösen, Zeitungen und Zeitschriften, Verlage zu schließen sowie Sondermilitärgerichte einzurichten. Wie weit die Grenzen dieser Willkürherrschaft ausgedehnt werden können, ist bereits in der Broschüre 'Türkei-Report' mit einzelnen Beispielen aufgezeigt worden. (245)

Alle zwei Monate kurz vor der Verlängerung des Ausnahmezustandes werden Verhaftungen durchgefuhrt, Waffen entdeckt, eine illegal gedruckte Zeitung, Flugblätter oder eine geheime Organisation aufgedeckt, damit der Ministerpräsident im türkischen Parlament erklären kann: "Die Wurzeln der Anarchisten sind noch nicht ausgerottet worden, die Gefahr für das Land liegt im Ausland, daher müssen wir den Kriegszustand für weitere zwei Monate verlängern." Im Grunde ist die Entscheidung für eine Verlängerung in der Geheimsitzung des "Nationalen Vertrauensrates", wo die Spitzen der Militäre sitzen, bereits vorher ge fallen. Alle wichtigen Entscheidungen werden von diesem Rat getroffen, bevor sie dem Parlament vorgelegt werden. Der Grund für diese Vorgehensweise liegt auf der Hand: die Weltöffentlichkeit und die breiten Massen im türkischen Volke sollen weite rhin glauben, daß das Parlament nach wie vor funktioniere. Und der Grund für weitere Verlängerung ist nicht, wie es mit kïnstlich erfundenen Anïssen begründet wird, die noch nicht ausgelöschte Anarchie oder die Gefahr für das Land aus dem Ausland, sondern nur der, daß die Bedingungen für eine Herrschaft ohne Kriegszustand aber objektiv doch mit Kriegsrecht noch nicht legalisiert worden sind. Es soll also ein solcher rechtlicher Zustand geschaffen werden, in dem die im Kriegszustand geschaffenen Gesetze ausreichen, jegliche oppositionelle Tätigkeit, die von der herrschenden Klasse als Gefahr angesehen wird, auf legale Art und Weise zu beseitigen.

Deshalb reichen die bereits vor einigen Monaten erfolgten Verfassungsänderungen - 40 Artikel wurden geändert - noch nicht aus. Die neue Regie rung Melen will folgende Verfassungsänderungen verwirklicht haben: 1. Gründung von Staats* sicherungs-Gerichten, 2. Einschränkung der Befugnisse der Verfassungs- und Verwaltungsgerichte, 3. Anderungen der Arbeitsform des Parlaments, 4. Anderungen des Artikels über die Parteien etc. (246)

Auch die Verfassungsänderungsvorhaben, wonach die Publikationsorgane unter cine schärfere Kontrolle gestellt und die Hochschulen unmitteibar durch das Kultusministerium reglementiert werden sollen, sind noch nicht fallengelassen worden. Da die türkische Verfassung von 1961 den Gerichten ihre volle Unabhängige keit gewährt und diese häufig äie rechtswidrigen Entscheidungen der Regierungen mirickgewiesen haben, soll deren Befugnis eingeschränkt werden, damit in $Z$ ukunft die willküliche Machtausubung nicht blockiert we rden kann. Die Iochschulen sollen mit neuen Verfassungsänderungen von oppositionellen Kräften (ob Professoren, Assistenten oder Studenten) gereinigt werden. Kurz, alles zielt darauf hin, unter der

245) Vgl. Türkei-Report, Sozialistisches Büro, Offenbach

246) Milliyet, 15.7 .1972 
Bedingung des Kriegszustandes, nachdem die oppositionellen Kräfte mundtot gemacht worden sind, die Basis dafür zu schaffen, nach der Aufhebung des Ausnahmezustandes die Macht der herrschenden Klasse langfristig zu konsolidieren und willkürlich auszuüben.

Seit anderthalb Jahren sind alle oppositionellen Zeitungen, Zeitschriften und Verlage durch strenge Pressezensur gleichgeschaltet, wenn nicht verboten. Oppositionelle Studentenvereine, Lehrer- und Jugendorganisationen sind verboten worden, deren führende Kräfte befinden sich in Haft oder noch immer vor den Sondermilitärgerichten. Hunderte von kritischen Büchern sind entweder beschlagnahmt oder von der Polizei aus Buchläden, Privathäusem und Bibliotheken entfernt worden. 138 Bücher wurden am 1. Juli 1972 konfisziert. Unter diesen Büchem befinden sich unter anderem Werke von Marx, Engels, Lenin, Trotzky, Dimitrov, Ho Tschi Minh, Jacques Duclos, Fidel Castro, Che Guevara, George Politzer, Max Beer, Emilie Burns, Stokely Carmichael, Leo Huberman, Mao Tse-Tung, C. Wright Mills, Sidney Lens, Isaac Deutscher, Nguyen Giap, Nkrumah, Nazim Himket und selbst die Romane des bekannten tïrkischen Schriftstellers Kemal Tahir und die Theaterstiicke von Hans Magnus Enzensberger.

Auch das 350 Jahre alte historische Buch über das Osmanische Reich "Serefname" wurde mit der Begründung beschlagnahmt, in ihm würde Propaganda für den Kommunismus getrieben.

Die Türkei ist zum erstenmal in unserer Geschichte in ein Land der Konzentrationslager oppositioneller Kräfte verwandelt worden, wobei unter Oppositionellen nicht nur Sozialisten, sondern auch viele kritisch denkende liberale Demokraten zu verstehen sind. Die Zahl der politischen Häftlinge wird von dem Weltgewerkschaftsbund mit ca. 10.000 geschätzt,(247) was die Zahl der Inhaftierten in Grie chenland weit übersteigt. Für über 100 türkische Patrioten wurde bis heute von der Staatsanwaltschaft der Sondermilitärgerichte die Todesstrafe beantragt.

Um das Leben von Deniz Gezmis, Yusuf Aslan und Hüseyin Inan zu retten, deren Todesurteile vom türkischen Parlament bestätigt worden waren, entführten Mahir Cayan und seine Freunde am 27.3.1972 zwei britische und einen kanadischen Techniker. Mahir Cayan, eines der Häupter der Untergrundbewegung, flüchtete Mitte November 1971 mit vier türkischen Untergrundkämpfern durch einen 15 Meter langen selbstgegrabenen Tunnel aus einem Gefängnis in Istanbul. Im Cayan-Prozess hatte die Staatsanwaltschaft für 12 Mitglieder der Organisation die Todesstrafe beantragt. Die unnachgiebige Haltung der Erim-Regierung führte zu einem Blutbad, 10 junge Türken und die drei Techniker wurden getötet. (248)

Auch der letzte Versuch, mit der Entfïhrung eines türkischen Flugzeuges nach Sofia mit 61 Insassen das Leben von Deniz Gezmis, Yusuf Aslan und Hüseyin Inan zu retten, fuihrte zu keinem Erfolg. Man vermutet, daß den Entführem die Aufhebung der Todesurteile zuvor von den Vermittlem versichert worden war, worauf sie sich ergaben. Am 6. Mai wurden die drei jungen Türken erhängt. Inzwischen ist auch Ziya Yilmaz durch das Sondermilitärgericht zum Tode verurteilt worden. Für mehrere junge Patrioten wurden Zuchthausstrafen von einigen Jahren bis lebenslänglich ausgesprochen.

Der bekannte Journalist und Schriftsteller Cetin Altan, der nach dem Memorandum der türhischen Militärs am 12. März mehrere Monate inhaftiert und wieder

247) Frankfurter Rundschau, Verhaftet wird jetzt eine Stunde später, von Peter Rhode,

7. Juni 1972

248) Vgl. Hasan Nokta, Links, Nr. 33, Mai 1972 
freigelassen worden war, ist zu einem Jahr Zuchthausstrafe verurteilt und sofort inhaftiert worden. Grund: Cetin Altan habe als Abgeordneter der Arbeiter-Partei der Türkei in eincr Rede im Jahre 1967 (also 5 Jahre vor dem Memorandum) den türkischen Staatspräsidenten Sunay beleidigt.

Auch die Frau des bekannten türkischen Verfassungsrechtlers Prof. Soysal erhielt we gen Beleidigung des türkischen Militärs ein Jahr schwere Zuchthausstrafe und vier Monate Hausarrest. Prof. Soysal selbst war längere Zeit in Haft. Für ihn verlangt die Staatsanwaltschaft wegen seines in den Hochschulen als Lehrbuch benutzten Buches "Einführung in die Verfassung" 6 Jahre Gefängnisstrafe. Prof. Muammer Aksoy, einer der Väter der Verfassung von 1961, stcht unter der Anklage, er habe 1968 in West-Berlin Vorträge für die türkischen Arbeiter und Studenten gehalten, er habc an dem Victnam-Kongress am 14/18. Februar 1968 und an der darauf folgenden Demonstration teilgenommen. Für seine Forschungsarbeit habe Aksoy auch in der Bibliothek der Humboldt-Universität gearbeitet.

Für Prof. Ugur Alacakaptan, chemaliger Rektor der juristischen Fakultät in Ankara, verlangt dic Staatsanwaltschalt des Sondermilitärgerichtes zweieinhalb, für den Dozenten Mukbil Özyörük sechs, für die Assistenz-Professoren Ugur Mumcu und Adil Özkol bis zu 15 Jahren Zuchthausstrafe, weil "sie sich in ihren Reden und Schriften vor dem 12. März 1971 für die Bescitigung der Verfassung eingesetzt, die Herrschaft einer sozialen Klasse über eine andere propagiert, die Regicrung beleidigt, Beamte verunglimpft und dem Pressegesetz Widerstand geleistet haben." (249)

Die bittere Ironie besteht darin, daß die genannten Verfassungsrechtler (alle Hochschullehrer der juristischen Fakultät in Ankara), zu den wenigen Vätern der Verfassung von 1961 gehören, die sich stets gegen die Verfassungsverstöße und gegen die Verfassungsänderungen mit aller Entschiedenheit vor und nach dem 12.März 1971 gewandt haben. Man kann ihnen nichts anderes vorwerfen, als daß sie ihr Werk, die Verfassung von 1961, vor den reaktionären Regierungen schützen wollten. Hätten gerade sic und ihre Gesinnungsfreunde ihr Werk beseitigen wollen? Sie werden vor den Sondermilitärgerichten, deren Vorsitzende noch nicht einmal Richter, sondern von Militärobersten eingesetzte Offiziere sind, zu beweisen haben, daß diese Verfassung bercits in 40 Artikeln radikal geändert worden ist. Wenn diese Beschuldigungen im geringsten zutreffen würden, wäre zu fragen, warum die Angeklagten nicht unmittelbar nach ihren Taten vor Gericht gestellt werden konnten, obwohl selbst damals eine Regicrung (Demirel-Regierung) an der Macht war, der sie Opposition le isteten.

Der Verlagsleiter Süleyman Ege, der die Übersetzung des Buches "Staat und Revolution" von Lenin gedruckt hatte, erhiclt sicbeneinhalb Jahre, Muhterem Bengi - er soll kommunistische Propaganda gemacht haben - neun Jahre Zuchthaus. Ugur Cankocak, Vertreter der "Progressiven Arbeitergewerkschaft" in Ankara, muß $11 / 2$ Jahre ins Gefängnis, weil er in einem Artikel 1970 die "nationalen Gefühle herabgesetzt habe." (250)

Dies sind cinige wenige Bcispicle von vielen bereits laufenden oder noch in Vorbereitung befindlichen Massenprozessen in der Türkei, bei denen Tausende von Demokraten und Sozialisten mit lächerlichsten Beschuldigungen angeklagt und bestraft werden.Breite Teile des Volkes bleiben von der Willkürherrschaft in der Türkei nicht verschont. Abgesehen davon, dafh durch Ausgangssperren, deren Länge nach Gutdünken verlängert oder verkürzt wird, dic Freiheit der Bewohner in den vom

249) Milliyct, 8.7. 1972

$2501 \mathrm{Vgl}$. Cumhuriyet, 15.10.1971, 1.10.1971 und 9.12.1971 
Kriegsrecht beherrschten Provinzen in jeder Hinsicht stark beschnitten ist, werden mit der noch immer andauernden Jagd nach "Anarchisten" jeder Zeit Hausdurchsuchungen durchgeführt. Wer vom Militär verbotene Veröffentlichungen zu Hause hat, wird sofort eingesperrt. Ende Januar 1972 fand wahrscheinlich eine der größten Razzien der Weltgeschichte statt: nach der Verhängung des Ausgehverbots in Istanbul für 15 Stunden durchsuchten 85.000 Soldaten und Polizisten jedes Haus.

\subsection{Die sozio-ökonomische Lage des Volkes wird unerträglich}

Im Ultimatum der unter NATO-Kommando stehenden Militärs wurde verkündet, eine zu bildende neue Regierung müsse "überparteilich" sein und die in der Verfassung vorgesehenen, von der Demirelregierung nicht verwirklichten Reformen schnellstens durchführen. Die Bodenreform, über die seit 1933 heftig diskutiert wird und für die Gesetzentwürfe vorbereitet werden, müßte als erstes von der "Reformregierung" Erim in die Tat umgesetzt werden. In dem Glauben, mit Hilfe der Regierung Reformen zu verwirklichen, arbeiteten einige idealistische Technokraten mit und arbeiteten eifrig ihre Reformkonzepte aus. Die Reformen im Gesundheits-, im Bildungs- und im Steuerwesen, im Bereich der Industrie, beim Außen- und Innenhandel, bei der Verstaatlichung der wichtigen Rohstoffe etc. sollten folgen.

Karaosmanoglu, stellvertretender Ministerpräsident für Wirtschaftsfragen, schilderte den miserablen Stand der Unterentwicklung der Türkei in seiner ersten Pressekonferenz und verkündigte in den folgenden Monaten feierlich, "die Bodenreform wird im Jahre 1972 praktiziert." (251) Ministerpräsident Erim betonte: "Die Reformen werden wir gegen alle Widerstände durchführen." (252)

Die Regie rung und ihre Mitglieder betonten immer wieder dem Volke gegenüber, daß die Reformen durchgeführt würden, damit die verzweifelten Massen durch Reformhoffnungen die ihren Interessen diametral entgegenlaufende Entwicklung zumindest für einige Zeit nicht erkennen konnten.

Doch Ende Oktober mußten sich die Minister im Erimkabinett, die geglaubt hatten ihre Reformpläne verwirklichen zu können, überzeugen, daß sie nur mit Illusionen gelebt hatten. Als Karaosmanoglu, progressivster Mann in der Regierung, seine in sieben Monaten vorbereitete letzte Fassung des Bodenreformkonzeptes der Unterkomission des Parlaments vorlegte, wurde diese von den reaktionären und konservativen Interessenvertretern der Komission entschieden abgelehnt. Sie verlangten die Streichung der wichtigsten Aspekte des Konzeptes, wie die Begrenzung des Großgrundbesitzes, worum es bei der Reform eigentlich geht. Auch alle anderen Reformpläne scheiterten. Am 3. November 1971 traten 11 Minister zurück, woraufhin auch Erim formal scinen Rücktritt erklärte, um mit der Bildung des neuen Kabinetts vom Staatspräsidenten beauftragt zu werden, was auch geschah.

Spätestens nach dem Rücktritt der 11 Minister wurde es klar, daß die ErimRegierung als Werkzeug der herrschenden Klasse und der imperialistischen Kräfte ins Leben gerufen war, nicht um Reformen zugunsten des Volkes durchzuführen, sondern um die Hierrschaft der Kompradorenbourgeoisie und ihrer Verbündeten zu konsolidieren. Anstelle de reformwilligen Technokraten in der 1. Erim-Regierung wurden in das neue Kabinett konservative Politiker der vier größten Parteien im Parlament aufgenommen. Auch die zweite Regierung Erim schwor immer wieder:

251) Cumhuriyet, 25.8 .1971

252) Cumhuriyet, 15.9 .1971

8 Probleme des Klassenkampis Nr. 5 
"Die Reformen werden wir durchsetzen." Im Regierungsprogramm sagte Erim: "In der gemischten Marktwirtschaftsordnung werden wir dem privaten Sektor Vertrauen entgegenbringen. Teuerung, künstliche Preissteigerungen und ungerechte Verdiener werden bekämpft." (253)

All die Versprechungen der beiden Erim-Regierungen waren wie erwähnt nur als Täuschungsmanöver für das Volk gedacht. Keine der im Programm erwähnten Reformen, keine der proklamierten Versprechen wurden in die Tat umgesetzt, außer denen, wofür das Militär eine solche Regierung lanciert hatte, nämlich die Unterdrückung des gerechten Kampfes des türkischen Volkes gegen Ausbeutung, Armut und Elend und für eine unabhängige und demokratische Türkei. Nur diese Unterdrückung durch brutalsten Terror wird als einziges Werk der beiden Erim-Regierungen in die Geschichte der Türkei eingehen. Als Erim am 17. April dieses Jahres zurücktreten mußte, hinterließ er dem türkischen Volk in seiner einjährigen Regierungszeit 25,9 \% Teuerung. Denn bei den gleichbleibenden, ja sogar zurückgegangenen Löhnen und Gehältern sind die Preise durchschnittlich in den Jahren 19701971 um 25,9\% gestiegen. (254) Diese Teuerung erschwert das Leben der armen Bauem, der Arbeiter und Beamten zu sehr. Karaosmanoglu erklärte zu den rapide steigenden Preisen: "Selbst als Minister merke ich es mit meinem konstanten Einkommen, wie teuer das Leben wurde."

Als Beispiel nennen wir die Preissteigerungen einiger wichtiger Bereiche und Produkte: Postgebühren stiegen um $100 \%$, Eisenbahngebühren um $40 \%$, Busgebühren um 66-180\%, Krankenhausgebühren um 50-100\%, Mieten um 40-45\%, Textilwaren um 40-70\%, Elektrizitätsgebühren um $30 \%$, Notargebühren um $50 \%$, Pa. pier um $30 \%$, Zeitungen um $50 \%$, Brot um $10 \%$, Fleisch um $25 \%$, Zement-, Eisenund Kohlepreise um 100-200\%.(255)

Am 10. Juni 1972 erklärte der Minister für Landwirtschaft, Prof. Ali Balaban, daß $69 \%$ der Bauern, das sind 18 Millionen, ein jährliches Prokopfeinkommen haben, das unter 485 Türkische Lira (TL) beträgt (256), das entspricht umgerechnet 120 DM. Ein durchschnittlicher Anzug kostet etwa 500 TL, ein Hemd 40 TL, ein Kilo Fleisch 20-35 TL. Wenn wir es umrechnen, beträgt das Einkommen eines Parlamentariers etwa im Monat das 312 fache dessen, was 18 Millionen arme Bauern pro Kopf im Monat verdienen. Und wenn ein Minister mit seinem Einkommen über Teuerung klagt, dann kann man sich sehr wohl vorstellen, unter welchen unerträglichen Lebensbedingungen die breiteren Massen des türkischen Volkes zu leben haben.

Selbst viele liberale Wirtschaftler klagen über die stagnierende und inflationistische Politik der Regierungen. Ahnlich wie Prof. Hatiboglu, beschreibt auch Prof. Mimaroglu die Wirtschaftssituation unter Erim's Regierungen mit folgenden Worten: "Die türkische Wirtschaft befindet sich in einer emsten Stagnation, die sich auf alle Bereiche der Wirtschaft erstreckt." Laut Mimaroglu kann die türkische National-Wirtschaft diese Stagnation nicht mehr lange aushalten. (258) Die Zahl der Ar-

253) Cumhuriyet, 17.12.1971

254) Vgl. Cumhuriyet, 2.2.1972

255) Vgl. Cumhiriyet, 26. 5., 30.5., 3.6., 15.6, 19.6., 21.6., 23.6., 30.6., 5. 7., 17.7., 16. 8., 29. 8., 12.9. 1971, Günaydin, 22.6., 27.6., 16. 7. 1971, Milliyet, 17.7.1971, Tercuman, 15.6., 18.7., 24.7.1971

256) Vgl. Milliyet, 10.7.1972

257) Cumhuriyet, 16.9.1971

258) Cumhuriyet, 13.9., 15.9. 1971 
beitslosen wird selbst in den Sommermonaten nach offiziellen Angaben auf 2 Millioneh geschätzt, 1,3 Millionen junge Türken warten darauf, ins Ausland als Arbeitskräfte zu gehen.

Nach Angaben des Schatzministers gibt es im Etat des Jahres 1972 ein Defizit von etwa 15 Milliarden TL, das ist knapp ein Drittel des ganzen Etats. (259) Durch Steuererhöhungen sollen 4,5 Milliarden des Defizits gedeckt werden. Das seit Jahren steigende Defizit der Zahlungsbilanz wurde im Jahre 1971 durch den stark angewachsenen Devisenzustrom durch die türkischen Arbeiter im Ausland gedeckt. 1971 betrug die Summe der in die Türkei transferierten Devisen der türkischen Arbeiter 460 Mio. Dollar, das sind $70 \%$ des gesamten Devisenzuflusses der Türkei. Durch die Devisen der türkischen Arbeiter im Ausland stiegen seit Jahren zum erstenmal in der Türkei die Dollarreserven auf 857 Mio. Dollar. (260)

Anscheinend wollen die Ferrschenden mit den z. Z. vorhandenen Devisen Waffen kaufen. Obwohl ein Drittel des türkischen Etats für das Militär, (mit über 550.000 Soldaten im Vergleich zur Bevölkerung die größte Armee in der NATO) ausgegeben wird, erklärte General Goodpaster, daß die Verteidigung der Türkei noch mehr moderne Waffen erfordere. (261) Kurz danach wurde beschlossen, für zehn Jahre einen Zusatz-Etat für den Kauf moderner Waffen einzurichten, wofür jährlich 1,6 Mrd. TL ausgege ben werden sollen. (262) Am 23. Juni 1972 wurde erklärt, daß von den USA 54-64 Phantom gekauft werden sollen, die pro Stück 5 Mio. Dollar kosten. (263) Ein großer Teil der von den USA und BRD unter "Entwicklungshilfe" aufgenommenen Anleihen werden so für den Kauf von Waffen vergeudet.

\subsection{Bedingungen für die Erkåmpfung der demokratischen Rechte in der Türkei}

Die Türkei befindet sich in einer Phase, in der die türkische Kompradorenbourgeoisie mit ihren imperialistischen Verbündeten ihre stärkste, konzentrierteste Generaloffersive gegen das tükische Volk eingeleitet hat mit dem Ziel, dessen gerechten Kampf gegen Unterdrückung und Alisbeutung, für eine sozial gerechte demokratische Gesellschaftsstruktur und für eine unabhängige Türkei langfristig zu unterbinden, um ihre Herrschaft zu konsolidieren. Dies konnte jedoch nicht geschehen, denn:

1. trotz aller Terrormaßnahmen und bereits untemommenen Schritte, eine solche Willkürherrschaft zu legalisieren, konnte die demokratische und sozialistische Basis im Volke nicht zerstört, ja noch nicht einmal un ter Kontrolle gebracht werden. Mit anderen Worten, die durchgeführten Maßnahmen haben den starken Willen und den Mut der Basis, dieser Willkuirherrschaft Widerstand zu leisten, nicht brechen können.

2. Die sozialen Konflkte haben sich seit der Ausübung der Terrorherrschaft, wie wir oben gesehen haben, verschärft.

3. Die Bourgenisie hat sick über das Ausmaß einer solchen Terrorherrschaft nicht einigen können, nicht etwa dem Volke zuliebe, sondern weil eine solche Willkurherrschaft den Interessen von Teilen der Bourgeoisie nicht ent-

259) Vgl. Cumhuriyet, 7. 1. 1972

260) Abdi Ipekci, Milliyet, 28. 2. 1972

261) Vgì. Milliyet, 1. 5. 1972

262) Vgl. Millizet, 10.7.1972

263) Vgl. Milliyet, 24.7.1972 
spricht, denn es ist ja lediglich die Herrschaft des parasitärsten Teils der Bourgeoisie, d.h. der Kompradorenbourgeoisie und ihrer Verbündeten im Ausland. 4. Ein letzter Gesichtspunkt wäre der, daß die demokratischen und fortschrittlichen Kräfte in den mit der Türkei verbündeten Ländern einer Terrorherrschaft in der Türkei zumindest ablehnend gegenüberstehen, wenn sie sie nicht oder noch nicht bekämpfen.

Oben sagten wir, daß die demokratische und sozialistische Opposition des türkischen Volkes trotz aller Versuche, sie zu untergraben, sich erfolgreich behaupten konnte. Was in der Türkei geschehen ist, ist nur das, was bei einer solchen Generaloffensive der Kompradorenweltbourgeoisie in jedem Lande erfolgen sollte, (falls natürlich für eine Gegenoffensive der demokratischen Kräfte die objektiven und subjektiven Bedingungen nicht vorhanden sind, was in der Türkei nicht der Fall war), nämlich: sich zurückzuziehen, sich zu behaupten, die Versuche der Herrschenden, die Terrorherrschaft zu legalisieren, aktiv zu bekämpfen, sich zu reorganisieren und den Kampf für die Rückeroberung der demokratischen Rechte und Unabhängigkeit des Volkes aufzunehmen.

Die Opposition des Volkes hat sich sowohl parlamentarisch als auch außerparlamentarisch behauptet, wobei die Stärke des Widerstandes naturgemäß den Umständen entsprach, also sich in Grenzen hielt.

Alle verbotenen Parteien, Jugendverbände, Berufsorganisationen, wie Lehrerund Juristenorganisationen, Gewerkschaften, Zeitungen und Zeitschriften, existieren nicht mehr legal, de facto aber konnte man sie nicht beseitigen. Da all diese Organisationen eine starke Basis hatten, konnte durch die Verhaftung von Kaderleuten deren Existenz nicht in Frage gestellt werden. Sie haben lediglich ihre offene Arbeit einstellen müssen.

Die wichtigste Entwicklung innerhalb der türkischen Opposition vollzog sich in der zweitgrößten Partei der Türkei, der "Republikanischen Volkspartei". Diese Partei wurde als erste in der Republik von Ataturk selbst gegründet. Nach dem Tode Atatürks 1938 übernahm Ismet Inönü den Vorsitz der Partei, Inönü, der Atatürks progressiven und antiimperialistischen Kurs bis 1945 fortsetzte, danach aber sich immer mehr an den westlichen NATO-Verbündeten und an den Interessen der türkischen Bourgeoisie orientierte, regierte die Partei bis zu seiner Abdankung am 8. Mai wie ein absoluter Herrscher. Er war lange Jahre Ministerpräsident, Staatspräsident und ununterbrochen 34 Jahre lang Vorsitzender der Republikanischen Volkspartei. Seine Autorität war bis vor kurzem unerschütterlich. Seit einigen Jahren hatte der linke Flügel der Partei unter Generalsekretär Bülent Ecevit die Führung inne. Dieser linke Flügel führte die Partei auf einen politischen Kurs, der als "links von der Mitte" bezeichnet wird.

Nach dem Memorandum des Militärs im März 1971 trat Ecevit von seinem Amt als Generalsekretär der Partei zurück, weil er den Charakter des Ultimatums sofort erkannte und die Unterstützung der zu bildenden "Überparteilichen Regierung" durch seine Partei ablehnte. Zu dem Ultimatum sagte er: "Das ist nichts anderes, als eine feinere Kopie der griechischen Militärjunta". Da aber Inönü für die Unterstützung der Regierung eintrat, verschärfte sich der Konflikt zwischen dem an Inönü orientierten rechten und dem an Ecevit orientierten linken Flügel. Ecevits Amt wurde von seinen Gesinnungsfreunden weitergefuihrt, während er hauptsächlich unter den Massen mit aller gebotenen Vorsicht seine Aufklärungsarbeit fortsetzte. Wegen seiner Popularität und Beliebtheit unter den Massen, trauten sich die Machthaber nicht, seine Immunität aufzuheben und ihn zu verhaften, obwohl dies öfter in 
Erwägung gezogen wurde. Auch jetzt sind in dieser Richtung Vorbereitungen im Gange, aber es scheint dafür schon zu spät zu sein, denn die Verhaftung des Vorsitzenden der zweitgrößten Partei der Türkei kann auf großen Widerstand stoßen.

Im außerordentlichen Generalkongress der Partei forderte Inönü die Delegierten auf, "entweder mich oder Ecevit" zu wählen, wobei er den Kurs Ecevits "nicht nut für die Partei, sondern auch für das Land für gefährlich" bezeichnet. Inönüs Versuche, Ecevit zu diffamieren, scheiterten. Die Delegierten wählten mit großer Mehrheit Anhänger Ecevits in den neuen Vorstand und zum Generalsekretär. Der absolute Herrscher Inönü konnte diese Entscheidung nicht hinnehmen und trat zurück. Der darauf folgende Kongress der Partei wählte Ecevit mit 1032 von 1085 Stimmen zum neuen Vorsitzenden.

14 Parlamentarier des rechten Flügels unter dem Vorsitz von Kemal Satir sahen sich daraufhin gezwungen, sich von der Partei zu trennen und eine neue Partei "Cumhuriyetci Parti" zu gründen. Sie attacktierten Ecevit aufs schärfste und warfen ihm vor, die Partei zu einer sozialistischen entwickelt zu haben.

Eine groß̊ Zahl von Parlamentariern, die auch zum rechten Flügel gehörten, blieb jedoch bis zum Austritt und zur Mandatniederlegung Inönüs am 5. November 1972 in der Partei. Zuvor hatte der Parteivorstand der Republikanischen Volkspartei, entsprechend dem immer mehr laut werdenden Wunsch der Parteibasis, den Beschluss gefaßt, ihre fünf Minister aus dem sogenannten "überparteilichen Melen-Kabine $\mathrm{tt}^{\text {" }}$ zurückzuziehen.

Bekanntlich verlangte das türkische Militär nach dem 12. März-Ultimatum "eine überparteiliche Regierung zu bilden", so daß gezwungener Weise auch die Republikanische Volkspartei selbst unter der Führung von Ecevit sich an dem Melen-Kabinett beteiligen mußte. Die Partei quälte sich jedoch in dem großen Widerspruch, einerseits einer Regierung der Industriebourgeoisie zu gehören, die die demokratischen Rechte des Volkes mit Terrormaßnahmen unterdrückt und ihre eigenen Klasseninteressen bewahrt, andererseits sich für die Herstellung der demokratischen Verhältnisse und für die Reformen zugunsten der breiteren Massen einzusetzen.

Der Druck der Parteibasis überstieg jedoch den Druck des Militärs, obwoh1 dem Vorstand die Folgen eines Austrittes aus dem Kabinett klar waren: nämlich Ausnutzung dieser Situation durch den rechten Flügel, die Partei zu zerstören. Mit der Begründung, daß die Politik der Partei in einer so kritischen Phase einen für das Land gefährlichen Kurs genommen habe, schien für Inönü der richtige Augenblick gekommen, um sich an seinen Kontrahenten zu rächen, ohne Rücksicht darauf, daß er einer der Gründer dieser Partei mit Atatürk war und bis vor kurzem 34 Jahre lang sie als absoluter Herrscher geleitet hatte. Bis heute haben 26 Parlamentarier Inönü Folge geleistet und ihren Austritt aus der Partei erklärt.

Somit ist die Partei mit dem Austritt von 40 Parlamentariern von den Vertretern der Großgrundbesitzer und der Großbourgeoisie gesäubert, die schon zumindest seit dem Vorsitz von Ecevit fehl am Platze waren. Mit 103 Abgeordneten von 450 bleibt die Republikanische Volkspartei weiterhin die zweitgrößte Partei der Türkei. Diese sind laut Ecevit solche, die erkannt haben, daß die "Republikanische Volkspartei nicht mehr die Ersatzreifen des Autos darstellt, das entsprechend den Interessen der Herrschenden auf ihrem Wege fährt." (264) "Keine Falle wird die Kraft der Republikanischen Volkspartei schwächen," (265) erklärte Ecevit.

264) Turan Günes, Toplum, 8. November 1972 , Nr. 32, S. 4

265) Cumhuriyet, 7. November 1972 
Dieses Ereignis ist in unserer jüngsten Geschichte insofern sehr wichtig, weil von dieser Zeit ab der Weg zur Einheit für die türkische Linke frei zu werden und die zweitgrößte Partei der Türkei nunmehr eine klare, linksorientierte Politik zu verfolgen scheint. Ecevits politischer Standort kann mit dem des linken Flügels der SPD verglichen werden. Diejenigen, die die Entwicklung dieser Partei mitverfolgt haben, können feststellen, daß es in der Türkei eine breite, sich selbst bewußte demokratische Basis gibt, die eine klare Konzeption hat. Trotz aller Propagandamöglichkeiten des rechten Flügels (die Fublikationsorgane unterstützten ihn), trotz mehrmaliger Appelle der bis dahin führenden Autorität und trotz der Behinderun gen pro Ecevit orientierter Delegierter, an dem außerordentlichen Kongress teilzunehmen, erhielt der rechte Flügel eine klare Absage.

Ein anderes Beispiel, daß die Basis nicht zu täuschen, nicht zu vernichten ist, zeigt die Entwicklung bei einer der größten, einflußreichsten Zeitungen der Türkei, CUMHURIYET. Unmittelbar nach den Ereignissen des 12. März durfte sie zunächs 10 Tage nicht erscheinen. Dann verlangten die Industriellen, daß die Redaktion der Zeitung, die hauptsächlich aus linksorientierten Intellektuellen bestand, entlassen werden müsse; sonst bekäme sie keine Anzeigen mehr. Der bekannte Kolunnist àer Zeitung Illhan Selcuk und der verantwortliche Redaktionscheff wurden veihaftet, später aber wieder freigelassen, weil sie nicht für schuldig befunden werden sonnten. Selbst der Teilinhaber und langjährige Chefredakteur der Zeitung Nadir Nadi wurde zum Abdanken gezwungen. Anstelle der linken Redaktion übernalmen rekaum mehr gelesen wurde. Durch diese Reaktion der Leser ging die Auffage vor 200.000 auf 55-30.000 zurück; entweder mußte die gleichgeschaltete Zeitung eingehen oder wieder zu ihrem alten Kurs zurückkehren. Die Inłabe der Zeitung zogen es doch vor, ihre Zeitung existieren zu lassen. Am 12. Juli $197 \%$ ibernahm erneut die alte Redaktion die Zeitung, diesmal fester als zuvor.

Diese Beispiele könnten erweitert werden. Sie zeigen deutlich, daß die demo. kratische Basis die Terrormaßnahmen überstehen konnte. Für die demokratischen Kräfte und für die türkische Linke war die Folge ihrer Uneinigkeit gegenüber den antidemokratischen und imperialistischen Kräften sehr lehrreich.

Der Generalangriff gegen alle sozialistischen und demokratischen Kräfte führ. te zu einer Annäherung zwischen den Fraktionen unter den Sozialisten, die vor dem '12. März-Ultimatum' zutiefst zersplittert waren. Alle Sozialisten sehen sich demselben Angriff desselben Feindes gegenüber und wissen, daß dieser Feind nur durch gemeinsamen Kampf aller Sozialisten zumindest in seinem weiteren Vorgehen angehalten und langfristig bekämpft werden kann.

Die Sozialisten wissen weiterhin, daß sie ein Bündnis mit allen antifaschistischen und antiimperialistischen Kräften schließen müssen, das insbesondere in tiesem Stadium dringend geboten ist. Diese Bündnispolitik zwischen den Sozialisten, Sozialdemokraten und Demokraten kann nicht auf organisatorischer Ebene stat finden - da die sozialistischen Organisationen verboten sind --, sondern sie kamn als Unterstützung der 'Republikanischen Volkspartei' durch die Sozirilisín erfolgen. Diese Unterstützung hieße nicht eine Unterordnung der sozialistischen Kräfte unter eine sozialdemokratische Partei, sondern vielmehr eine zeitweilige Büntnispolitik bis zur Wiedererlangung demokratischer Rechte und legaler Arbeitsmöglich. keiten für alle Sozialisten. Erforderlich ist jedoch eine genaue Abgrenzung der Sozialisten von den Sozialdemokraten, um eine Verwirrung unter dem Volke zu vermeiden. 
Anhand der Erfahrungen der bisherigen Praxis des Jahres 1972 kann gesagt werden, daß die Sozialisten (wenn auch ohne Geschlossenheit) die sozialdemokratisch orientierte Politik Bülent Ecevits soweit zu unterstützen scheinen, wie die Republikanische Volkspartei ihren Kampf für eine demokratische, sozial gerechte politische Ordnung und gegen die Kompradorenbourgeoisie und imperialistische Monopole ohne Konzessionen zu führen bereit ist.

Die türkischen Sozialisten scheinen sich darüber klar zu sein, wie notwendig legale Arbeitsmöglichkeiten sind und wie die Bedingungen dafür erneut erkämpft werden können. Sie sind sich bewußt, daß es eines der Hauptziele der herrschenden Klasse der Türkei ist, die sozialistische Bewegung in Illegalität und Kriminalisierung $\mathrm{zu}$ treiben. Daher wird entschiedener Widerstand gegen diese Versuche geleistet und deshalb werden all die Kräfte unterstützt, deren Demokratieverständnis den Sozialisten legale Tätigkeitsmöglichkeiten bietet.

Ecevits Partei könnte auch dann den Beistand der Sozialisten erfahren, wenn sie es mit ihrem Programm wie z. B. Nationalisie rung und Verstaatlichung der im privaten Sektor befindlichen Rohstoffe, Verstaatlichung des Bankwesens, des Außenhandels, Durchführung einer radikalen Bodenreform etc., ernst meint. Es ist durchaus zu erwarten, daß eine Einheitsfront aller linken Gruppierungen mit allen antifaschistischen und antiimperialistischen Kräften als Reaktion auf die Willkürherrschaft erfolgen wird.Bülent Ecevit, dynamischer Führer der republikanischen Volkspartei kann all diese Kräfte mitziehen, wenn er seine bisherige konzessionslose Linie gegenüber der Kompradorenbourgeoisie weiterhin fortsetzt. Es wäre dann allerdings die Pflicht aller sozialistischen Kräfte, diesen demokratischen und antiimperialistischen Kampf zu unterstützen.

Es wäre falsch, aus unseren letzten Beispielen Schlußfolgerungen zu ziehen, daß das türkische Volk durch die Generaloffensive der Herrschenden keine Verluste gehabt hätte. Unser Volk ist vieler demokratischer Rechte beraubt, die demokratische und sozialistische Bewegung in unserem Lande für einige Jahre zurïckgeworfen worden. Die Aufgabe und Pflicht aller antifaschistischen, antiimperialistischen und sozialistischen Kräfte der Türkei kann in diesem Stadium nichts anderes sein, als zunächst die Gründung einer Einheitsfront zu ermöglichen: 1. um die Versuche der Herrschenden, ihre Terrorherrschaft zu legalisieren, rechtzeitig zu unterbinden und 2. um die geraubten Rechte unseres Volkes zurückzuerobern und sie weiter auszudehnen. Erste Maßnahmen dieser zu verwirklichenden Einheitsfront sind unseres Erachtens:

1. die Versuche des Terrorregimes, die demokratischen Rechte des Volkes weiterhin einzuschränken, müssen bekämpft werden (gemeint sind die oben erwähnten Vorhaben der Regierung Melen, wie $z$. B. die Verfassungsänderung etc.).

2. Das Verlangen nach baldiger Aufhebung des Kriegszustandes.

3. Abhaltung von freien Wahlen ohne Verzögerung also 1973 und

4. eine Generalamnestie für alle politischen Gefangenen und Wiederzulassung der verbotenen Organisationen, Zeitungen und Zeitschriften.

Zur Erreichung dieser Ziele können die demokratischen und sozialistischen Kräfte im Ausland einen großen Beitrag leisten, wenn der Druck dieser Kräfte auf die Herrschenden in der Türkei sich verstärken würde. Der Druck aus dem Ausland hat bis heute, was die Türkei anbelangt, einen großen Effekt gehabt. Bei der Freilassung mancher inhaftierter namhafter Professoren, Journalisten, Gewerkschaftler und Schriftsteller und bei der in der letzten Zeit erfolgten Lockerung für die 
Presse spielte die ablehnende Haltung des Auslandes eine große Rolle, ebenso wie bei der tendenziell bemerkbaren Zurückhaltung der Herrschenden bei weiteren Einschränkungen demokratischer Rechte. Nun käme es darauf an, diesen Druck des Auslands zu verstärken. Wie?

1. Durch verstärktes Engagement der demokratischen und fortschrittlichen Publikationsorgane bezüglich der Situation in der Türkei,

2. durch Druck auf die demokratischen Regierungen, daß sie ihrerseits bei der türkischen Regierung intervenieren und zu verstehen geben, daß, falls die oben genannten vier Punkte nicht verwirklicht werden, Maßnahmen in wirtschaft licher und politischer Hinsicht zu erwarten seien.

Da die Türkei von der Bundesrepublik in jeder Hinsicht abhängig ist, könnten die demokratischen und sozialistischen Kräfte in der BRD für die Sache des türkischen Volkes, für die Verwirklichung seiner demokratischen Rechte wirkungsvoll eintreten.

Die Errichtung einer echten Demokratie, die Unabhängigkeit der Tükei und die Verwirklichung einer Gesellschaftsordnung, in der das Volk selbst regiert und seine Interessen wahrnimmt, kann und wird jedoch nur das Werk des türkischen Volkes selbst sein.

\section{GEGEN DEN PLAN DES KAPITALS IN DER SCHWEIZ - KAMPF DER ARBEIT!}

Diese Broschüre, herausgegeben von der nationalen Schweizer Gruppe KLASSENKAMPF - LOTTA DI CLASSE - LUTTE $D E C L A S S E$ ist der erste Versuch einer umfassenden theoretischen und empirischen Analyse der Strategie des Kapitals in der Schweiz. Einbezogen in die Analyse sind auch Beiträge über die Rolle der Emigration im kapitalistischen Plankonzept und eine Untersuchung über einen der größten schweizerischen multinationalen Konzerne, nämlich die Brown-Boveri (BBC).

Diese Beiträge machen die Broschüre auch für den bundesdeutschen Leser lesenswert, berühren sie doch Probleme. die sich für die Analyse des Kapitals und die politische Arbeit in der BRD in ähnlichen Termini stellen.

Die Broschüre ist auch in italienischer und französischer Sprache erhältlich.

Erhältlich in den linken Buchläden. Vertrieb an den Buchhandel: POLITLADEN ERLANGEN 852 Erlangen, Wemer von Siemens-Str. 8, Auslieferurig in der Schweiz: ECO-LIBRO, Engelgasse 62, Zürich. 